\title{
Recherches archéologiques dans la nécropole de la Porte médiane à Cumes
}

Campagne 2016

Jean-Pierre Brun, Priscilla Munzi, Guilhem Chapelin, Marina Covolan, Bastien Lemaire, Marcella Leone, Nicola Meluziis et Géraldine SachauCarcel

\section{OpenEdition}

Journals

Édition électronique

URL : http://journals.openedition.org/cefr/1786

DOI : $10.4000 /$ cefr. 1786

ISSN : 2282-5703

Éditeur

École française de Rome

Référence électronique

Jean-Pierre Brun, Priscilla Munzi, Guilhem Chapelin, Marina Covolan, Bastien Lemaire, Marcella Leone, Nicola Meluziis et Géraldine Sachau-Carcel, « Recherches archéologiques dans la nécropole de la Porte médiane à Cumes », Chronique des activités archéologiques de l'École française de Rome [En ligne], Italie du Sud, mis en ligne le 24 août 2017, consulté le 02 mai 2019. URL : http://

journals.openedition.org/cefr/1786 ; DOI : 10.4000/cefr.1786

Ce document a été généré automatiquement le 2 mai 2019.

(c) École française de Rome 


\title{
Recherches archéologiques dans la nécropole de la Porte médiane à Cumes
}

Campagne 2016

\author{
Jean-Pierre Brun, Priscilla Munzi, Guilhem Chapelin, Marina Covolan, \\ Bastien Lemaire, Marcella Leone, Nicola Meluziis et Géraldine Sachau- \\ Carcel
}

\section{NOTE DE L'ÉDITEUR}

Les opérations de fouille ont été conduites sous la direction de Jean-Pierre Brun (Collège de France) et de Priscilla Munzi (CNRS, Centre Jean Bérard, USR 3133 CNRS-EFR). La responsabilité des sondages a été confiée à des jeunes collaborateurs : Marina Covolan, Bastien Lemaire, Nicola Meluziis et Géraldine Sachau-Carcel. L'étude céramologique a été réalisée par Marcella Leone (CNRS, Centre Jean Bérard), alors que l'étude anthropologique a été faite par Géraldine Sachau-Carcel (CNRS, UMR 5140 Lattes). Les relevés et la DAO ont été réalisés par Guilhem Chapelin (CNRS, Centre Jean Bérard), avec l'aide des responsables de secteur et des étudiants. Les dessins de la céramique sont de Giuseppina Stelo (EFR, Centre Jean Bérard).

La Mission archéologique de Cumes a associé en 2016 sur le terrain 19 étudiants et doctorants : Antoine Boisson, Elisa Conca, Anselme Cormier, Barbara Del Mastro, Saverio De Rosa, Macarena Enriquez de Salamanca Alcon, Renan Falcheti Peixoto, Noémie Ledouble, Flore Lerosier, Théophile Leylavergne, Emilio Marino, Diane Naftalski, Souad Ait-Salah, Thierry Sturbois, Alessandra Vuoso. Les recherches à l'extérieur de la Porte médiane de Cumes ont été poursuivies, grâce aux crédits du Ministère de l'Europe et des Affaires étrangères et en collaboration avec la Soprintendenza Archeologia Campania, dirigée par la Surintendante Adele Campanelli, et l'Ufficio per i beni archeologici di Cuma, dirigé par Francesco Sirano, que nous remercions. 


\section{Introduction}

1 Les recherches du Centre Jean Bérard à Cumes se concentrent depuis plusieurs années dans la nécropole romaine située à l'extérieur de la Porte médiane des fortifications septentrionales. L'impossibilité de poursuivre les recherches en profondeur à cause du niveau élevé de la nappe phréatique (sur une stratigraphie de 6 mètres de puissance, la moitié des sédiments est sous l'eau) nous a incités, depuis 2014, à étendre nos recherches en surface en menant des investigations sous des structures agricoles des Temps modernes dépendant de la Masseria di Matteo il Procidano (fig. 24). Ainsi nous avons pu commencer d'explorer ce qui s'avère être un grand complexe monumental construit sous Trajan en avant de la Porte médiane et flanquant à l'est la place construite dans les dernières années du règne de Domitien. Ce complexe comportait certainement deux niveaux. Le niveau supérieur a été détruit à l'époque byzantine mais le rez-de-chaussée, relativement bien conservé, comportait des pièces, dont une boutique, ouvrant sur la place. La construction de ce monument a oblitéré la nécropole dont les derniers tombeaux sont datables $\mathrm{du} \mathrm{I}^{\mathrm{er}}$ siècle avant notre ère. Construit en grand appareil de calcaire et décoré de blocs et sculptures en marbre blanc (totalement spoliés), le complexe a été utilisé jusqu'au III ${ }^{\mathrm{e}}$ siècle de notre ère, puis occupé par des tombes aux IV ${ }^{\mathrm{e}}$ et $\mathrm{V}^{\mathrm{e}}$ siècles. Au moment de son démantèlement après le milieu du $\mathrm{VI}^{\mathrm{e}}$ siècle, ses ruines furent utilisées pour implanter des fours à tuiles. Totalement abandonné dès la fin du $\mathrm{VI}^{\mathrm{e}}$ siècle, le bâtiment, dont l'ossature en maçonnerie était encore debout, fut utilisé au Moyen Âge pour installer une ferme dont nous avons retrouvé les pièces d'habitation, le puits et la cave aménagée dans un tombeau monumental construit à l'époque tibérienne puis détruit et spolié à la période byzantine.

2 La campagne de fouille 2016 s'est déroulée entre le 23 mai et le 24 juin 2016. Elle a porté sur quatre secteurs à proximité de la Porte médiane, dont deux déjà explorés en 2014 (fig. 1) $)^{1}$ :

3 - Le grand complexe trajanien D60. Nous avons fouillé une des boutiques qui est construite sur un mausolée arasé du $\mathrm{I}^{\mathrm{er}}$ siècle et qui était en fait une taverne dotée d'un comptoir en $\mathrm{U}$ caractéristique. Après son abandon, dans le courant du III siècle, le bâtiment s'est ruiné. Un four de tuiliers a été implanté sur les niveaux de gravats dans la seconde moitié du $\mathrm{VI}^{\mathrm{e}}$ siècle. Après une nouvelle phase de délabrement/sédimentation, une ferme a été construite en utilisant les substructions existantes; elle fut occupée durant un siècle environ avant d'être abandonnée dans le courant du XIII ${ }^{\mathrm{e}}$ siècle. Sur ses couches d'effondrement un bâtiment agricole, la Masseria di Matteo il Procidano, fut construit au XVIII ${ }^{e}$ siècle et utilisé jusqu'au XIX ${ }^{\mathrm{e}}$ siècle.

4 - Le mausolée MSL43003. Connu depuis nos dégagements de la place en 2005, ce mausolée, est totalement dépouillé de son parement de blocs de calcaire et de marbre blanc et réduit à un moignon de maçonnerie compacte. La fouille entreprise cette année a permis de comprendre qu'il avait été réutilisé à la période médiévale comme cave : un accès a alors été ouvert à travers le noyau de maçonnerie sur le côté opposé à la porte antique. La chambre funéraire a été atteinte, pillée et vidée; elle comportait deux lits funéraires latéraux et l'emplacement d'une urne scellée dans le lit majeur, au fond de la chambre. L'intérieur de la chambre a livré des céramiques médiévales. La datation du monument a été acquise par la fouille, à l'extérieur, des niveaux de construction caractérisés par des 
couches d'éclats de taille des blocs de calcaire et de marbre. Il s'avère qu'il faut dater le monument du $1^{\mathrm{er}}$ quart du I ${ }^{\mathrm{er}}$ siècle de notre ère, probablement sous Tibère.

- L'enclos funéraire A42 et l'ambitus A19. La fouille de ce passage qui dessert les enclos funéraires A42, A53, A52 et A54 a permis d'assurer la datation de l'enclos A42, de l'extrême fin du $\mathrm{I}^{\mathrm{er}}$-début du II $\mathrm{II}^{\mathrm{e}}$ siècle de notre ère et de mieux comprendre l'évolution de sa fréquentation : à partir des $\mathrm{III}^{\mathrm{e}}$ et $\mathrm{IV}^{\mathrm{e}}$ siècles, il a cessé d'être utilisé comme passage pour accueillir de nombreuses sépultures à inhumation en fosse couvertes de tuiles.

Fig. 1 - PLAN gÉnÉrAL et LOCALISATION DES ZONES d'ÉtUde ( CJB).

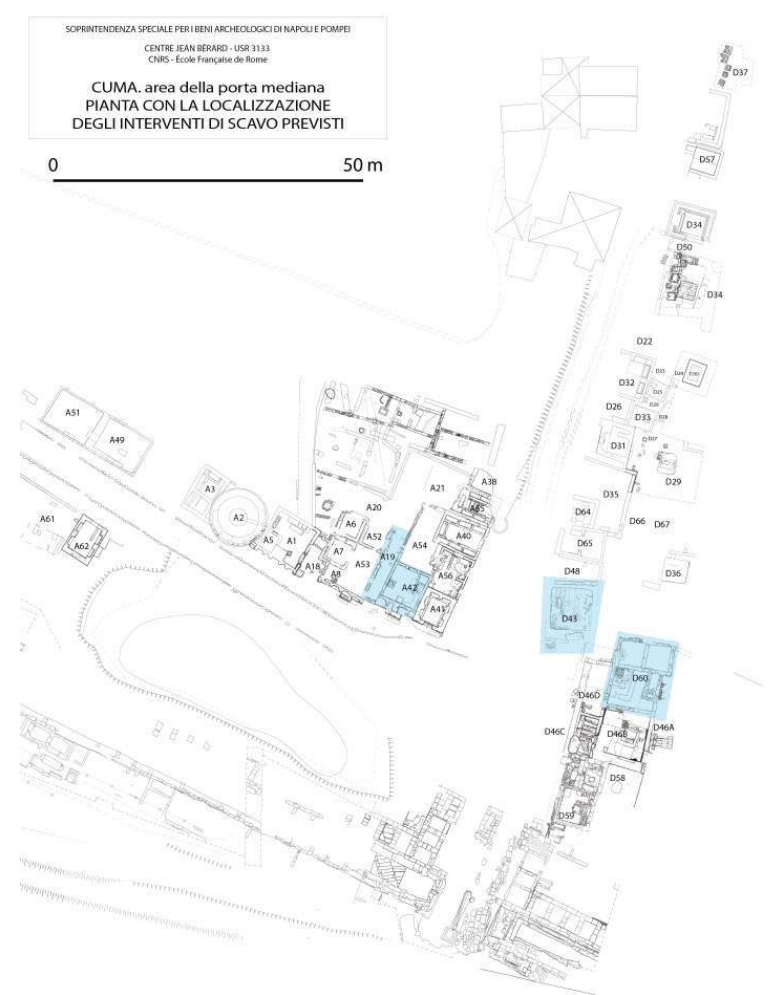

\section{La zone D60}

\section{Introduction}

La zone D60 se situe au nord de la Porte médiane. La configuration du secteur a évolué en lien avec l'implantation des trois grands axes desservant successivement la Porte : une voie orientée vers le nord (existant déjà à l'époque archaïque), une autre vers le nord-est (depuis le II ${ }^{\mathrm{e}}$ siècle avant notre ère) et une dernière vers l'ouest en direction du littoral (depuis le $\mathrm{I}^{\text {er }}$ siècle avant notre ère). À partir de 95 de notre ère, l'aménagement de l'espace devant la Porte et la construction de la via Domitiana au-dessus de l'axe routier se dirigeant vers le nord-est, entrânent l'abandon de la voie nord-est au profit de nouveaux espaces funéraires construits vers l'ouest et le nord. Par la suite, de nombreux réaménagements viendront modifier cet espace périurbain au nord de la ville, jusqu'aux époques médiévale et moderne (fig. 2). 

(C) CJB).

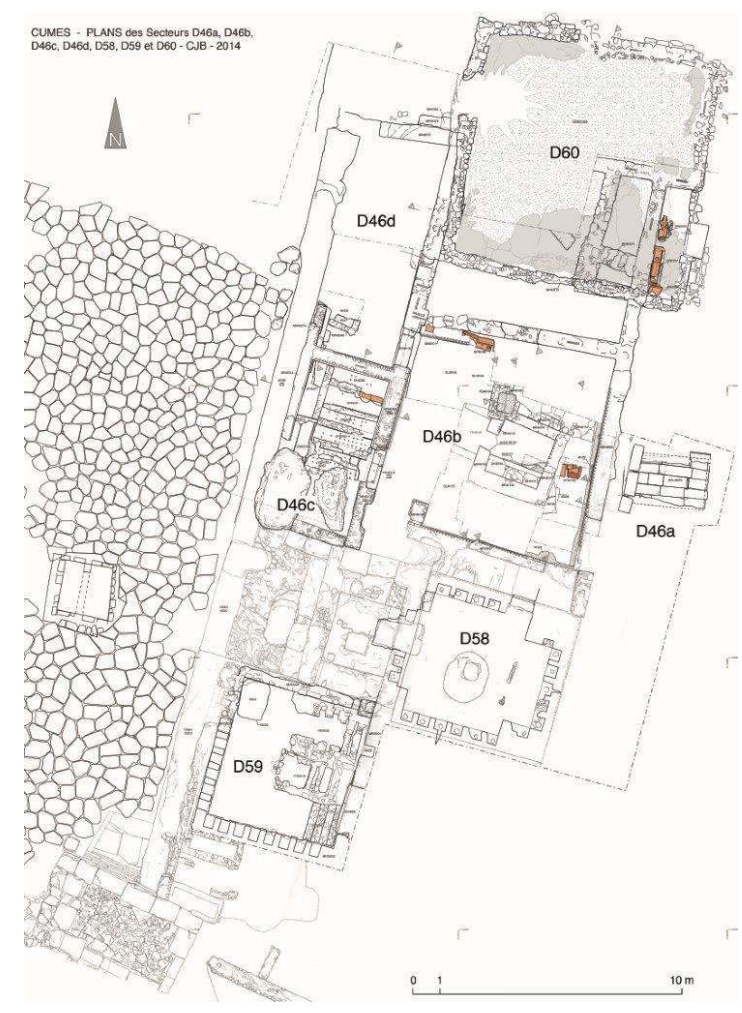

En 2016, la campagne de fouilles a concerné la zone D60, divisée en trois secteurs distincts: D60a (au sud), D60b (au nord-est) et D60c (au nord-ouest). La puissance stratigraphique a permis une bonne conservation des vestiges. Ainsi, une fois les structures modernes fouillées, des vestiges d'époque médiévale ont été découverts dans un très bon état de conservation. En effet, le secteur D60b, correspond à une pièce faisant partie du grand bâtiment du début $d u \mathrm{II}^{\mathrm{e}}$ siècle. Cette pièce et celle située à l'ouest (secteur D60c) furent réutilisées à l'époque médiévale dans la construction d'un corps de ferme. L'ensemble forme une habitation à deux niveaux fondée sur deux pièces d'époque romaine. L'accès se faisait au premier étage par un escalier situé au sud, dont il ne reste que les fondations. On accédait aux deux salles basses par un escalier intérieur en bois. Les sols étaient réalisés en mortier de chaux et le premier étage était surmonté d'une terrasse elle aussi en mortier dont le sol a été retrouvé effondré. Sous les niveaux médiévaux, des couches datant de l'Antiquité tardive ont été fouillées ; elles ont révélé un four (FR60086), dans l'angle nord-est du secteur D60a. Les constructions et les niveaux de fréquentation liés aux grands travaux $d u \mathrm{II}^{\mathrm{e}}$ siècle de notre ère ont été ensuite mis au jour (boutique BTQ60066). Sous ces niveaux, a été découvert un mausolée plus ancien (MSL60111), arasé lors de la construction du bâtiment du $\mathrm{II}^{\mathrm{e}}$ siècle ; il appartient à une phase déjà documentée dans le secteur situé au sud : D46B².

\section{Résumé de la chronologie (fig. 3 et 4)}

$8 \quad$ Un essai de phasage provisoire de la zone située à l'est de la place a été proposé ${ }^{3}$, mais il est possible d'insérer aujourd'hui la zone D60 dans le phasage général de la nécropole. 
9 Les phases 1 à 3 (âge du Fer à la conquête samnite) ne sont pas encore représentées dans cette zone. Les constructions les plus anciennes jusqu'à présent retrouvées dans le secteur correspondent au tombeau MSL46070 (D46a), en grand appareil de bloc de tuf et voute en berceau, de la fin du $\mathrm{II}^{\mathrm{e}}$ siècle avant notre ère (phase 4) et les monuments à chambre hypogée EFN46346 (D46d), MSL46144 (D46b), MSL46175 (D46b) et enfin MSL60111 construits dans la deuxième moitié du $\mathrm{I}^{\mathrm{er}}$ siècle avant notre ère (phase 5).

10 La phase 6A désigne les grands travaux effectués dans toute la zone située au nord de la Porte médiane occasionnant notamment l'arasement des monuments EFN46346, MSL46144, MSL46175 et du mausolée MSL60111. Ces destructions et la monumentalisation de cet espace (construction notamment de la boutique BTQ60066) ont eu lieu entre 95 et le début $\mathrm{du} \mathrm{II}^{\mathrm{e}}$ siècle de notre ère. Après la phase $6 \mathrm{~B}$ qui marque l'occupation de ce bâtiment, la phase $6 \mathrm{C}$ désigne une phase de destruction et d'abandon des structures de la phase $6 \mathrm{~A}$ à partir du III ${ }^{\mathrm{e}}$ siècle. Lors de la phase $6 \mathrm{D}$, trois tombes sont installées contre le parement extérieur du mur est (MR46005) de la boutique BTQ60066.

11 La phase 7A correspond au démantèlement de la façade en grand appareil du bâtiment donnant sur la place, ainsi qu'à la démolition du rempart, après le milieu du $\mathrm{VI}^{\mathrm{e}}$ siècle. Trois fours à matériaux ont alors été implantés dans les ruines (phase 7B) : deux dans le secteur D59 et un autre dans le secteur D60 (FR60086).

Une longue phase d'abandon, entre le VII et le XIII ${ }^{e}$ siècle, se manifeste ensuite par des couches d'effondrement et de colluvions (phase 8). Lors de la phase 9A au cours du XIII ${ }^{\mathrm{e}}$ siècle, une ferme est construite sur des murs antiques. Après l'abandon suite vraisemblablement à un incendie, un niveau de destruction recouvre les structures médiévales (phase 9B). La phase 10 est représentée par un bâtiment moderne SB60011 qui couronne l'accumulation des ruines. Ce bâtiment fut abandonné et endommagé au cours de la période contemporaine (phase 11). 
Fig. 3 - PLAN gÉnÉrAL de LA zone d60 (@ CJB).

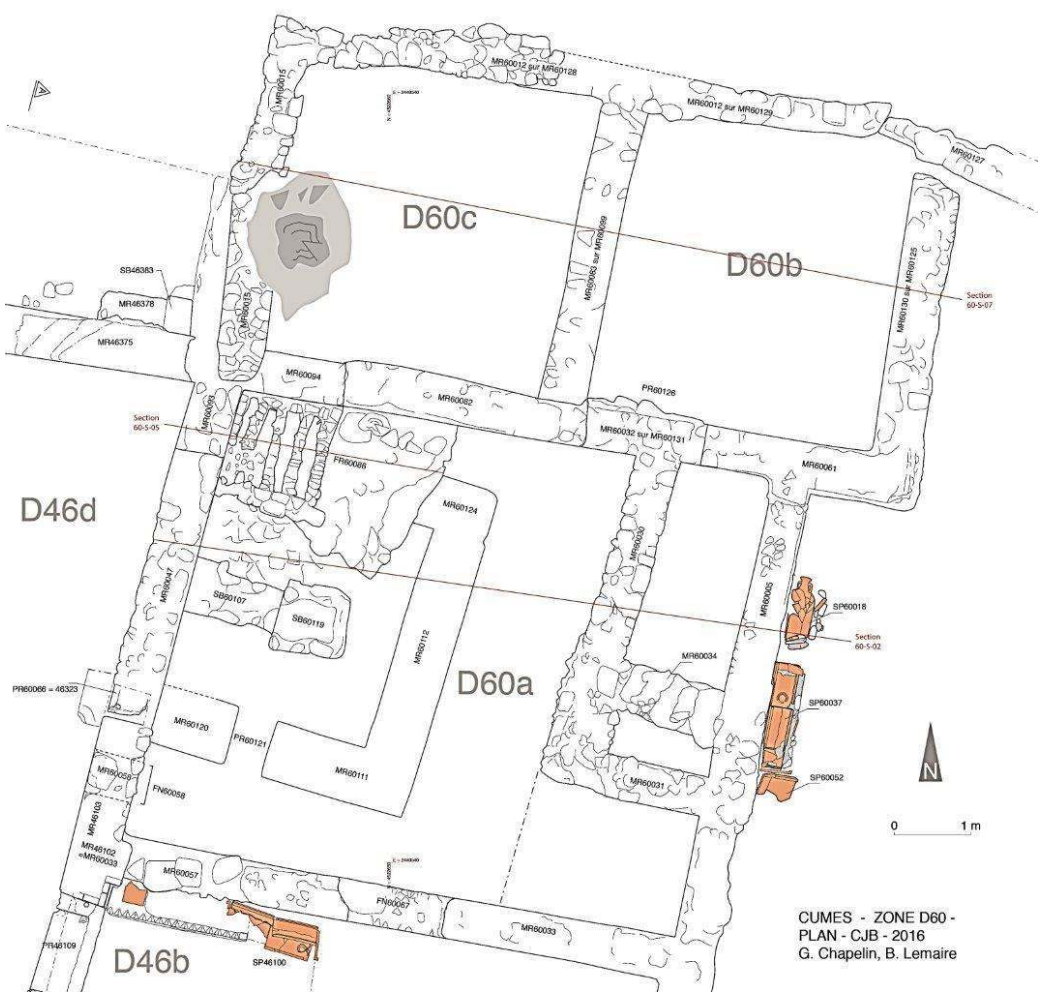

FIg. 4 - PLANS dES PHASES DE LA ZONE D60 ( CJB).

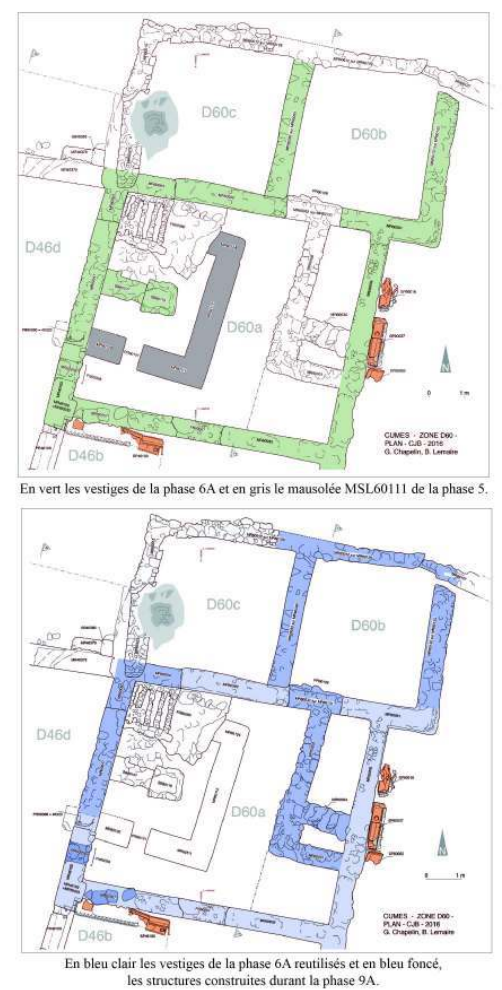




\section{Phase 5 : Installation du mausolée MSL60111 et construction du mur MR72002}

13 Contemporain des mausolées MSL46144 et MSL46175 (secteur D46b), présents à quelques mètres au sud-est du secteur D60a et datant de la fin du $\mathrm{I}^{\mathrm{er}}$ siècle avant notre ère ou des premières décennies du $\mathrm{I}^{\mathrm{er}}$ siècle de notre ère, le mausolée MSL60111 a été découvert en 2016 et représente la plus ancienne structure observée dans la zone D60 jusqu'à présent (fig. 5). Il est légèrement désaxé par rapport aux installations du début du II ${ }^{e}$ siècle de notre ère, comme les deux mausolées précédemment cités. Seul le niveau d'arase de ce monument funéraire a pu être observé, en dehors des parements externes sud et est, partiellement dégagés. Ces parements présentent des traces de banchage, mais des éléments de chaînage ont pu être distingués au niveau de la porte PR60121, présente du côté sud. Les murs délimitent un monument quadrangulaire de $4,40 \mathrm{~m}$ du nord au sud, et $4,40 \mathrm{~m}$ restitué, d'est en ouest; au centre se trouve une chambre funéraire carrée de 3,00 m de côté. La partie nord-ouest du bâtiment n'a pu être observée en plan en raison de la présence du four postérieur FR60086 (phase 7B) et sa partie occidentale a été recoupée par les installations de l'état 6A (les murs MR46103, MR60093 et le seuil PR60066).

\section{Fig. 5 - VUE ZÉNITHALE dU MAUSOLÉE MSL60111, APPARAISSANT EN fin dE FOUILLE (๑ CJB).}

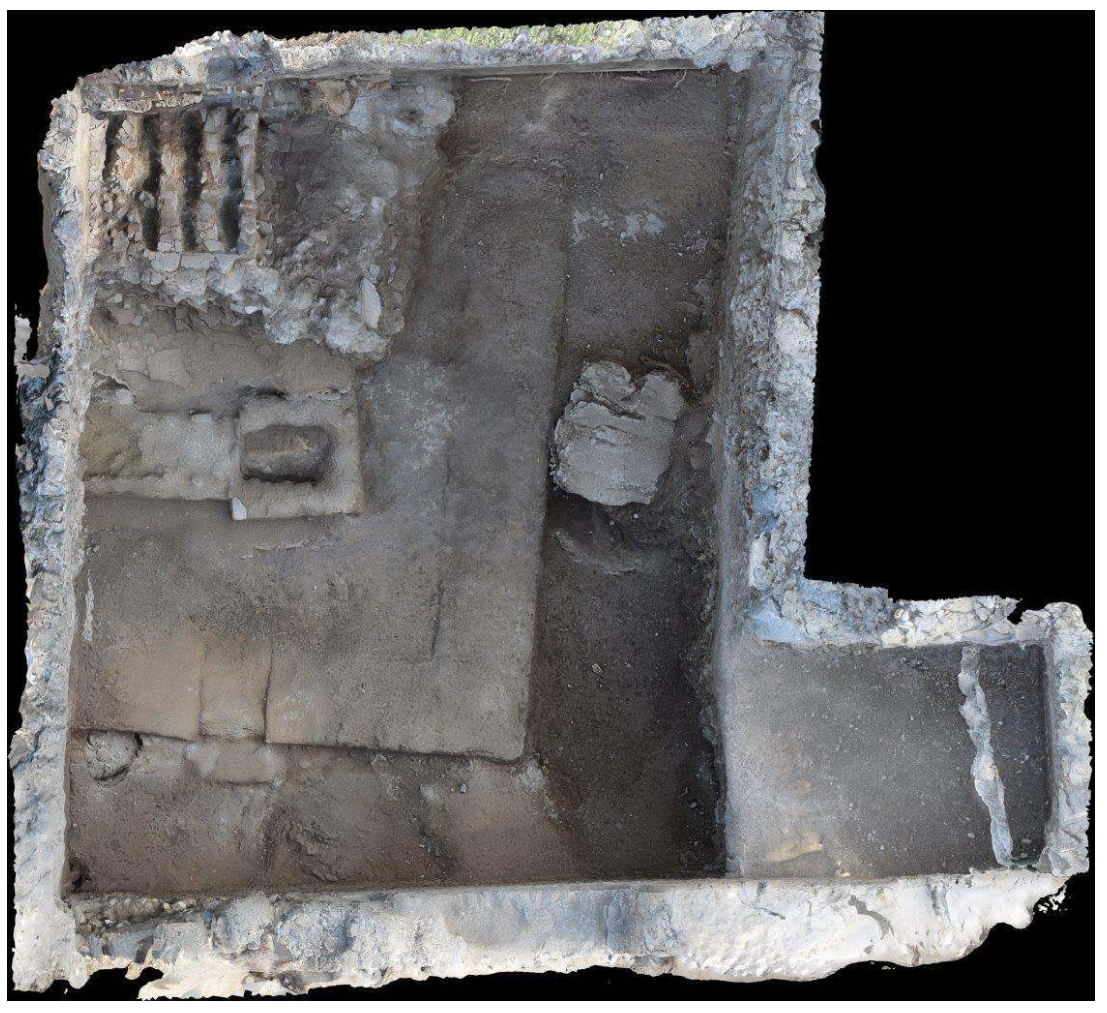

Aucune installation n'a pu être mise en évidence à l'intérieur de ce monument funéraire car le niveau d'arase et les remblais nivellant les structures de l'état 5 n'ont pas été fouillés lors de cette campagne.

Un grand mur oblique qui clôture une vaste esplanade s'étendant jusqu'à la Masseria de Matteo el Procidano est construit au cours de la période flavienne quelque temps avant la via Domitiana (à la fin de la phase 5, donc en phase 5E). Il est possible que cet enclos situé sur les niveaux anciens de la nécropole recouverts de remblais corresponde à un campus. 


\section{Phase $6 \mathrm{~A}$ : les aménagements du début II ${ }^{\mathrm{e}}$ siècle}

Au début du II $\mathrm{II}^{\mathrm{e}}$ siècle de notre ère, à la suite de la construction de la via Domitiana, un mur de façade en grand appareil de calcaire est construit sur le côté est de la place dallée aménagée devant la porte.

\section{Les espaces}

Dans le secteur D60a, ces travaux comportent la construction d'une boutique (BTQ60066) délimitée par des murs en opus reticulatum: MR60033 au sud, mitoyen de l'espace funéraire du secteur D46B (EFN46104); MR46005, prolongement du mur de clôture oriental de ce même ensemble EFN46104; MR60061 et MR60082 au nord (séparés par une porte menant à une seconde pièce (secteur D60b). Côté ouest, l'espace était accessible depuis la place par une large ouverture (PR60066) pourvue d'un seuil à rainure d'environ 3,55 m en calcaire blanc (fig. 6).

\section{Fig. 6 - LE SEUIL PR60066, À L'OUEST de L'ESPACE D60-A ET LE PAREMENT OCCIDENTAL du MUR MR60047, VUS DE L'OUEST (๑ CJB).}

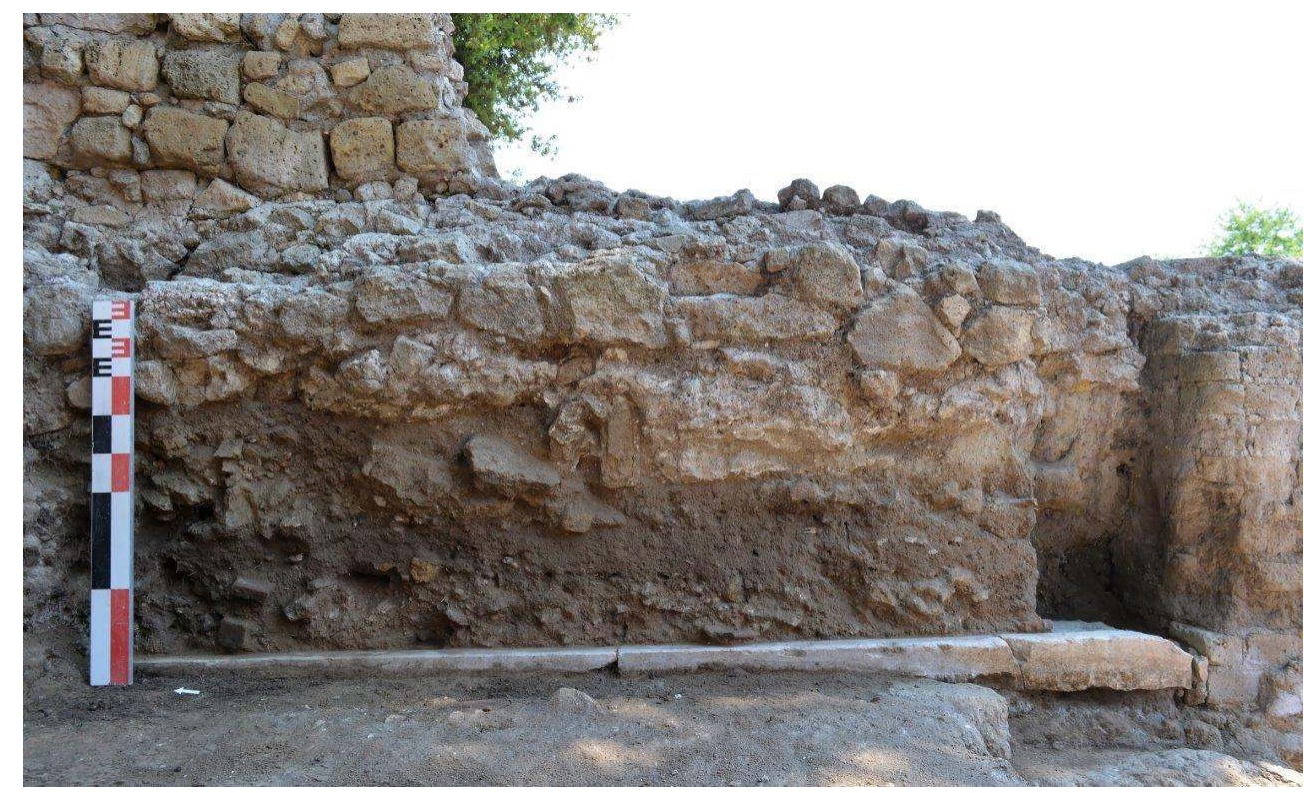

Dans l'axe de ce seuil se trouvent deux murs en opus reticulatum: MR46103 au sud et MR60093 au nord. Ces murs (MR46005 et MR60061 mitoyen du secteur D60b), sont chainés aux angles en opus vittatum. Les parements internes des murs de l'espace BTQ60066 étaient recouverts d'un enduit blanc. Ces travaux ont été réalisés au cours d'une seule et même phase de construction afin de créer un espace fermé dont l'écroulement s'est produit au cours de la phase 6C (US 60096).

Reliée à la pièce D60a par la porte PR60126, la pièce D60b a été construite lors de ces travaux en s'appuyant sur le mur oblique MR72002 préexistant qui a été partiellement bûché à cette occasion.

Les murs du secteur forment un espace de 3,70 m d'est en ouest et 4,00 du nord au sud. Cette pièce est ceinturée par des murs en opus reticulatum au sud, à l'est et à l'ouest (respectivement MR60061, MR60125 et MR60099), mais aucun mur de cet état n'a pu être 
observé au nord (le secteur étant délimité par le mur médiéval MR60129) (fig. 7). Au sudouest de la pièce, la porte PR60126 mesure 1,20 m ; elle donnait accès à la boutique BTQ60066 au sud. Tous les murs de la phase 6A sont chaînés entre eux.

FIg. 7. LES MURS DE L'ESPACE D60B : A) VUE DES MURS SUd DE LA PIÈCE : MR60061 (PHASE 6A : À gAUCHE), MR60032 ET MR60131 (PHASE 9A : BOUCHAgES DE LA PORTE PR60126, À DROITE) ; B) VUE DES MURS EST DE LA PIÈCE : MR60125 (PHASE 6A : PARTIE INFÉRIEURE) ET MR60130 (PHASE 9A : PARTIE SUPÉRIEURE) ; C) VUE DES MURS OUEST DE LA PIĖCE D60B : MR60099 (PHASE 6A : PARTIE INFÉRIEURE) ET MR60083 (PHASE 9A : PARTIE SUPÉRIEURE) ; D) VUE DES MURS NORD DE LA PIÈCE : MR60129 (PHASE 9A : PARTIE INFÉRIEURE), MR60012 (PHASE 10 : PARTIE SUPÉRIEURE) ET MR60127 (À DROITE) (๑ CJB).
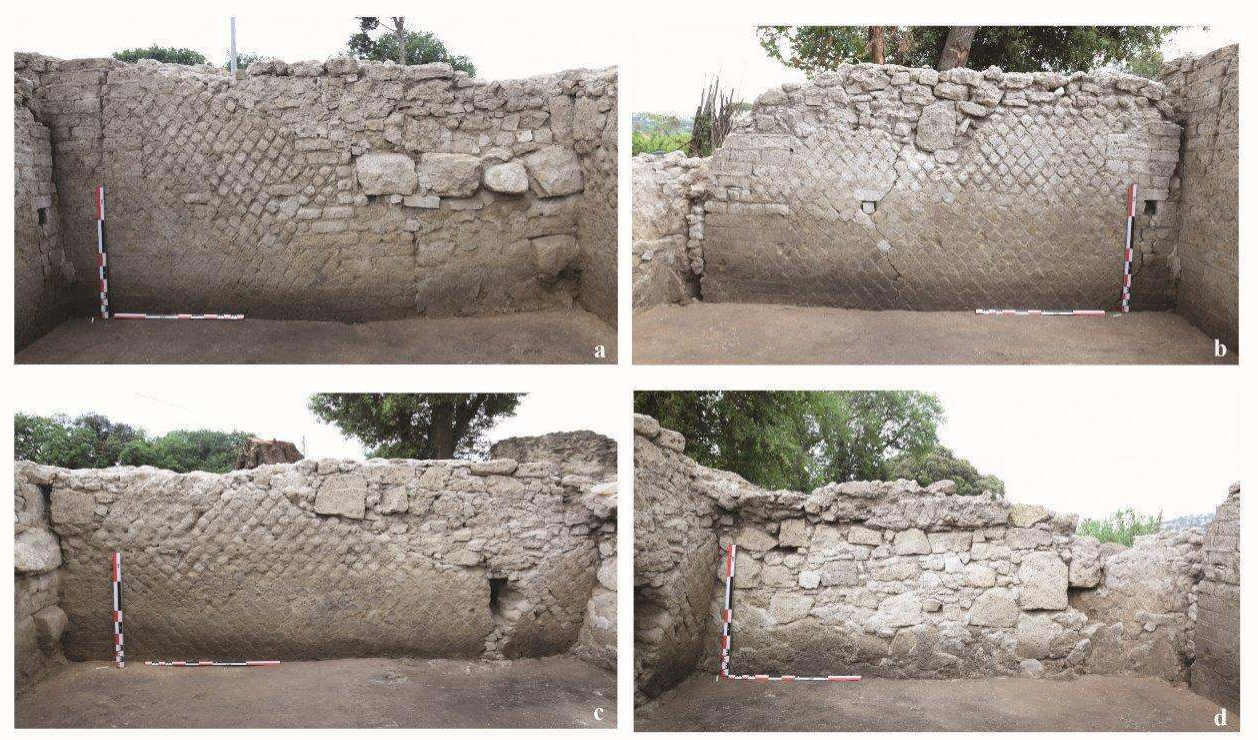

Directement au nord du secteur D60a et à l'ouest de D60b, une seconde pièce a été en partie dégagée. Elle mesure 3,70 $\mathrm{m}$ d'est en ouest et $3,90 \mathrm{~m}$ du nord au sud. Cependant, aucun accès depuis les deux secteurs mitoyens n'a été repéré. Bien que la pièce n'ait été que partiellement fouillée, elle doit faire partie de la phase $6 \mathrm{~A}$, comme l'attestent les murs mitoyens au sud (MR60082) et à l'est (MR60083). Au nord et à l'ouest, seuls les murs médiévaux et modernes ferment cet espace (respectivement MR60128 et MR60012 au nord ; MR60015 à l'ouest) (fig. 7).

\section{Les niveaux de fréquentation}

Dans le secteur D60a, des niveaux d'installation et de fréquentation de la phase 6A sont conservés. Au moment de la construction des murs précédemment présentés, le mausolée MSL60111 fut arasé et comblé par des remblais.

Sur l'arase du mausolée et sur les remblais de nivellement, un niveau de sol SL60110 a été établi (fig. 5). Cette couche met à niveau l'ensemble de la pièce et pourrait correspondre à un niveau de chantier. Cependant, les parties à l'est et au sud du mausolée arasé sont aujourd'hui plus basses en raison d'effondrements occasionnés par des tunnels de pilleurs datant du XIX ${ }^{\mathrm{e}}$ siècle.

Sur ce sol, un second niveau de sol et/ou de sédimentation (SL60109) a été identifié ; également affecté par des effondrements liés aux pillages (fig. 8), il se situe sous les niveaux de destruction du bâtiment (US 60096 et 60106) et représente la dernière 
occupation (phase 6B). Une monnaie de Gordien III (238-244), ainsi que des tessons de céramique donnent un terminus postérieur au second quart du $\mathrm{III}^{\mathrm{e}}$ siècle de notre ère.

FIg. 8 - VUE DU SOL SL60109, RECOUVRANT L'ESPACE D60A, DEPUIS LE SUD-EST. LES DIFFÉRENCES DE NIVEAUX SONT DUES AUX TUNNELS DES PILLARDS, AYANT LONgÉ LES FACES SUD ET EST DU MAUSOLÉE MSL60111 ET ENTRAîNÉS DES AFFAISSEMENTS (@ CJB).

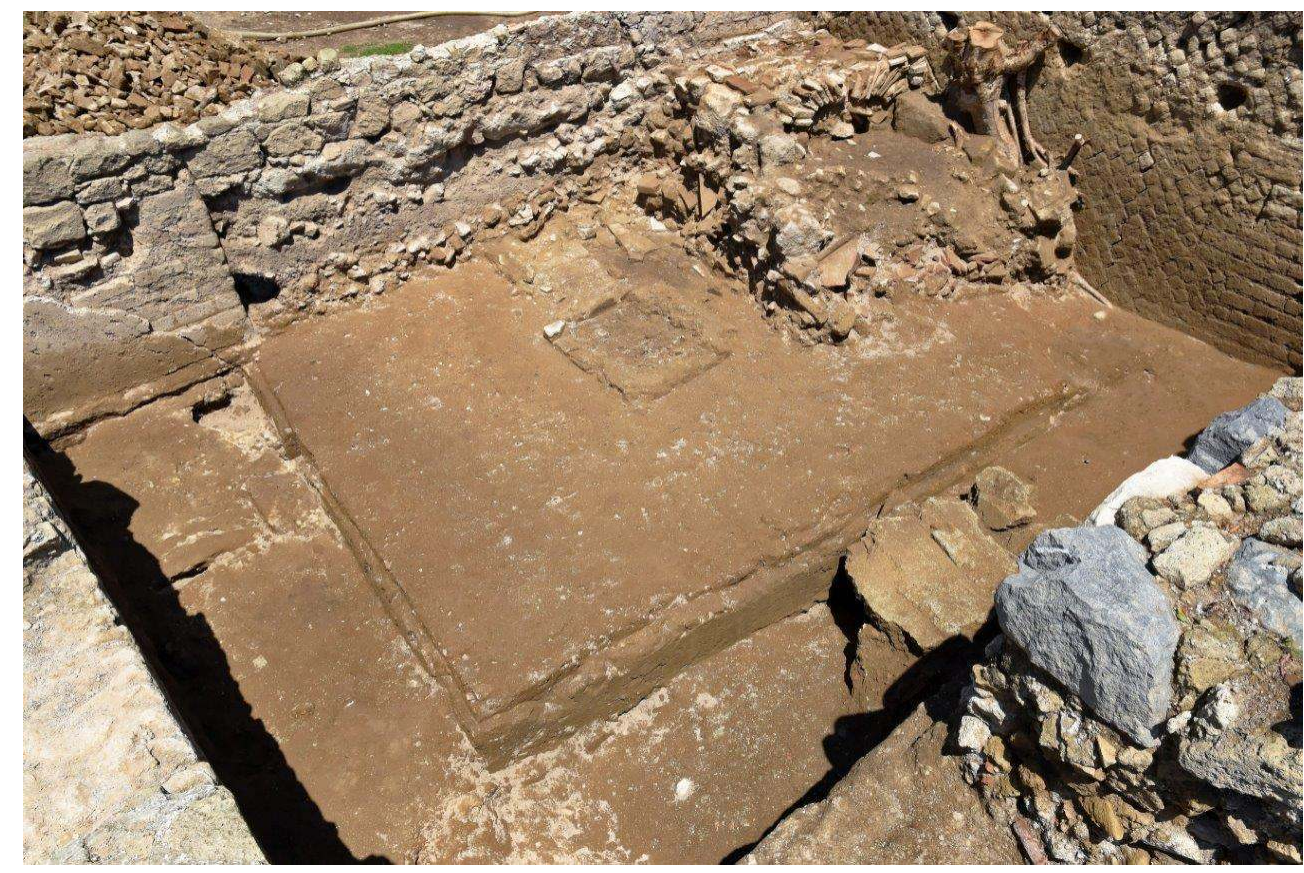

Fonctionnant avec les niveaux d'utilisation de cette boutique, deux structures bâties sont alignées d'ouest en est, directement à l'est de l'accès (PR60066) présent sur le côté occidental du secteur D60a, ont été identifiées : il pourrait s'agir de la base d'un comptoir.

La première structure (SB60107) mesure entre 0,54 et 0,68 $\mathrm{m}$ de large ; elle a été observée sur $1,21 \mathrm{~m}$ et se poursuit vers l'ouest (fig.9). Sur son côté sud, mieux conservé, on distingue une construction mêlant l'opus vittatum et l'opus reticulatum, formant un opus quasi mixtum. La poursuite de la fouille permettra de mieux caractériser cette structure et d'observer son lien avec le seuil de la pièce (PR60066). Venant s'appuyer contre le parement oriental de la structure précédente, une construction postérieure (SB60119) et moins bien fondée a été mise en évidence. Elle mesure $0,86 \mathrm{~m}$ d'est en ouest, $0,94 \mathrm{~m}$ du nord au sud et est réalisée en moellons de tuf liés au mortier. Cette structure bâtie présente un parement sur ses côtés sud, est et nord, mais un comblement interne différent (US 60118). 
Fig. 9 - VUE des StRUCtURES bÂties SB60107 (À gAUCHE) ET SB60119 (À DROITE), DEPUIS LE SUD.

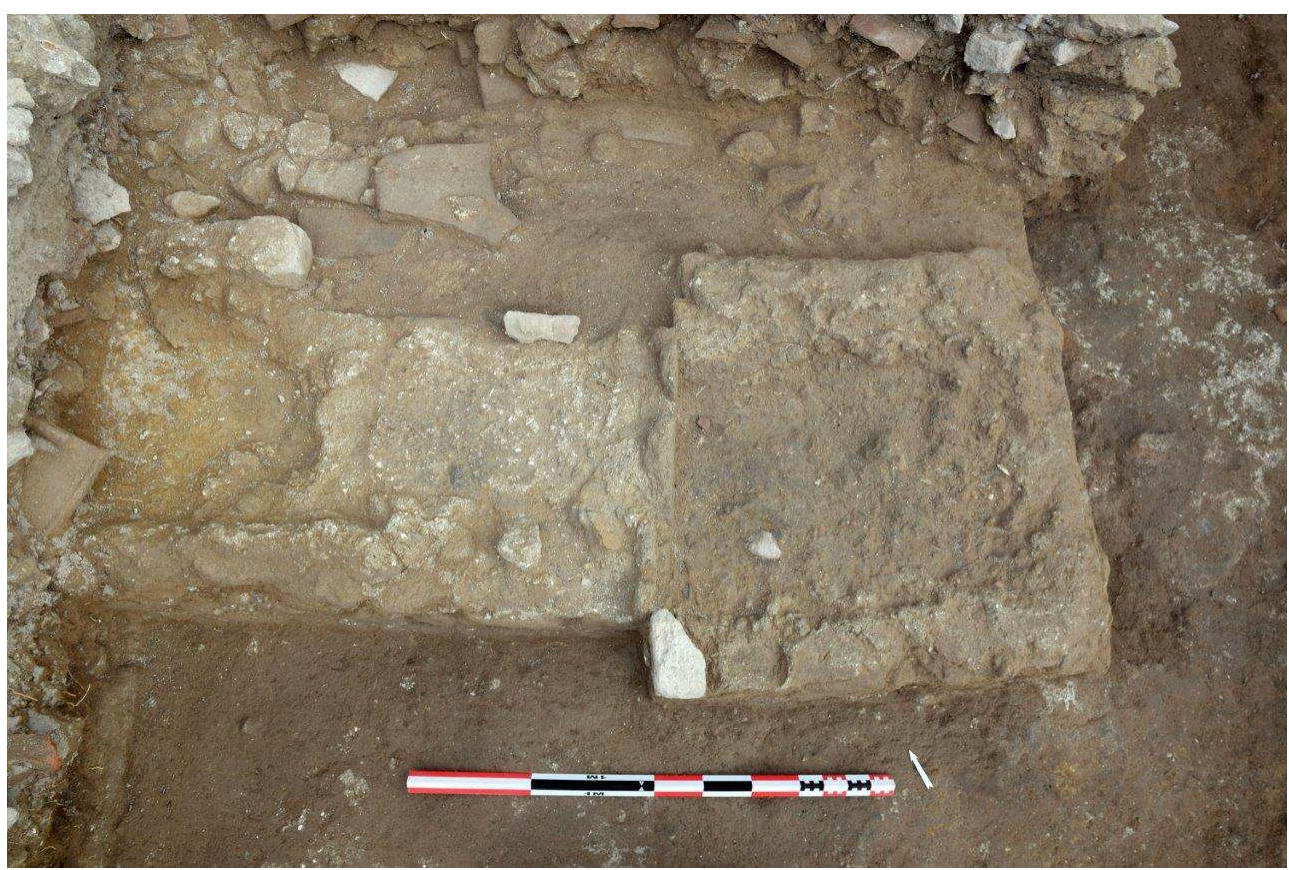

\section{Phase $6 \mathrm{C}$ : abandon et destruction des constructions de la phase $6 \mathrm{~A}$}

Lors de cette campagne, des niveaux de destruction des structures de l'état $6 \mathrm{~A}$ ont uniquement été observés dans l'espace D60a, notamment en raison des remaniements et de l'état d'avancement des fouilles dans les espaces D60b et D60c.

Sur le dernier niveau de fréquentation de la boutique (phase 6B: SL60109), un premier niveau de destruction a été mis en évidence (US 60106) (fig. 10). Il s'agit principalement de moellons de tuf, ainsi que de rares fragment de calcaire et notamment des fragments de sol provenant de l'effondrement d'un premier étage, directement présent sous le niveau de tuiles (US 60096). Ces éléments sont noyés dans une matrice de limon argileux compact. Les tuiles trouvées dans ce niveau sont probablement issues de l'effondrement de la toiture. Les blocs de maçonnerie provenant du sol de l'étage, sont faits de mortier coulé enserrant de petits moellons et présentant des traces de planches et/ou bastaings de bois d'un côté et d'une couche de mortier plus fin et lissé de l'autre côté. Trois monnaies ont été trouvées dans cette couche, émises entre les règnes de Tibère et d'Hadrien. Cependant, très peu d'éléments ont été découverts si l'on considère que le sol du premier étage couvrait la surface entière de la boutique. Il est donc envisageable qu'une partie de ces éléments ait été récupérée avant l'effondrement de la toiture en tuiles (US 60096). 
FIg. 10 - VUE DU NIVEAU DE DESTRUCTION 60106, DEPUIS LE NORD-EST (@ CJB).

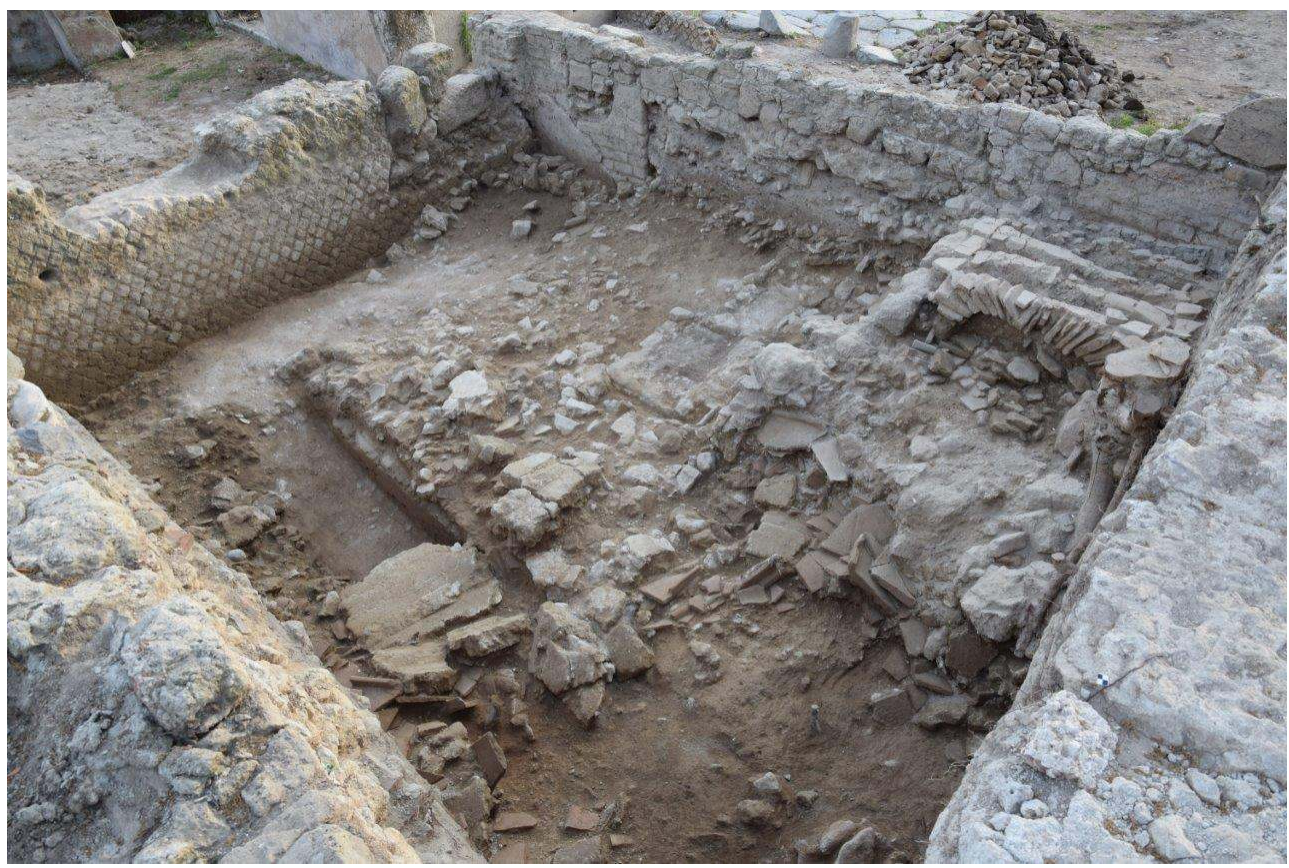

29 Au dessus des vestiges d'un sol de l'étage, un niveau d'effondrement de toiture (US 60096) a été observé (fig. 11). Présentant un pendage vers l'est, il est caractérisé par l'association de tegulae et d'imbrices. Des scellements d'imbrices, ainsi que des clous et de rares fragments de verre ont été identifiés dans une matrice de limon sableux. Cette couche scelle les niveaux de fréquentation et de destruction de la boutique, mais n'a pu être mise en évidence dans la pièce D60b à cause des remaniements médiévaux.

FIg. 11 - VUE dU NIVEAU d'EFFONDREMENT DE LA TOITURE US 60096, DEPUIS L'EST. AU PREMIER PLAN EST VISIBLE L'UN DES TUNNELS DES PILLEURS, LONgEANT LE CÔTÉ ORIENTAL DU MAUSOLÉE MSL60111 (C) CJB).

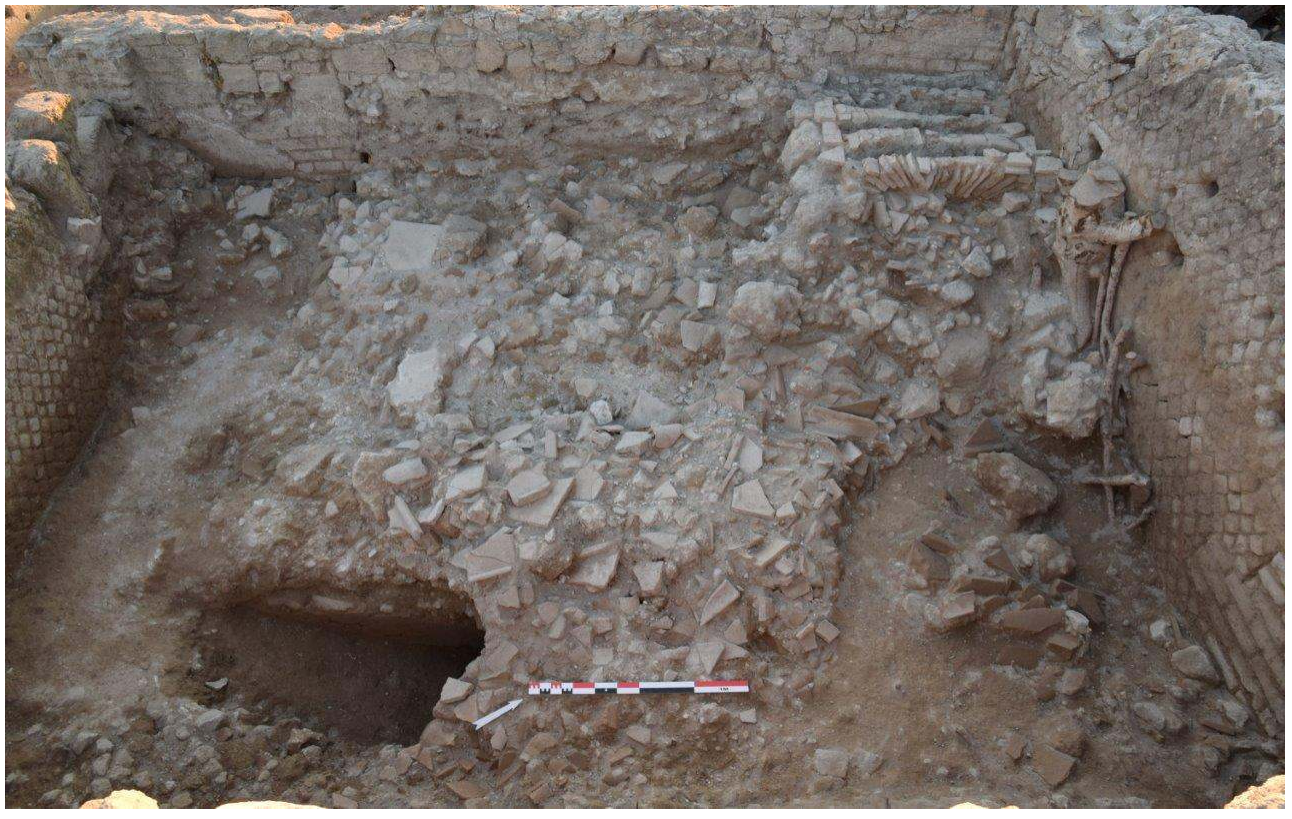




\section{Phase 7 : démantèlement et installations artisanales byzantines}

Durant la seconde moitié du VI et le début du VII ${ }^{\mathrm{e}}$ siècle, une campagne de spoliation des bâtiments eut lieu (Phase 7A) : elle concerne non seulement le mur de façade (nord-sud) en grand appareil de calcaire qui venait border la place sur son côté est, mais aussi des espaces/boutiques en arrière. Ce phénomène de récupération est probablement à mettre en relation avec la démolition des remparts après le milieu du $\mathrm{VI}^{\mathrm{e}}$ siècle. À la même époque, ou peu après (phase 7B), on observe la construction de fours de tuilier et d'un four à chaux fouillé par l'Université de «l'Orientale » dans l'espace de la Porte.

\section{Phase $7 A$ : démantèlement et récupération de matériaux}

31 Recouvrant l'ensemble de la zone fouillée dans l'espace D60a, une importante couche d'abandon (fig. 12) présentant un pendage vers l'est a été mise en évidence (US 60091). Il s'agit d'un niveau de moellons et de rares petits blocs de tuf jaune, pris dans une matrice de limon sableux. Cette couche semble correspondre à un long abandon après la récupération des blocs utilisables: ne restaient donc sur place que les pierres et les fragments de mortier informes. Quelques fragments de céramique et des os ont été découverts. Dans ces niveaux, les pilleurs du XVIII ${ }^{\mathrm{e}}$ siècle ou du XIX ${ }^{\mathrm{e}}$ siècle) ont creusé des tunnels.

FIg. 12 - VUE ZÉNITHALE DU NIVEAU D'ABANDON US 60091. ON OBSERVE L'APPARITION D'UN TUNNEL DE PILLEURS, EN BAS À gAUCHE (๑ CJB).

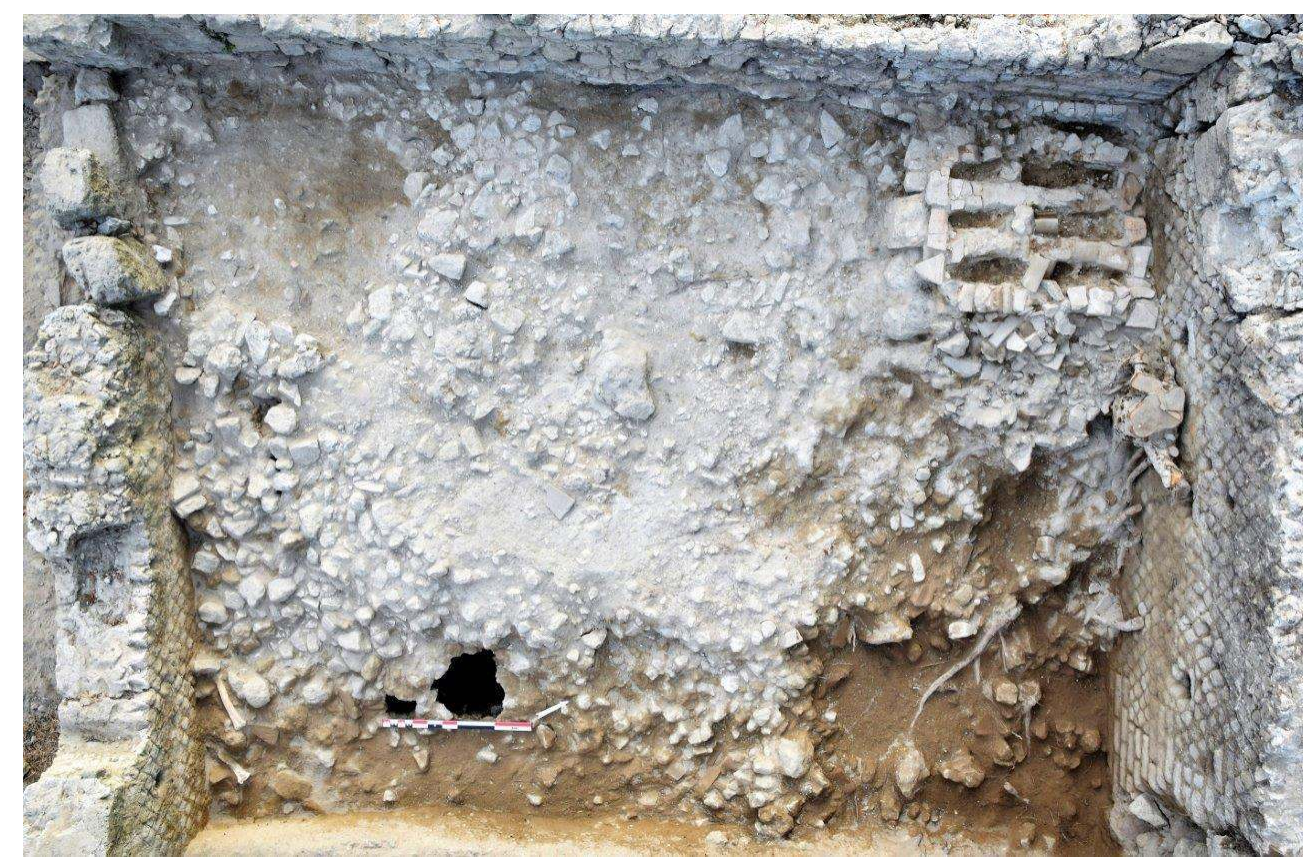

Phase 7B : installations artisanales

$\mathrm{Au}$ dessus des couches de destruction et d'abandon, un four - FR60086 - est installé dans l'angle nord-ouest de l'espace D60a. Aucun niveau de fréquentation proprement dit n'a été clairement mis en évidence; le sol doit correspondre à la surface du niveau de destruction US 60091. Le four est construit contre les murs MR60082 et MR60093 de la 
phase 6A, respectivement au nord et à l'ouest. Des traces de rubéfaction sont visibles sur ces murs, mais non sur leurs reprises d'époque médiévale (MR60094 au nord et MR60047 à l'ouest). Le four, rectangulaire, mesure 1,48 $\mathrm{m}$ de largeur du nord au sud et une longueur restituée de 2,14 m, d'est en ouest. Il présente une ouverture vers l'est; il est partiellement détruit sur son côté oriental, en raison des récupérations pus tardives et à cause des racines d'un arbre. Seuls les murs nord et sud sont conservés, ainsi que quatre arcs de soutènement de la sole. Les parois sont réalisées en blocs de tuf jaune irréguliers, alors que le reste de la structure est réalisé en fragments de tuiles liés à la terre. Tous ces matériaux portent des traces de rubéfaction dues à l'utilisation de la structure de cuisson. Comme cela a pu être effectué sur l'un des deux fours découverts à l'intérieur de la chambre funéraire du mausolée D59 (FR59006), l'analyse archéomagnétique des parois en place précisera la datation de la dernière utilisation de la structure ${ }^{4}$. Le croisement des analyses de ces deux structures permettrait de vérifier si leur utilisation fut contemporaine.

Un niveau de comblement et d'éléments issus de l'effondrement du four FR60086 (US 60104) a pu être identifié et partiellement fouillé dans la partie orientale de la structure. En effet, cette partie du four étant détruite et très perturbée par les racines, il a été possible de fouiller ce niveau présentant des éléments provenant de la construction des arcs de soutènement de la sole, liés dans une matrice limono-argileuse compacte. Un niveau cendreux (US $60087=60105$ ), présentant de rares fragments de charbons, a été observé sur près de $1,00 \mathrm{~m}$ du nord au sud et $0,75 \mathrm{~m}$ d'est en ouest.

\section{Phase 8 : abandon de la zone}

Après les démantèlements et les occupations d'époque byzantine, une longue phase d'abandon s'est traduite par d'importants dépôts. Sur l'effondrement (US 60104) du four FR60086, deux niveaux ont été identifiés : tout d'abord une couche de limon argileux (US 60103), présentant des fragments de tuiles, de tuf jaune et de rares fragments de mortier. Ensuite, un second niveau recouvrit le précédent (US 60092). Il correspond à un limon peu compact, perturbé par les racines de l'arbre présent contre le parement sud du mur MR60082.

Sur la couche précédente, sur le four FR60086, ainsi que dans l'ensemble de l'espace D60a, un épais niveau de sédimentation naturelle a été observé (US 60079). Identifié lors de la campagne 2014 (US 60024), il avait été placé dans une phase d'abandon antérieure (phase 6C). Cependant, la découverte du four FR60086 et des niveaux associés permet d'avancer qu'il s'agit d'une phase postérieure au début de la période byzantine. Cette épaisse couche présente un pendage vers l'est et elle est constituée d'un limon argileux compact contenant peu de mobilier céramique résiduel.

Une couche postérieure (US 60078) constitué de nombreux blocs de tuf, ainsi que de gros blocs de maçonnerie (opus reticulatum et opus vittatum) avait déjà été mise au jour lors de la campagne de 2014 (US 60009, 60038 et 60036). Ces éléments sont pris dans une matrice de limon argileux et correspondent à une phase d'abandon de la zone, durant laquelle se sont effondrés des murs de la phase 6A) qui était encore en élévation (principalement MR46005, MR60061, MR60082 et MR60033).

Sur ce niveau d'effondrement caractéristique, un dernier niveau d'abandon avait été observé (US 60046) dans ce secteur D60a lors de la campagne de 2014. Il s'agit d'un limon 
brun foncé, compact incluant de rares blocs de maçonnerie, de tuiles et quelques tessons de céramique.

\section{Phase 9 : installations médiévales (fig. 4) \\ Phase 9 : le bâtiment d'époque médiévale}

Beaucoup mieux appréhendés que lors de la campagne de 2014, durant laquelle les éléments de cet état se limitaient principalement à des structures et des niveaux d'occupation ténus, de notables vestiges médiévaux ont été identifiés en 2016. L'espace délimité et occupé par cette habitation médiévale a pu être cerné et caractérisé.

L'espace occupé au Moyen Âge concerne l'ensemble de la zone D60 et donc les trois secteurs. Sur le secteur D60a, des niveaux d'habitation sont associés à du matériel céramique, ainsi qu'une structure identifiée comme la base d'un escalier menant à une habitation. Cette dernière, dont les niveaux conservés dans les secteurs D60b et D60c correspondent à des pièces de stockage auxquelles on accédait depuis l'étage. Il pourrait s'agir d'une « maison forte » comme il en existe dans la campagne à cette époque.

Le secteur D60a: les installations relatives à cette période d'occupation reprennent les murs d'époque impériale (phase 6A), les ouvertures étant bouchées afin d'obtenir un espace entièrement fermé. Ainsi, sur le secteur D60a, les murs d'époque romaine MR46005 à l'est, MR60033 au sud, MR60061 et MR60082 au nord, MR60093 et MR46103 à l'ouest, sont complétés par les murs MR60057 au sud-ouest, MR60047 et MR60058 à l'ouest, MR60094 et MR60032 au nord. Le bouchage MR60057, orienté est-ouest, est présent dans la partie ouest du mur MR60033 (coupé à cette extrémité). Il est fait de quatre blocs de tuf jaune de taille moyenne et mesure $1,50 \mathrm{~m}$ de longueur sur $0,40 \mathrm{~m}$ de largeur.

41 Présentant une construction semblable et bouchant la fenêtre FN60068 du mur MR46103, le mur MR60058 (fig. 13) est constitué d'un gros bloc de tuf jaune et de blocs plus petits, liés par du mortier. Cette maçonnerie mesure 0,64 $\mathrm{m}$ (est-ouest), 0,52 m (nord-sud) et $0,68 \mathrm{~m}$ de hauteur conservée.

\section{FIg. 13 - L'OUVERTURE FN60068 ET SON MUR DE BOUCHAgE (MR60058), INSTALLÉS DANS LE MUR MR46103, DIRECTEMENT AU SUD DU SEUIL PR60066, VUS DEPUIS L'OUEST (@ CJB).}

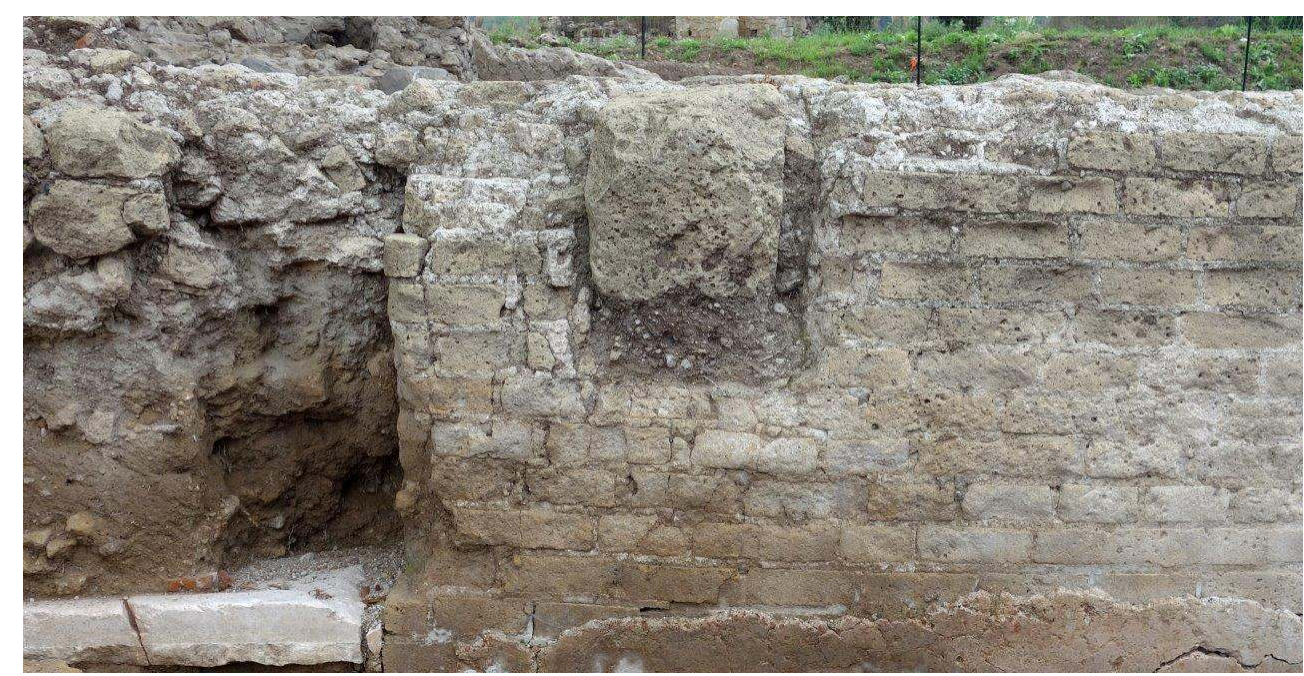



et MR60093, fermant l'espace sur son côté occidental. Ce mur reprend l'emprise du seuil PR60066 de la boutique et se poursuit au nord, jusqu'à rejoindre le mur MR60094. La fondation coulée en mortier gris et cailloutis (US 60048) mesure 0,60 à 0,64 m de largeur, pour 0,30 à $0,40 \mathrm{~m}$ d'épaisseur. Le mur MR60047, orienté nord-sud, est construit sur cette couche, dans l'axe des structures clôturant la boutique BTQ60066 (MR46103 et MR60093). Il est composé de blocs de tuf de différentes tailles avec quelques fragments de tuiles, le tout lié dans un mortier blanc. Ce mur mesure 3,70 m de longueur, sur 0,64 m de largeur maximale et $0,52 \mathrm{~m}$ de hauteur conservée.

Au nord-ouest de l'espace se trouve le mur MR60094, à l'extrémité occidentale du mur MR60082 (phase 6A), fermant la boutique au nord. Celui-ci vient reprendre le mur antique ; il est chaîné avec le mur MR60047 et réalisé en blocs irréguliers de tuf jaune, liés avec un mortier de terre et chaux de couleur grise ; il mesure 1,36 $\mathrm{m}$ de longueur, 0,55 m de largeur et il est conservé sur $0,90 \mathrm{~m}$ de hauteur.

44 À l'est du précédent, le mur MR60032 (fig. 7) bouche la porte PR60126, entre les murs MR60082 et MR60066. Chaîné au mur MR60030, affirmant leur contemporanéité, il est construit en blocs de tuf jaune de tailles différentes et de quelques fragments de béton de tuileau, liés dans un mortier de terre et chaux. Une assise de quatre gros blocs de tuf traversant est installée en partie inférieure (saillant par rapport au reste du parement sud). Il mesure $3,00 \mathrm{~m}$ de longueur, $0,56 \mathrm{~m}$ de largeur et est conservé sur $0,98 \mathrm{~m}$ de hauteur. Il est à noter qu'un bouchage inférieur (MR60131, non traversant) a pu être observé dans le secteur D60b. Ce dernier intervient au moment de l'aménagement de la pièce inférieure de l'habitation et cela explique pourquoi il n'est pas visible dans le secteur D60a.

L'espace délimité par ces murs correspond à l'emprise du secteur D60a (fig. 4), soit 7,30 m d'est en ouest et $6,10 \mathrm{~m}$ du nord au sud, mais sa fonction reste imprécise. Il pourrait s'agir des limites d'une cour devant l'habitation (secteurs D60b et D60c). En effet, dans l'angle nord-est, un ensemble de murs définissant un ensemble ENS60030 avait été mis en évidence lors de la campagne de 2014. Bien qu'identifié comme médiéval, sa fonction restait difficile à définir. A la lumière des découvertes de 2016, il convient de l'interpréter comme la fondation d'un escalier donnant accès au premier étage de l'habitation.

Cet ensemble ENS60030 est constitué des murs MR60030, MR60031 et MR60032, qui délimitent un espace avec le mur MR46005. Le mur MR60030, orienté nord-sud est chaîné au nord au mur MR60032 et au sud au mur MR60031. Il mesure 4,40 $\mathrm{m}$ de longueur, pour une largeur allant de $0,60 \mathrm{~m}$ à $0,80 \mathrm{~m}$ (côté sud) et il est conservé sur une hauteur maximale de 0,80 $\mathrm{m}$. Il est construit en blocs de tuf de tailles différentes, de fragments de tuiles plates, de blocs ou de fragments de blocs de trachyte extraits de la via Domitiana et d'un bloc béton de tuileau; tous ces éléments sont liés par un mortier sableux clair. Comme le puits creusé au centre de la place est contemporain de cette phase, il est probable que les blocs de trachyte proviennent de ce creusement.

47 Le mur MR60031, orienté est-ouest est chainé à l'ouest au mur MR60030 et s'appuie sur le mur MR46005 à l'est. Il mesure 2,15 $\mathrm{m}$ de longueur, pour une largeur maximale de 0,60 m et une hauteur conservée de 0,45 $\mathrm{m}$. Il est construit en blocs de tuf de tailles différentes et de quelques fragments de blocs de la via Domitiana, liés par un mortier sableux clair.

Le mur MR60032, orienté est-ouest est chaîné au mur MR60030. Il a été dégagé sur 2,20 m de longueur, pour une largeur maximale de $0,54 \mathrm{~m}$ et sur une hauteur conservée de 0,90 
m. Il est construit en blocs de tuf de tailles différentes et de quelques blocs de béton de tuileau, liés par un mortier sableux clair. Ce mur est une reprise du mur sud (MR60061) du mausolée antique MSL60023. Il s'agit d'un réaménagement profond de ce mur, endommagé à une époque encore indéterminée, qui semble se poursuivre à l'ouest du mur MR60030.

Les trois murs MR60030, MR60031 et MR60032, délimitent, avec le mur MR46005 une structure de 4,40 m (nord-sud), sur 2,15 m (est-ouest) et un espace interne de 4,00 m, sur $1,30 \mathrm{~m}$ (fig. 14). Dans la partie sud de cet espace, un autre mur (MR60034) est lié aux murs précédents et vient raccourcir un peu cet espace. Ce mur est orienté est-ouest et vient s'appuyer à l'ouest contre le mur MR60030 et contre le mur MR46005 à l'est. Il mesure 1,46 $\mathrm{m}$ de longueur, pour une largeur maximale de $0,80 \mathrm{~m}$ et une hauteur conservée de $0,66 \mathrm{~m}$. Sa construction comprend deux niveaux (fig. 15) : tout d'abord, il comporte, sur $0,30 \mathrm{~m}$ d'épaisseur, de gros galets de basalte et quelques fragments de tuiles plates. Ensuite, une partie supérieure est composée de trois grosses dalles de la via Domitiana, retournées, le tout lié par un mortier blanc.

Fig. 14 - VUE ZÉNITHALE dE L'ENSEMBLE ENS60030 (๑ CJB).

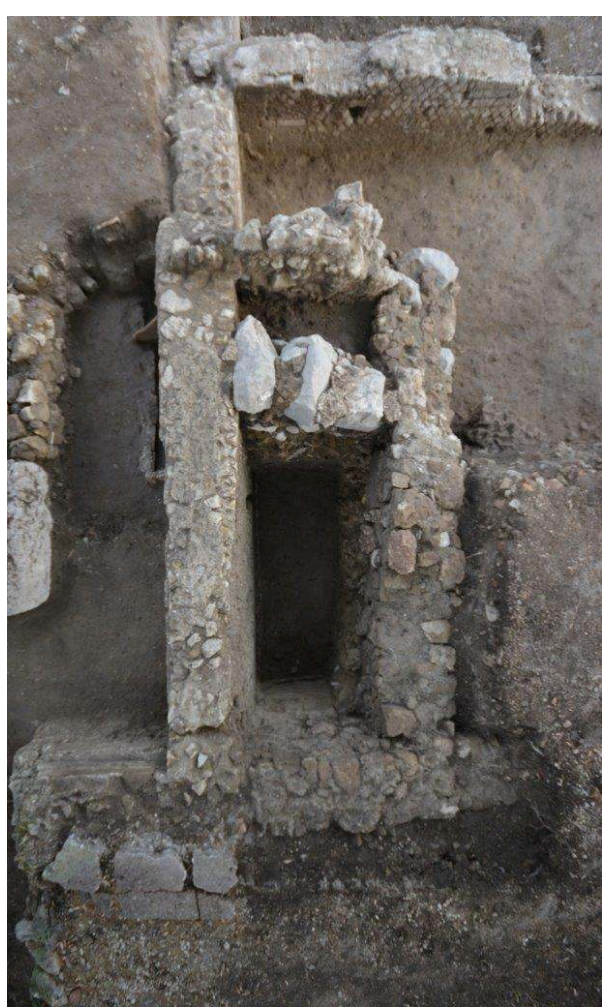


FIg. 15 - LE PAREMENT NORD DU MUR MR60034 ET LES NIVEAUX ANTÉRIEURS (US 60009 ET US 60024), VUS DU NORD (๑ CJB).

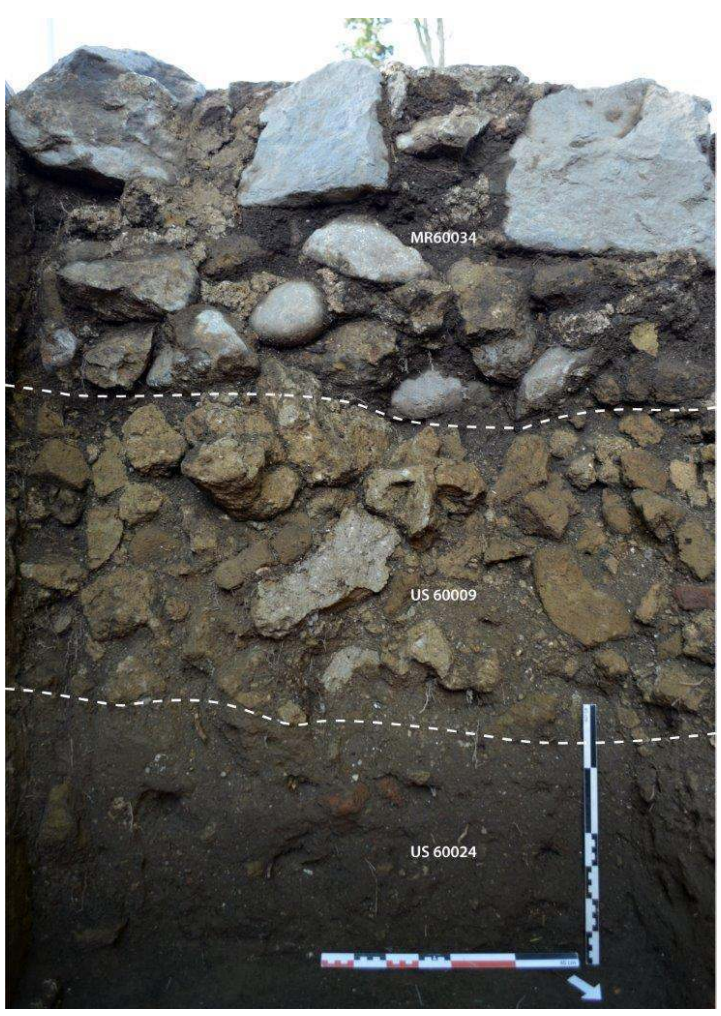

Les secteurs D60b et D60c: au nord du secteur D60a, caractérisé par un espace clos avec les vestiges d'un probable escalier d'accès, se trouvent les secteurs D60b et D60c (respectivement au nord-est et au nord-ouest) présentant l'emprise d'une habitation (fig. 4). Ces deux secteurs correspondent à deux pièces distinctes, partiellement enterrées. La pièce D60b est délimitée par les murs antiques au sud, à l'est et à l'ouest (respectivement MR60061, MR60125 et MR60099), qui sont repris par des murs de la phase médiévale. L'espace ainsi délimité (3,70 $\mathrm{m}$ d'est en ouest et 4,00 $\mathrm{m}$ du nord au sud) est fermé au nord par le mur MR60129 (fig. 7). Ce dernier, mesurant 0,44 $\mathrm{m}$ de large, a été observé sur 1,22 m de hauteur. Il s'agit d'une maçonnerie de gros moellons irréguliers de tuf jaune portant des traces d'outils, ainsi que quelques fragments de tuiles et de poteries. Ces éléments sont liés par un mortier gris sableux recouvert en partie basse par un enduit semblable mais un peu plus clair.

51 Au sud, le mur MR60032 bouche la partie haute de la porte antique PR60126 et complète le mur MR60061 (fig. 7). Ce mur, présenté précédemment (cf. description des structures du secteur mitoyen D60a) est édifié sur le bouchage inférieur de la porte. Ce dernier (MR60131) n'est pas traversant, mais soutient les épaisses couches de destruction antiques présentes au sud, dans le secteur voisin. Cela trouve une explication dans la réalisation de l'habitation médiévale et la volonté d'avoir des pièces au niveau inférieur, reprenant la plupart des structures antiques des deux pièces D60b et D60c. Ainsi, les remblais comblant ces espaces, dus à la destruction et l'abandon pièces D60b et D60c ont été enlevés au Moyen Âge. Le bouchage (MR60131) présente un parement fait de moellons irréguliers de tuf jaune, liés au mortier terreux. Il mesure 1,20 m de large, 0,90 $\mathrm{m}$ de hauteur, sur une épaisseur inconnue. Il est à noter qu'un bloc de plus grande dimension est saillant par rapport au parement. Il inclut quelques fragments de tuiles plates posées à 
plat en haut de ce mur, réalisant un lit horizontal pour poser les blocs de grandes dimensions en tuf jaune appartenant au mur supérieur MR60032. La partie inférieure de ce mur présente de l'enduit, proche du mortier servant de liant à la maçonnerie.

À l'est, le mur MR60130 reprend le mur antique MR60125 et correspond à une maçonnerie de gros moellons irréguliers de tuf jaune, ainsi que de quelques fragments de tuiles et de rares remplois de blocs de maçonnerie. Ces éléments sont liés par un mortier gris sableux.

À l'ouest, le mur MR60083 mitoyen avec le secteur D60c, reprend le mur antique MR60099 (fig. 7). Il mesure 0,55 à 0,57 $\mathrm{m}$ de large pour une hauteur conservée de 0,10 à $1 \mathrm{~m}$. Il est réalisé en gros moellons irréguliers de tuf jaune, avec quelques fragments de tuiles et de rares blocs de maçonnerie liés par un mortier de terre gris sableux.

Dans l'espace D60c, mesurant 3,90 m d'est en ouest et 3,96 m du nord au sud, les structures médiévales sont encore peu dégagées, en dehors des murs précédemment décrits MR60083 (cf. secteur D60b) et MR60094 (cf. secteur D60a). En effet, l'espace quasiment identique au secteur D60b est délimité par les structures antiques (MR60082, au sud et MR60099 à l'est), et par les murs modernes reprenant les structures médiévales (MR60012, au nord et MR60015 à l'ouest).

En conclusion, l'habitation médiévale observée dans la zone D60 comprend un espace au sud, délimité par les murs antiques encore visibles et des murs construits afin de créer une habitation de près de $44,50 \mathrm{~m}^{2}$ au sol, avec un escalier au nord-est. Cette habitation possédait deux niveaux et dont deux pièces semi-enterrées d'environ 15 à $15,5 \mathrm{~m}^{2}$ chacune.

\section{Phase 9B : occupation d'époque médiévale}

Les niveaux de fréquentation de l'époque médiévale ont été aperçus dans le secteur D60a, mais sont surtout illustrés par les niveaux d'occupation retrouvés dans le secteur D60b. Ces derniers présentent un contexte très intéressant en raison de leur état de conservation lié à un incendie et à l'effondrement des structures, venues le sceller.

Un niveau d'occupation difficilement identifiable avait été observé et partiellement fouillé lors de la campagne 2014 (SL60072 = SL60077), à l'ouest et au sud de la structure ENS60030 (fondation de l'escalier) localisée dans l'angle nord-est du secteur D60a. À l'intérieur de cette structure, le sondage réalisé n'avait pas permis d'identifier ce niveau de fréquentation, ce qui est logique si, comme nous le pensons, cet espace est un escalier.

Ce niveau de sol, en lien avec les structures médiévales, se trouve à l'interface entre les niveaux de destruction de la phase 8 (US 60046) et les niveaux d'abandon et d'effondrement (US 60073 $=60076$ ) des structures médiévales (phase 9C). Il est visible dans l'espace à l'ouest du mur MR60030 et présente un pendage vers l'ouest avant de disparaître aux abords du mur MR60047. Du matériel céramique caractéristique du XIII ${ }^{\mathrm{e}} \mathrm{s}$. fait le lien avec les éléments découverts dans le secteur D60b.

Dans le secteur D60b, la construction du bâtiment de la phase 9A est caractérisée par le sol SL60114, réalisé en mortier gris très compact (fig. 16). Ce sol repose sur des remblais de destruction et d'abandon (identifiés dans le secteur voisin D60a) dont une grande part a été prélevée afin de créer une pièce semi-enterrée (cf. supra). Ce niveau de mortier remonte légèrement sur les bords, à proximité des murs antiques, mais aussi du mur fermant l'espace au nord, attestant donc sa postériorité même brève. Ce sol SL60114 a été 
réalisé afin de créer une pièce relativement saine et protégée, dont l'accès se faisait par le niveau supérieur, et dont la vocation de stockage semble assurée.

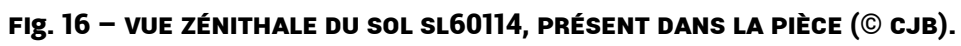

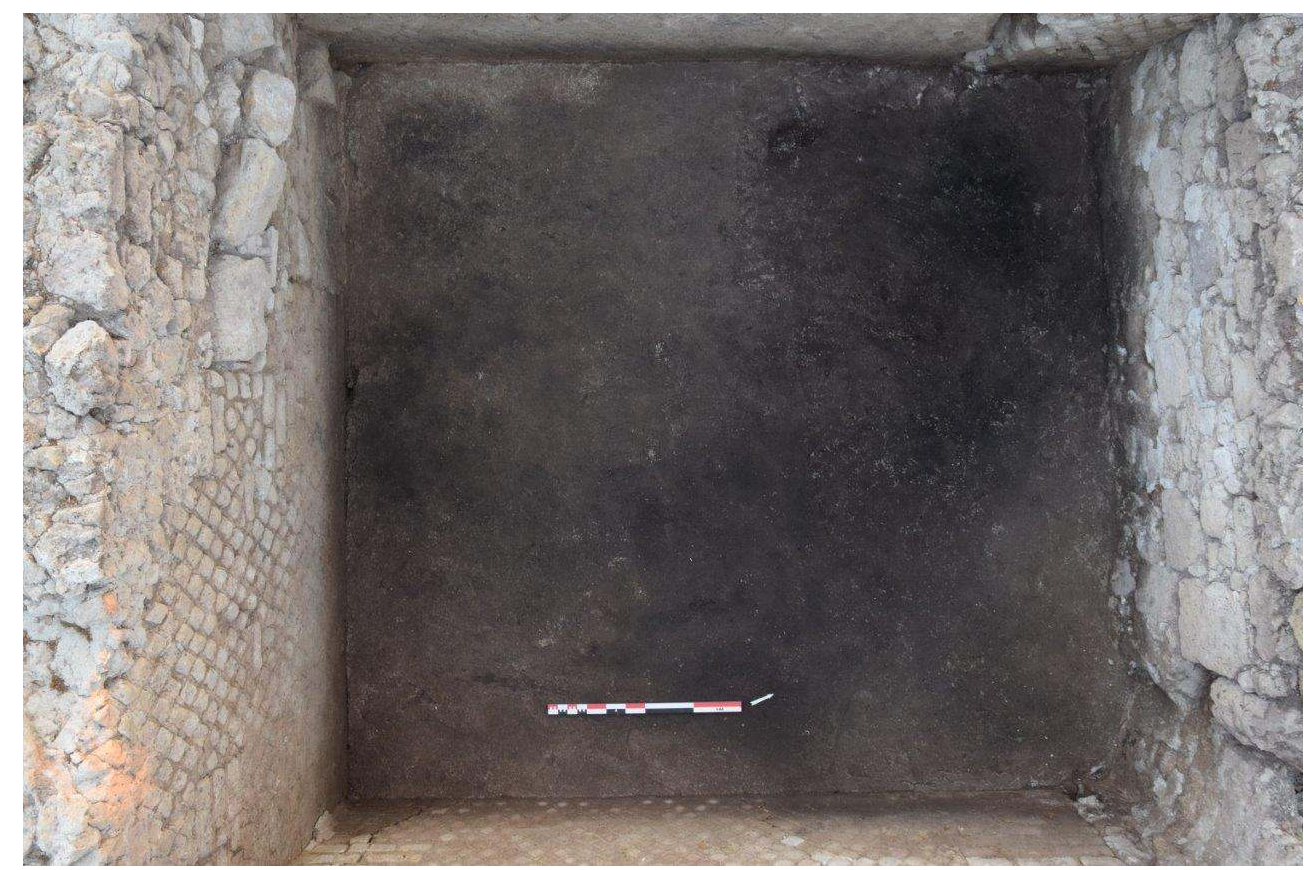

Sur ce sol, deux niveaux de sédimentation ont pu être identifiés. L'un (US 60108) est localisé dans l'angle sud-ouest de la pièce et mesure 1,10 $\mathrm{m}$ du nord au sud 0,66 $\mathrm{m}$ d'est en ouest et jusqu'à 3 à $5 \mathrm{~cm}$ d'épaisseur. L'autre (US 60113) est localisé dans l'angle nord-est de la pièce et mesure $1,30 \mathrm{~m}$ du nord au sud 1,60 m d'est en ouest et jusqu'à 3 à $4 \mathrm{~cm}$ d'épaisseur. Les deux couches sont constituées d'un limon argileux gris moyen et compact, présentant quelques inclusions de mortier.

61 Sur l'ensemble des niveaux de sol et de sédimentation, une importante quantité de matériel a été découvert dans les niveaux d'incendie et de destruction de l'édifice. Ces couches d'incendie (US 60090) du niveau inférieur et d'effondrement de l'étage (US 60098) et de ses installations sont parfois difficilement dissociables en raison des bouleversements occasionnés.

62 Le niveau US 60090 (fig. 17) est caractérisé par un limon brun, peu compact et très foncé, en raison de la forte présence de charbons de bois. Le sédiment de ce niveau a été prélevé. De nombreux objets, principalement en fer et en céramique, ont été découverts, ainsi que cinq monnaies, des coquillages et des ossements. 
FIg. 17 - VUE DU NIVEAU d'INCENDIE US 60090 ET DE LA JARRE DANS L'ANgLE NORD-OUEST DE LA PIÈCE D60B, DEPUIS L'OUEST (৫) CJB).

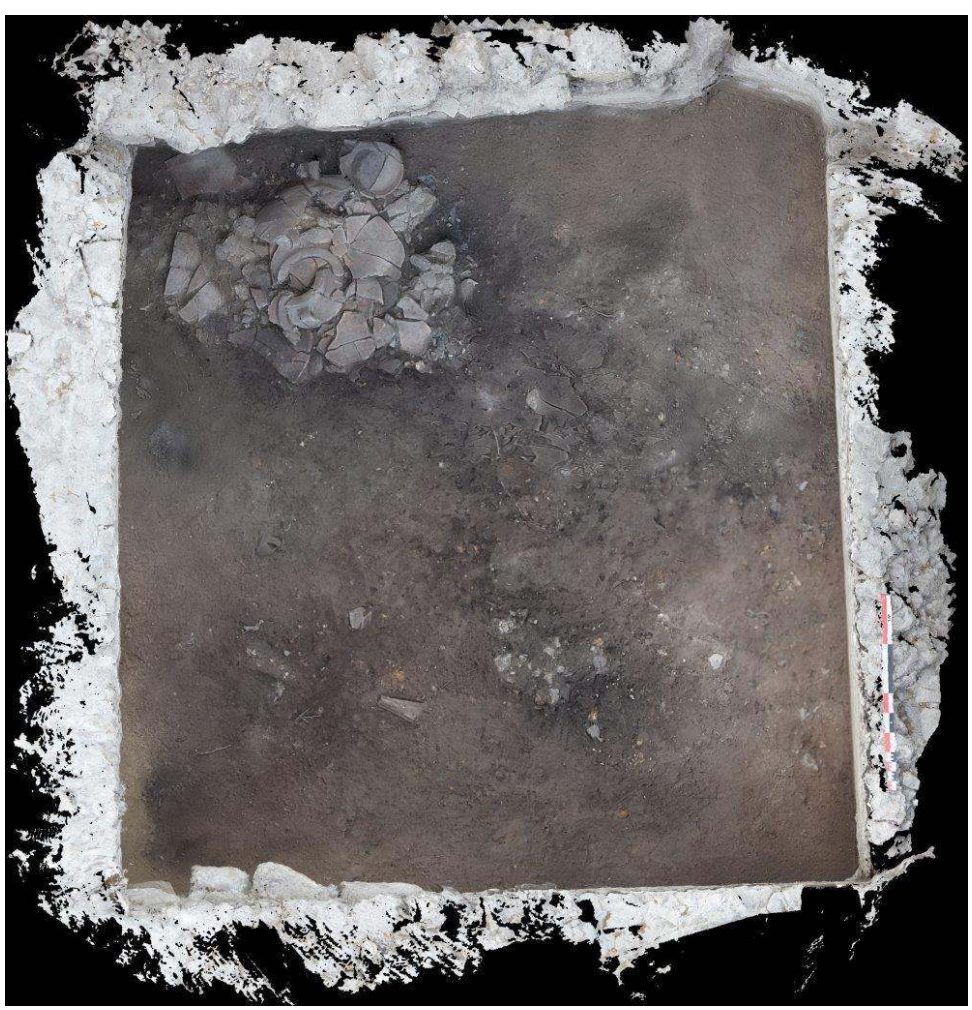

63 La jarre en céramique 60090-CE01 ( = 60102) a été enregistrée dans la couche US 60090, mais lors de son prélèvement, des fragments du sol de l'étage (US 60098) ont été découverts en dessous, attestant qu'elle devait probablement s'y trouver à l'origine. Quoi qu'il en soit, cette jarre date de la dernière occupation.

64 Le niveau US 60098 correspond à l'effondrement du sol de l'étage du bâtiment. Il est présenté succinctement ici car le mobilier s'est mélangé lors de la chute de grandes plaques de sols, directement sur le niveau d'incendie US 60090.

65 Une première étude des monnaies permet de les dater des $\mathrm{XII}^{\mathrm{e}}-\mathrm{XIII}{ }^{\mathrm{e}}$ siècles. Les céramiques permettent d'avancer une datation autour du XIII ${ }^{\mathrm{e}}$ siècle (fig. 18).

Fig. 18 - PRÉSENTATION dU TYPe de MATÉRIEL CÉRAMIQUe CARACTÉRISTIQUE dE LA PHASE 9B (๑ CJB).

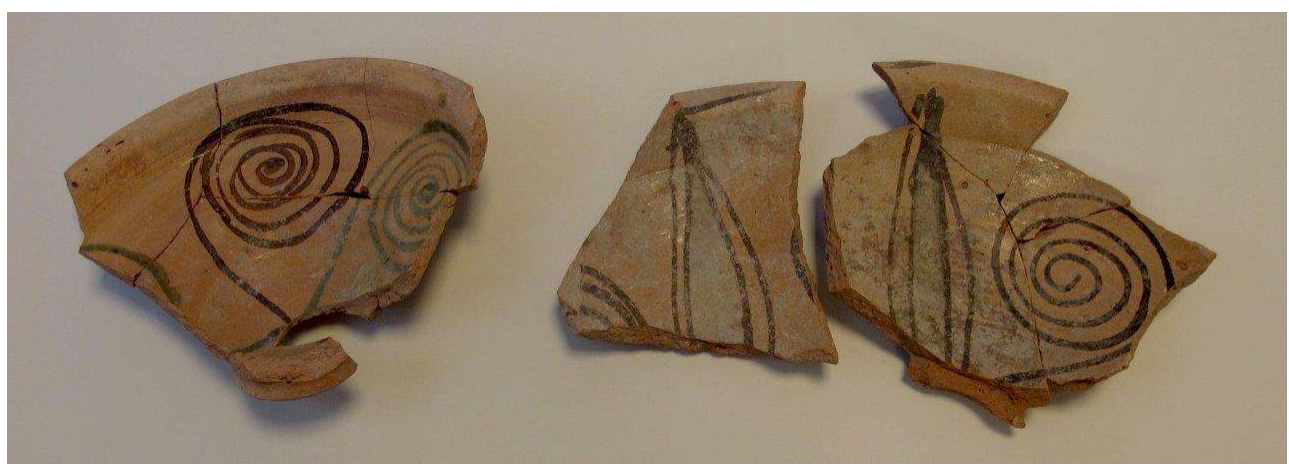




\section{Phase 9C: destruction et abandon des structures d'époque médiévale}

Venant sceller les niveaux d'occupation de l'ensemble d'époque médiévale, des niveaux de destruction et d'effondrement ont été identifiés, notamment dans les secteurs D60b et D60c.

Le secteur D60a: au-dessus du niveau de sol SL60072 ( = SL60077), une couche de destruction (US 60073 $=60076$ ) a été observée. Cependant, ce niveau de blocs épars, provenant de la destruction des structures, a pu faire l'objet de récupérations. Par dessus ce niveau, la couche US $60008=60075$ pourrait correspondre à une lente sédimentation caractérisant un abandon qui s'arrêterait avec la construction de la structure moderne SB60011. Ce niveau présente un limon brun foncé pratiquement sans inclusions et vient buter contre les structures médiévales.

Les secteurs D60b et D60c : au-dessus de la couche d'incendie (US 60090), découvert sur le sol SL60114 de la pièce D60b, un premier niveau d'effondrement (US 60098) correspond au sol du premier étage du bâtiment (fig. 19). Il présente notamment plusieurs grandes plaques fragmentées et effondrées à plat. Du matériel céramique, métallique et de la faune ont été découverts dans cette couche, en plus de fragments de tuf jaune rubéfiés et très friables. Les fragments de sol présentent une sorte de hérisson de petites pierres (autour de $6 \mathrm{~cm}$ d'épaisseur), recouvert par un mortier relativement grossier et lissé en surface (autour de $5 \mathrm{~cm}$ ).

FIg. 19 - LE NIVEAU d'EFFONDREMENT dU SOL dU PREMIER ÉtAge (US 60098) ET LA JARRE 60102, VUS DEPUIS L'OUEST (@ CJB).

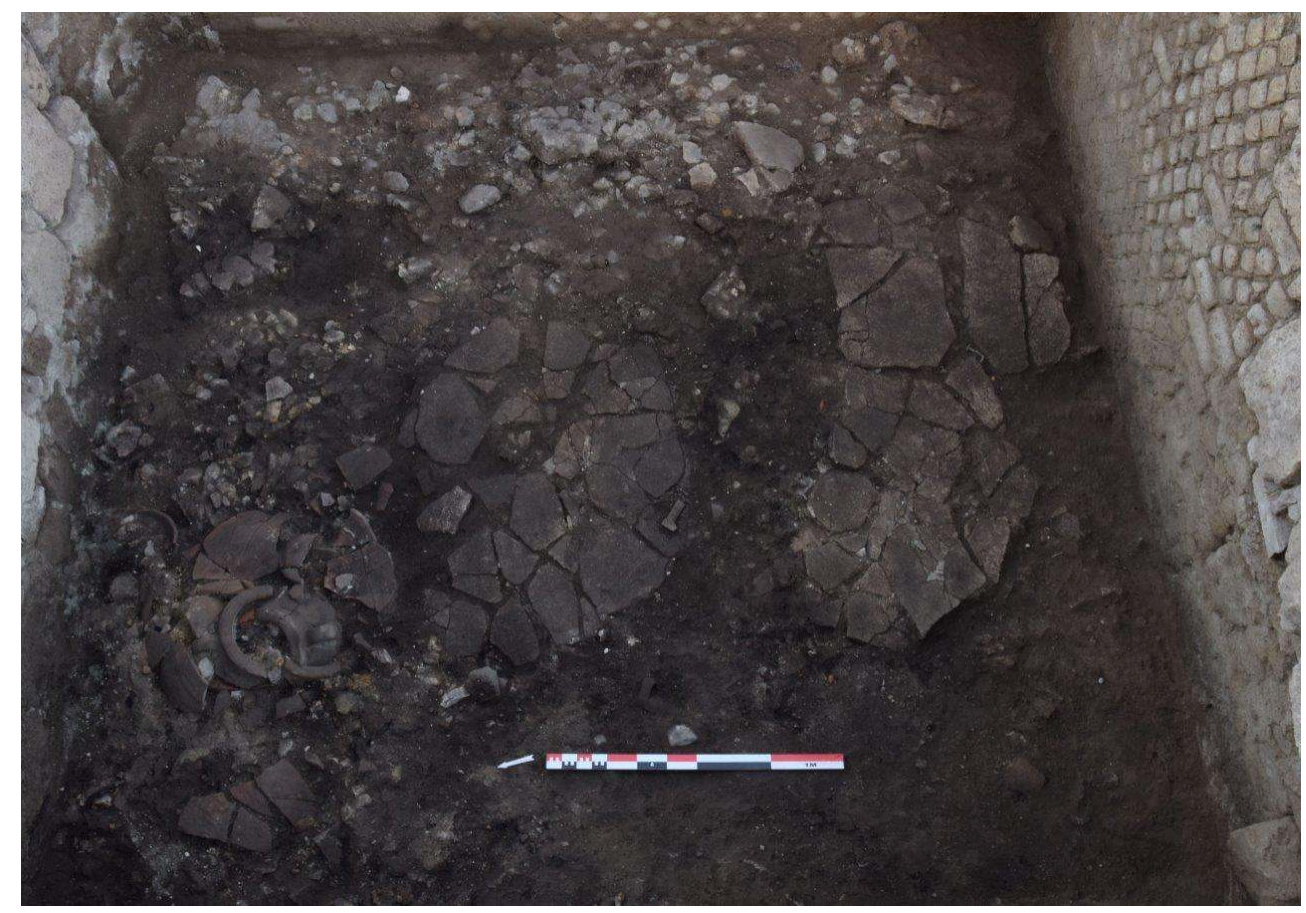

Une couche d'effondrement d'éléments de sol et de toiture (US 60089) vient recouvrir les niveaux précédents (fig. 20). Les éléments provenant des sols et/ou du système de couverture (terrasse et tuiles?), sont pris dans une matrice de limon brun foncé présentant quelques charbons. De nombreux blocs et plaques de béton (de 10 à $15 \mathrm{~cm}$ d'épaisseur et lissés d'un seul côté) ont été retrouvés à plat ou en vrac. Des tuiles ont été 
systématiquement prélevées, mais leur nombre ne laisse pas penser à une toiture uniquement en tuiles, mais peut-être mixte ; sous réserve qu'elles n'aient pas fait l'objet de récupération ou que l'effondrement du toit ne soit pas uniquement localisé dans l'espace fouillé.

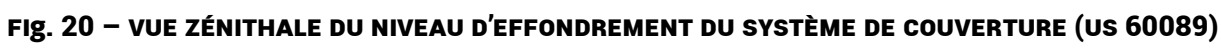
(๑ CJB).

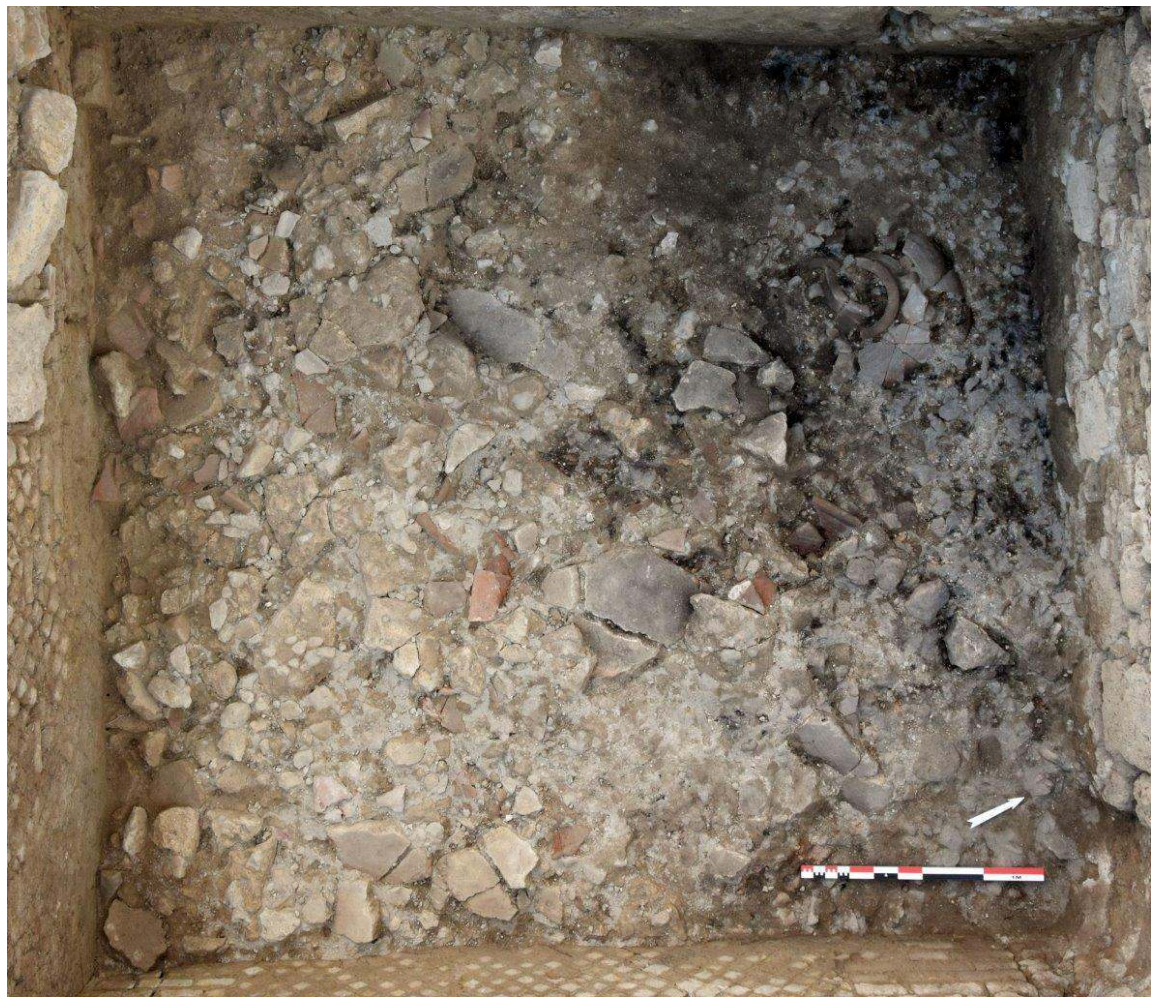

Enfin, un niveau de blocs traduisant l'effondrement des parties hautes des murs de l'édifice a pu être mis en évidence dans les pièces D60b (US 60089), mais aussi D60c (US 60097). Ces niveaux sont constitués de gros blocs de tuf jaune taillés de manière irrégulière (fig. 21), ainsi que de rares blocs de basalte, certains pouvant correspondre à des encadrements de porte ou fenêtre. Ces blocs sont noyés dans une matrice de limon brun moyen, présentant des fragments de tuf et de mortier, issus des mêmes murs effondrés. 
FIg. 21 - VUE dU NIVEAU d'EFFONDREMENT DES PARTIES HAUTES dU BÂTIMENT (US 60097) DANS LA PIÈCE D60C, SUR LEQUEL VIENDRA SE FONDER LE MUR MODERNE MR60015 (PHASE 10), DEPUIS L'EST (๑ CJB).

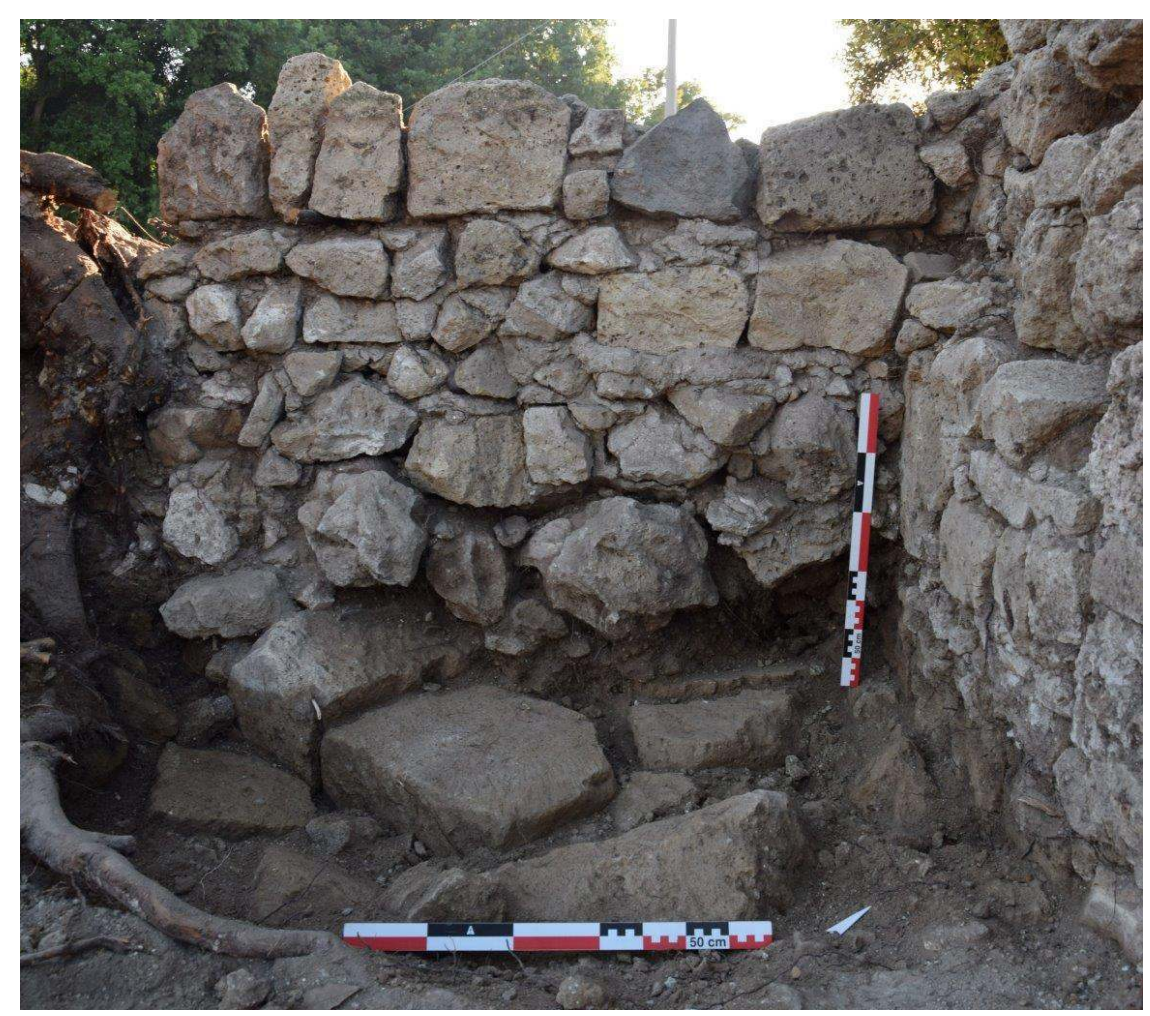

Phase 10A : nivellement de la zone

Déjà observé lors de la campagne de 2014 : après un long abandon, le secteur est nivelé à une cote autour de 6,45 m s.l.m. En effet, les structures antiques et médiévales sont arasées à la même hauteur que la sédimentation d'abandon (US 60008 du secteur D60a) de la phase 9C. Un remblai (US 60007) de petits blocs, fragments de tuiles et céramiques, est étalé sur l'ensemble de l'emprise de la structure moderne (SB60011) construite par la suite, lors de la phase 10B.

72 Sous ce remblai général (US $60007=600075$ ) et sur les niveaux d'effondrement des parties supérieures du bâtiment d'époque médiévale se trouve un premier niveau de remblais venant combler les espace D60b (US 60080) (fig. 22) et D60c (US 60081), jusqu'au niveau d'arase des structures. Ces remblais de nivellement sont constitués d'une matrice de limon brun moyen, peu compacte, incluant de nombreux petits moellons de tuf jaune, ainsi que des fragments de mortier et de tuiles. 

(C) CJB).

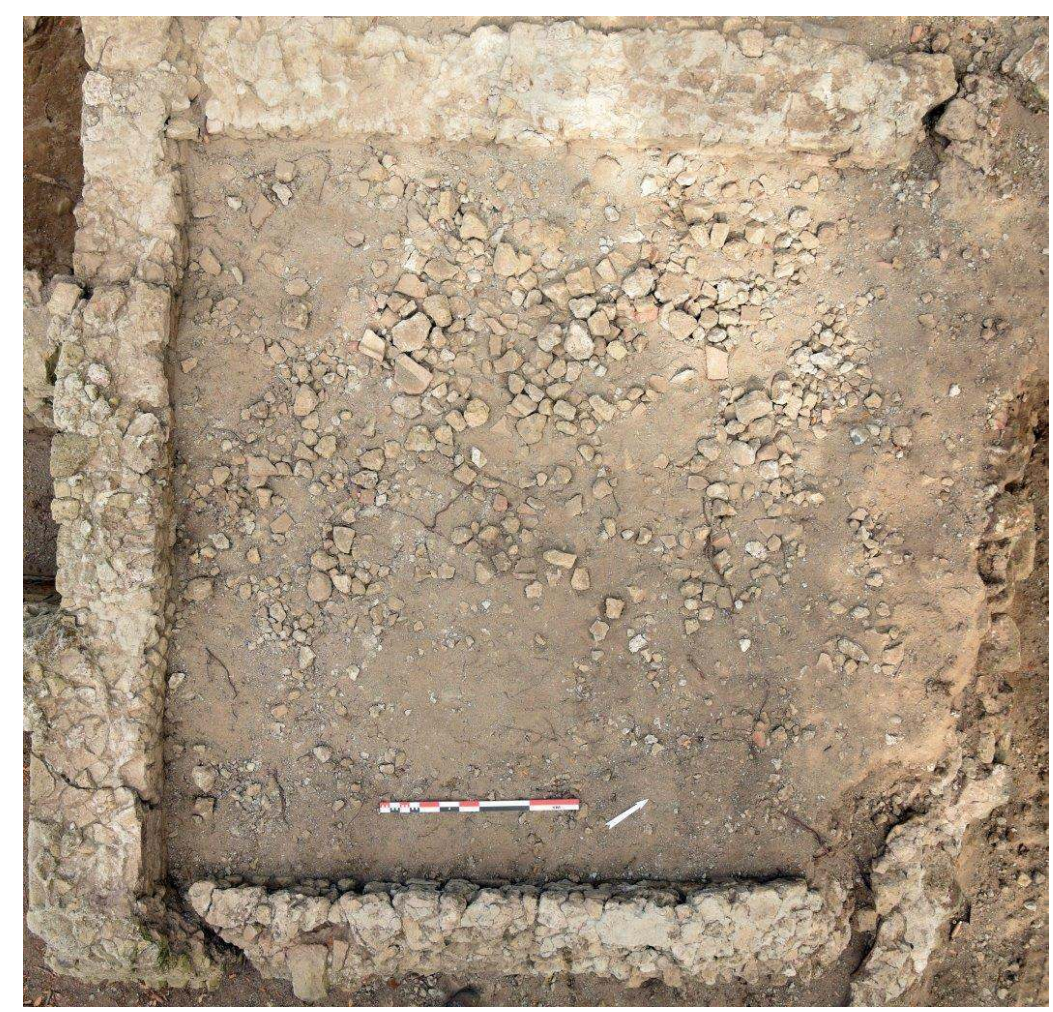

\section{Phase 10B : construction moderne SB60011}

Une fois le secteur nivelé grâce aux remblais US 60080 et 60081, puis US 60007 (Phase 10A), une structure a été construite. Fouillée et documentée lors de la campagne 2014, cette structure SB60011 (fig. 23) est constituée de quatre murs fondés sur les vestiges antérieurs antiques et médiévaux. En fait, il ne reste pratiquement rien de cette construction, mis à part les fondations des murs et des élévations qui ne dépassent que très peu $(30 \mathrm{~cm})$ le niveau du sol SL60011. Les murs sont peu fondés lorsqu'ils s'appuient sur des structures déjà existantes, comme le mur MR60010 qui s'installe sur le mausolée antique MSL60023, ou encore le mur MR60014 qui se fonde en partie sur le mur médiéval MR60031. Ce phénomène se retrouve aussi avec le mur MR60015, qui vient se fonder sur le mur médiéval MR60047, ainsi que sur le niveau d'effondrement (US 60097) du bâtiment de la phase 6A (fig. 21). L'abandon de cette structure (phase 11) a également été documenté lors de la précédente campagne, bien que sa datation reste imprécise. 
FIg. 23 - LA STRUCTURE BÂTIE SB60011 EN fin DE FOUILLE, VUE DE L'EST (@ CJB).

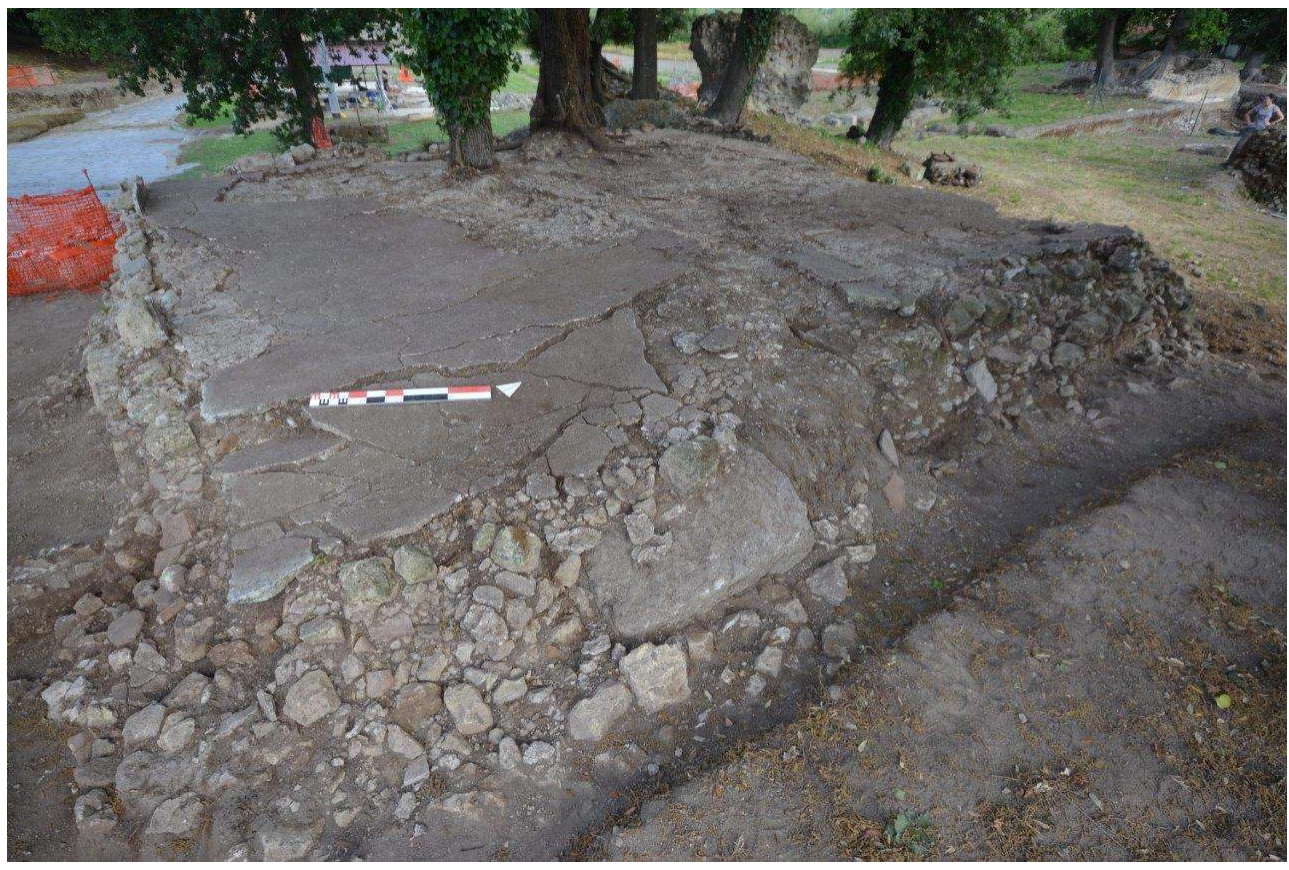

Fig. 24 - LA MASSERIA de MAtTeo SCOtto d'ANIELlo le PROCIDANo (@ CJB).

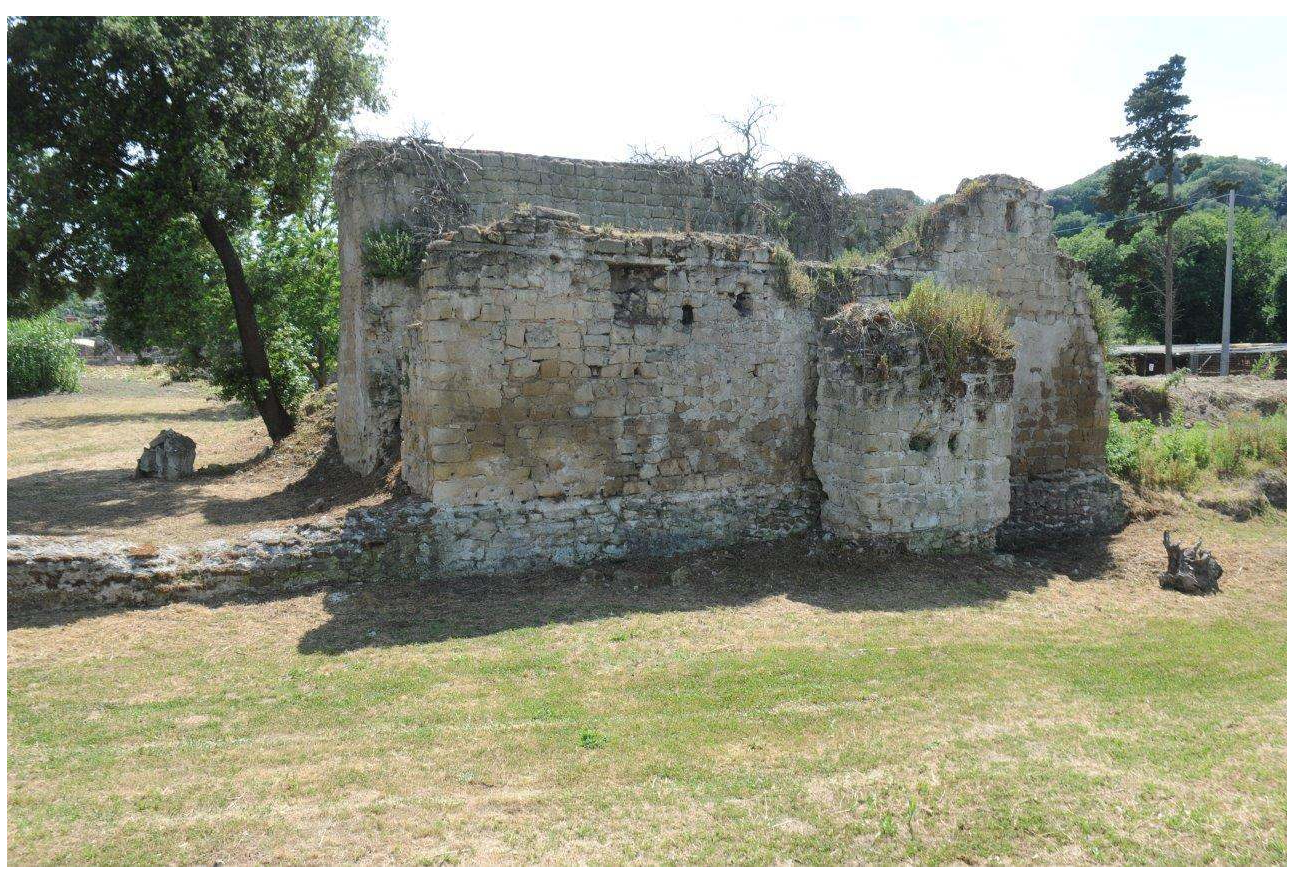

\section{II monumento funerario MSL43003}

\section{Introduzione}

Il monumento funerario MSL43003 si colloca lungo il lato est dell'asse stradale che uscendo dalla Porta mediana prosegue in direzione nord (figg. 1 e 25). Il mausoleo doveva 
essere il primo di una lunga fila di monumenti che sin dalla fine del II secolo a.C. caratterizzavano per la loro presenza la direttrice viaria che costeggiava i margini orientali della laguna di Licola. Oggi il mausoleo non si presenta nella sua integrità ; fortemente compromesso prima dall'innalzamento dei piani di calpestio per l'impostazione della via Domitiana e dalla costruzione sul lato nord del monumento funerario D48, deve aver subito in seguito a partire dall'epoca tardo-antica, la spoliazione del paramento esterno e la manomissione della camera funeraria.

FIg. 25 - PIANTA DELLA ZONA D43 CON IL MAUSOLEO MSL43003.

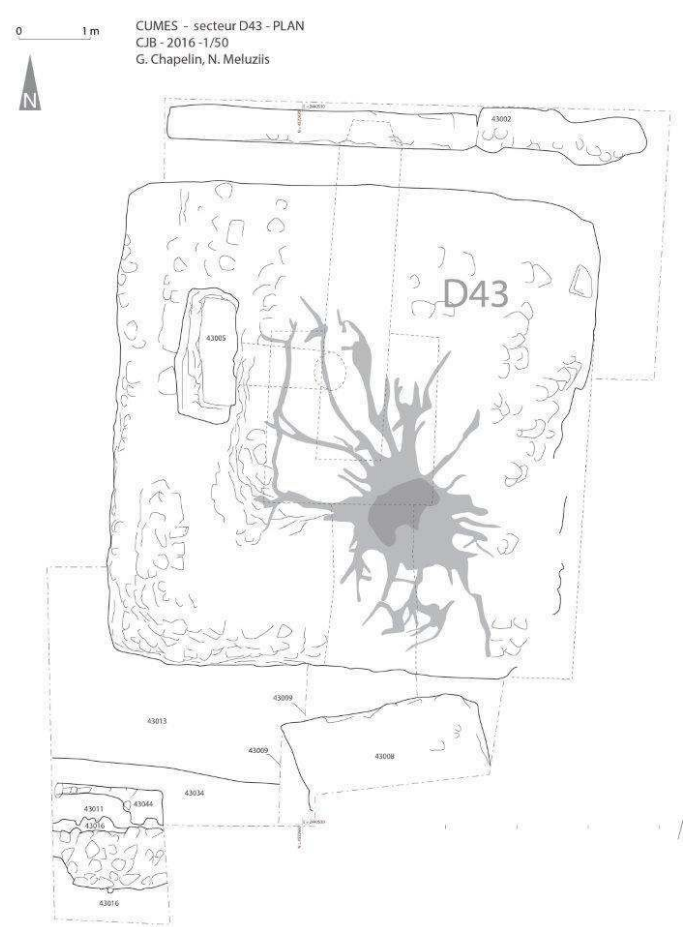

\section{Lo scavo}

\section{Fase $5 \mathrm{C}$ : età tardo augustea/tiberiana}

Verso la fine dell'epoca augustea, inizio del regno di Tiberio, avviene la costruzione del mausoleo MSL43003. Il monumento funerario è composto da una camera ipogea, sormontata da una struttura piena in conglomerato, scaglie di tufo e di marmo (fig. 26) ; la fondazione è realizzata in aggetto di $1,20 \mathrm{~m}$ rispetto alla verticale della struttura superiore. 
FIg. 26 - MSL43003 VISTA ESTERNA LATO SUD (๑ CJB).

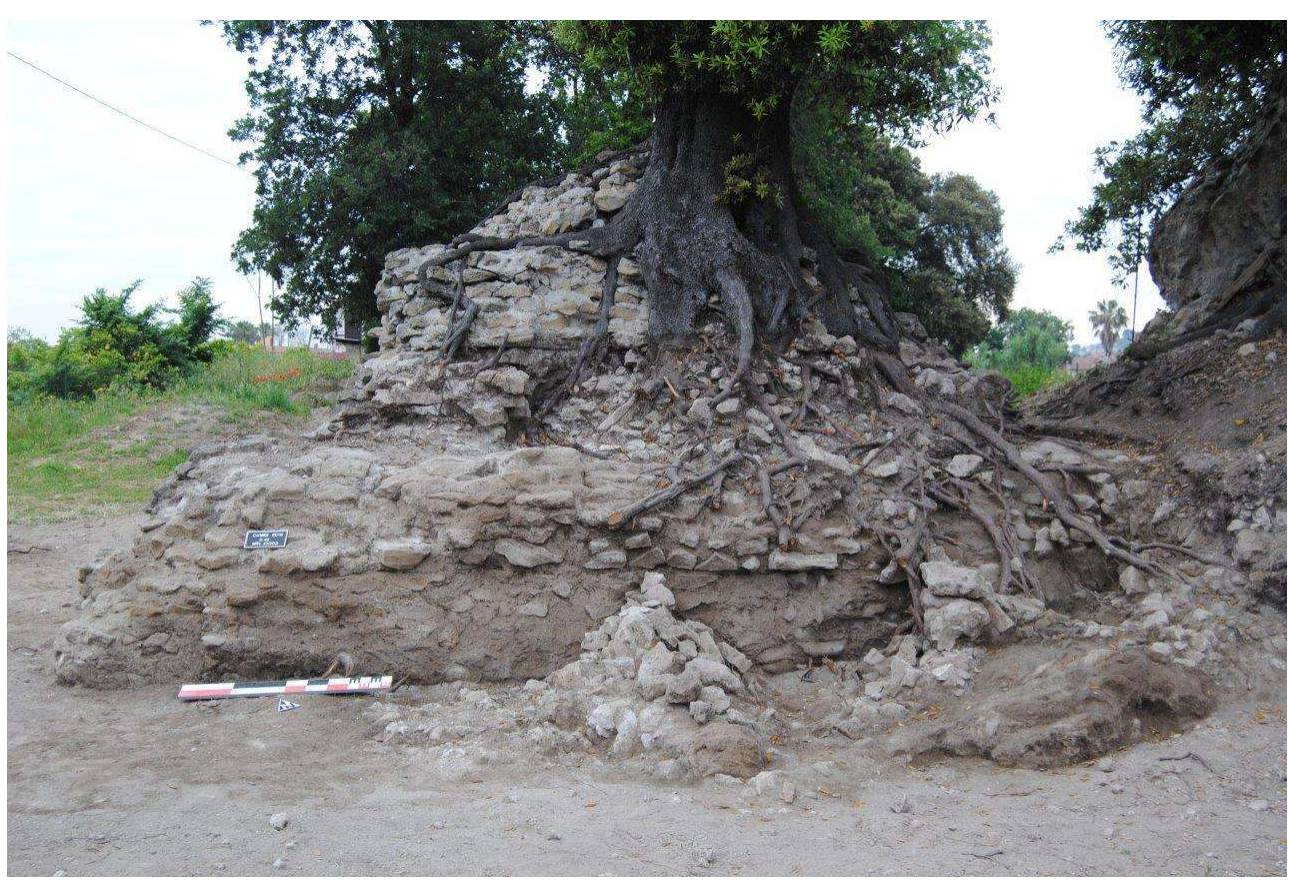

Al momento dello scavo la struttura si presentava priva del rivestimento. Sul conglomerato sono visibili, malgrado i danni provocati dalle radici di un albero cresciuto direttamente sulla sommità della struttura, le impronte dei blocchi di rivestimento. Il rinvenimento nei livelli di fondazione di uno strato ricco in scaglie di lavorazione in calcare conferma la natura del materiale impiegato per la realizzazione dei blocchi.

La camera ipogea, a pianta quadrangolare $(2,33 \times 2,38 \mathrm{~m}, \mathrm{~h} .2,42 \mathrm{~m})$, presenta i muri costruiti in opera reticolata e una volta a botte (US 43044), orientata in senso NS e i cui piani d'imposta si trovano a circa $1,20 \mathrm{~m}$ dal piano di calpestio. All'ambiente si accedeva dal lato nord attraverso un corridoio (lungh. 2,65 m, larg. 0,87 m, h. 2,06 m) alla cui estremità è presente la porta di accesso (PR43027) che misura 0,65 $\mathrm{m}$ di larghezza, 1,39 $\mathrm{m}$ di altezza ed ha uno spessore di 0,45 metri ; essa risulta ancora chiusa da un monolite di tufo (US 43023) dalle dimensioni leggermente inferiori (circa 0,61 $\mathrm{m}$ di larghezza e 1,37 m di altezza). Verosimilmente l'accesso dall'esterno doveva farsi tramite una rampa o una scala la cui presenza potrà essere accertata solo con la prosecuzione dello scavo. Il corridoio presenta una copertura con volta a botte (US 43046) del tipo a sesto ribassato avente il piano di imposta corrispondente alla sommità delle pareti.

All'interno della camera funeraria, rivestita di intonaco bianco, lo spazio è organizzato con due letti in muratura lungo le pareti est (MR43041: lung. 2,33 m, h. visibile 0,61 m) ed ovest (MR43042 : lungh. 2,38 m, h. visibile 0,61 m) e un bancone sul lato sud (MR43040), lasciando libera la parete nord (MR43043; largh. 2,33 m, h. max 1,85 m) nella quale è ricavato il vano di accesso (fig. 27). I letti funerari (SP43035 e SP43036) e un bancone (SP43037) sono realizzati in conglomerato cementizio e rivestititi di intonaco bianco. Al centro del bancone (lungh. 2,33 m, largh. $0,60 \mathrm{~m}$, h. dal pavimento $0,58 \mathrm{~m}$ ) è un foro di forma circolare (US 43038), parzialmente conservato, dal diametro di 0,45 m ed un'altezza di $0,30 \mathrm{~m}$, che ben si configura come alloggiamento per un'urna cineraria. Le pareti interne del foro sono rivestite dello stesso intonaco presente sulle pareti della camera. 
FIg. 27 - MSL D43003. INTERNO DELLA CAMERA FUNERARIA. (๑ CJB).

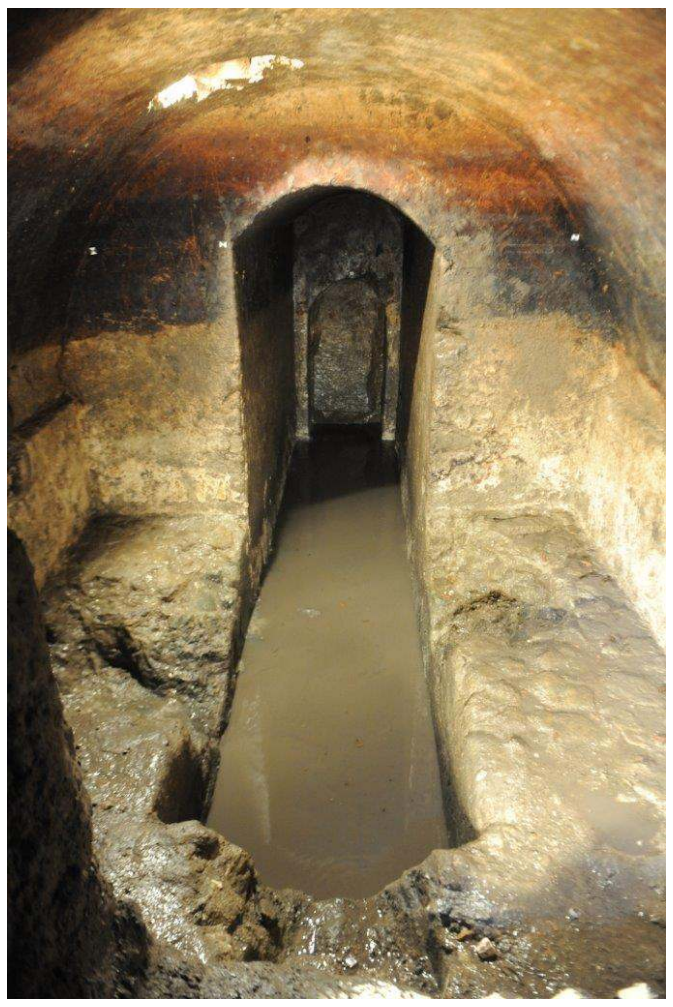

78 All'esterno del mausoleo, lungo la facciata sud, si è condotto un saggio in profondità con lo scopo di mettere in luce i livelli di costruzione e di uso della struttura funeraria. L'indagine ha permesso di individuare due livelli di costruzione (US 43015 e US 43032), intervallati da uno strato limo sabbioso (US 43030) e caratterizzati rispettivamente dalla presenza di scaglie di lavorazione in marmo e in calcare bianco, da attribuire senza dubbio alla realizzazione della facciata esterna del mausoleo. Entrambi gli strati risultano tagliati dalla sepolture SP43020 (Fase 6D ?) e dalla fossa di spoliazione tarda (FS43012) (fig. 28). 
FIg. 28 - US 43033. SUOLO ESTERNO TAgLIATO DALLA FOSSA DI COSTRUZIONE DEL MAUSOLEO, COPERTO DIRETTAMENTE DAI LIVELLI DI LAVORAZIONE IN SCAgLIE DI CALCARE E MARMO (๑ CJB).

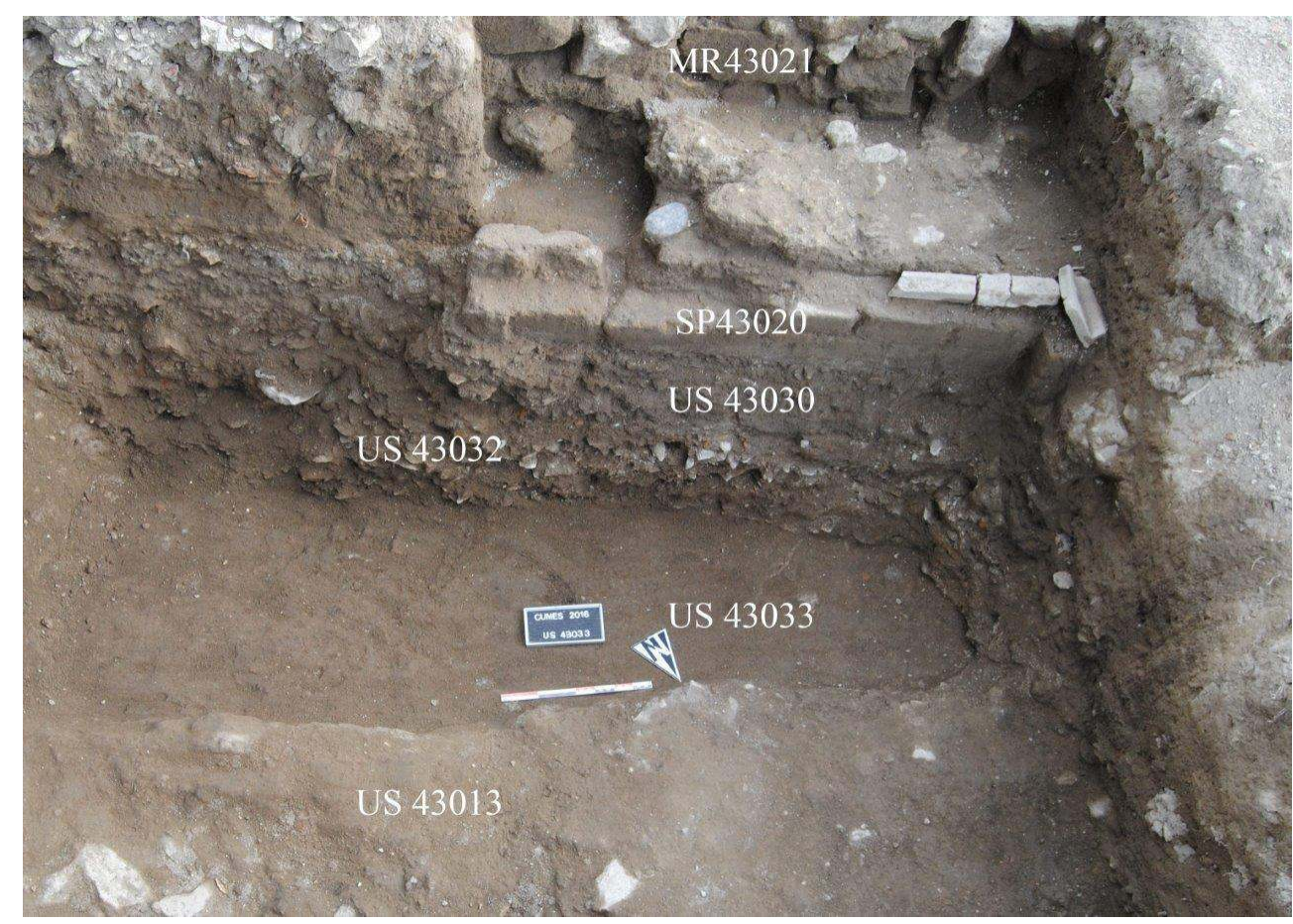

L'asportazione dell'US 43032 ha permesso di mettere in luce due livelli di frequentazione in terra battuta. I due battuti (US 43033 e US 43034) sono tagliati dalla fossa di fondazione del mausoleo (US 43047). Il primo livello risulta essere il piano di frequentazione in fase con la costruzione del monumento. La ceramica trovata in strato (US 43033) data la costruzione del monumento tra la fine dell'epoca augustea e gli inizi del regno di Tiberio. In particolare si segnala un frammento di pareti sottili attribuibile alla forma Mayet $5 \mathrm{~b}$ databile alla fine del primo quarto del I secolo d.C. e alcuni frammenti di sigillata italica tra i quali un labbro riferibile alla forma Conspectus 1, un labbro riferibile alla forma Conspectus 18 ed un'ansa attribuibile ad una coppa biansata Conspectus 30. Al di sotto del primo livello di frequentazione lo scavo ha portato in luce un secondo piano di frequentazione molto compatto (US 43034). Lo strato non è stato asportato.

\section{Fase 6D?}

Ascrivibile ad una fase successiva alla costruzione del monumento funerario MSL43003 è una sepoltura (SP43020) sistemata lungo la parete sud del mausoleo e quasi completamente distrutta dalla fossa di spoliazione (US 43012 ; Fase 7) del rivestimento del monumento (fig. 28). Dai dati di scavo, risulta che doveva trattarsi di una tomba a fossa con cassa in muratura e copertura di tegole. Di questa erano ancora in situ pochi resti : un muretto in mattoni di tufo legati con malta e alcuni frammenti di tegole pertinenti alla copertura. Non ci sono elementi che permettano di precisare la datazione della sua installazione, ma la tipologia fa pensare ad una tomba della tarda antichità. 


\section{Fase 7 : età bizantina}

Probabilmente in età alto medievale è da collocare l'azione di spoliazione che ha interessato il mausoleo privandolo del suo rivestimento e dell'apparato decorativo. Lo scavo ha permesso l'individuazione lungo il lato meridionale del mausoleo di una fossa di forma rettangolare (US 43012; misure 3,30 x 1,80 m), il cui riempimento (US 43011) era coperto direttamente dall'US 43016 corrispondente ad un piano in terra battuta in quota con il basolato della piazza antistante la Porta. Il taglio individuato è da attribuire all'azione di spoliazione dell'apparato decorativo del mausoleo. Il margine della fossa, individuato a circa $1,80 \mathrm{~m}$ di distanza dal mausoleo, ha tagliato quasi tutti i livelli stratigrafici rinvenuti. Il suo riempimento, composto principalmente da uno strato di limo sabbioso, deve probabilmente leggersi come il risultato di una progressiva sedimentazione. L'azione di spoliazione ha messo in luce le fondazioni del mausoleo fino ad $1,20 \mathrm{~m}$ di profondità.

È forse già in questa fase, o in un periodo di poco successivo, che la struttura funeraria viene impiegata come cisterna per l'acqua (fig. 29). Sul lato ovest è aperto un condotto (largh. $0,88 \times 1,60 \mathrm{~m}$ ) che, attaverso la struttura in conglomerato, permetteva di introdurre nella camera funeraria i contenitori per la captazione dell'acqua.

\section{Fig. 29 - LA FOSSA FS43005. IL POZZO SCAVATO SUl LATO OVEST (@ CJB).}

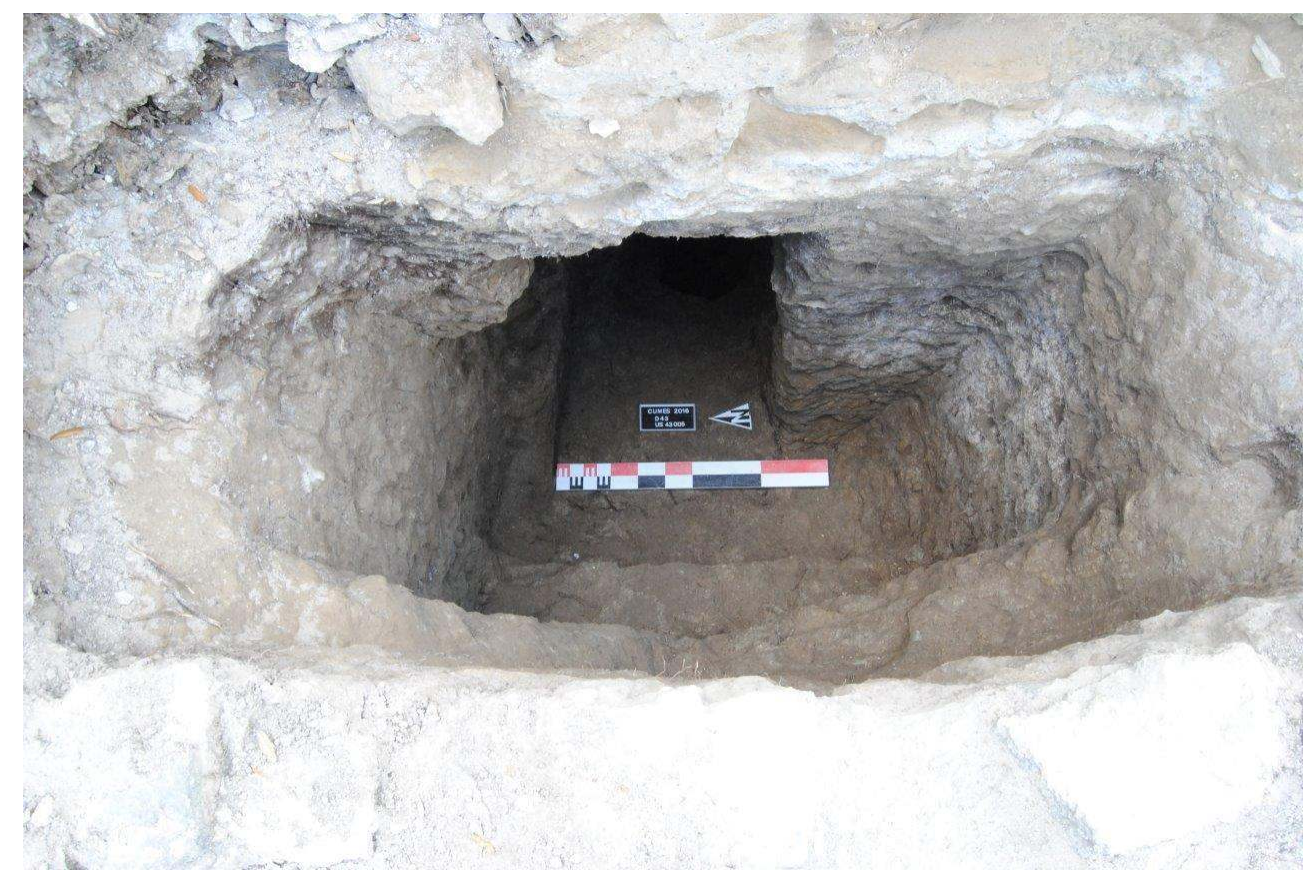

Le trasformazioni che subisce in questa fase il monumento MSL43003 sono da mettere in relazione con i numerosi cambiamenti che subisce l'area all'esterno della Porta mediana tra il VI e il VII secolo d.C. L'asportazione del rivestimento e dell'apparato decorativo dell'edificio funerario, in marmo e in calcare, potrebbero essere messi in relazione il funzionamento della calcara intercettata dagli scavi dell'Università "L'Orientale » di Napoli all'interno della Porta mediana. Il riutilizzo del mausoleo MSL43003 come cisterna potrebbe essere funzionale alla sistemazione del quartiere artigianale negli edifici che si affacciano sul lato est della piazza (zone D59 e D60a). 


\section{Fase 9 : età medievale}

epoca medievale il monumento MSL43003 subisce ulteriori modifiche. La trasformazione più evidente è l'apertura di un passaggio (US 43010) nella parete sud del monumento. L'accesso (largh. 1,18 m x h. 1,43 m) è localizzato nella parte alta della parete interna, al di sopra del bancone funerario (fig. 30). In questa fase, la camera non subisce sostanziali trasformazioni, se non alcuni scassi realizzati al centro dei letti funerari e del bancone. Funzionale alla nuova entrata è la sistemazione di una rampa (US 43009) che dalla piazza basolata raggiungeva la nuova apertura. Della rampa lo scavo ha evidenziato unicamente il tratto inziale che taglia la fondazione del mausoleo (US 43013). Il resto della struttura è ancora coperto dai livelli di obliterazione che hanno interessato l'intera area, nonché da alcune parti degli elevati in crollo appartenenti agli edifici presenti ad est del mausoleo. La scelta di aprire un nuovo accesso, in luogo di quello originario, deve essere stata motivata dal fatto che l'ingresso settentrionale alla camera funeraria non era più fruibile perché obliterato da livelli più recenti della necropoli. Inoltre, il nuovo accesso era direttamente praticabile dall'area aperta posta a sud, al di sopra dello spiazzo basolato.

FIg. 30 - us 43010 . L'APERTURA SUL LATO SUd DELLA CAMERA IPOgEA. (C CJB).

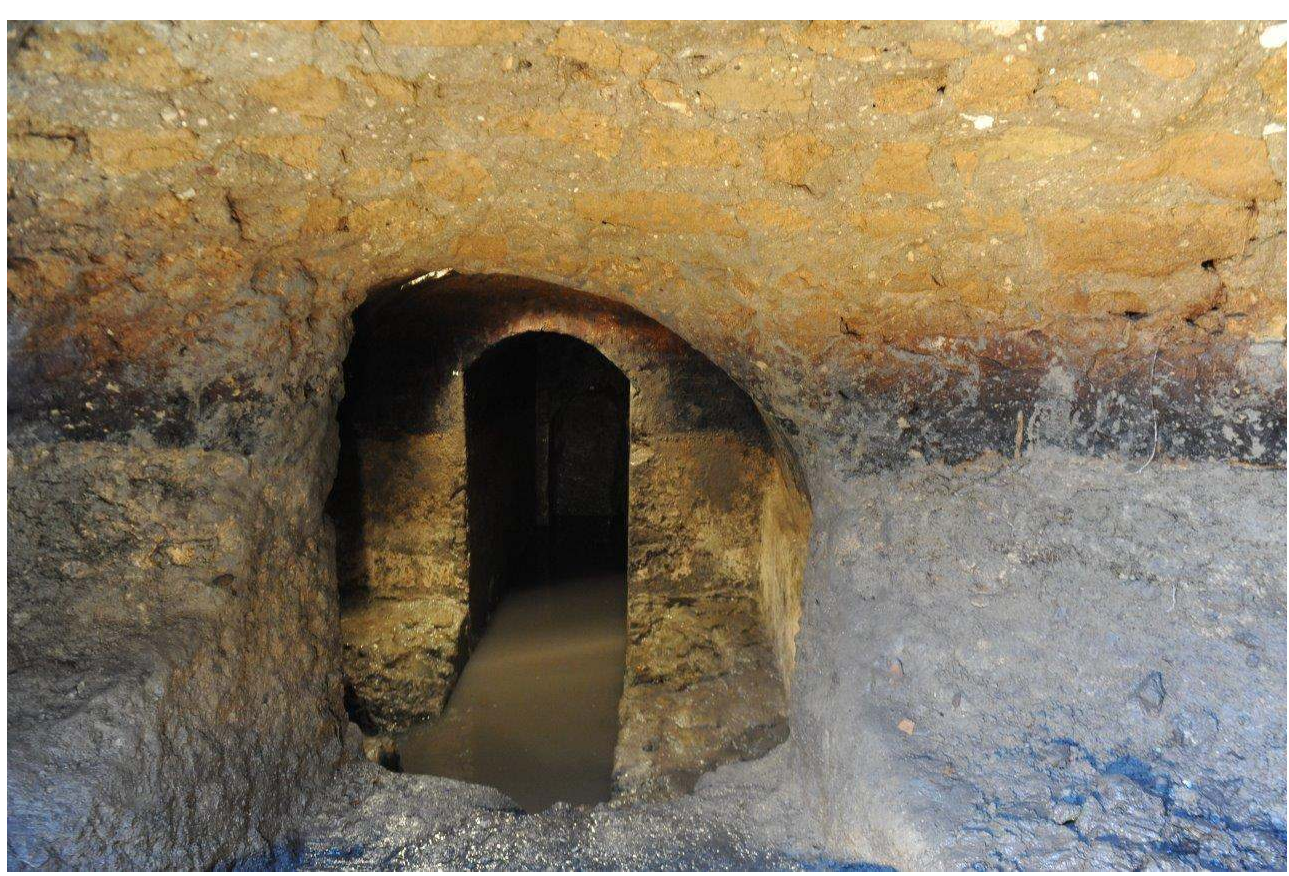

La rampa e la camera funeraria al momento dello scavo risultavano completamente obliterate da un potente strato a matrice terrosa, ricco di pietrame e di materiale ceramico (US 43008). La disamina del materiale ha portato ad isolare il materiale più tardo che dovrebbe determinare il terminus post quem per l'abbandono della struttura e verosimilmente dell'area. Si tratta di ceramica di epoca bassomedievale ben documentato nell'area (zona D60) e la cui datazione si colloca tra il XIII e il XIV secolo. Il particolare è documentata la presenza di alcuni bacini con decorazione spiral ware, diversi frammenti di ceramica invetriata ed una notevole quantità di ceramica comune dipinta a bande, soprattutto brocche e anfore, quest'ultime caratterizzate da larghe anse a nastro. Infine si 
segnalano due frammenti in maiolica, pertinenti ad una brocca trilobata e ad un piatto, la cui datazione potrebbe collocarsi entro il XIV secolo.

\section{L'edificio funerario A42 e l'ambitus A19}

\section{Introduzione}

Il monumento funerario A42 (EFN42001) e l'ambitus A19 si collocano lungo il lato nord della via Domitiana, in prossimità della piazza basolata antistante la Porta mediana. L'edificio A42, riferibile alla tipologia dei recinti funerari, è attorniato a est e a nord rispettivamente dai monumenti A41 e A54, a nord-est da A56 e ad ovest dal passaggio A19. Quest'ultimo si trova a confinare con i complessi funerari A53 e A52 a ovest, mentre ad est oltre ad A42 è adiacente anche allo spazio A54. Entrambi i contesti di scavo verso sud si trovano in rapporto diretto con la via Domitiana: l'edificio A42 presenta la facciata monumentale verso l'asse stradale, mentre il passaggio A19 si apre direttamente verso la via.

Dai dati disponibili dallo scavo stratigrafico possiamo osservare come entrambi i settori si presentano nelle forme che ancora oggi si conservano, in concomitanza con la sistemazione della via Domitiana, attorno al 95 d.C. In questo periodo tutta la zona antistante la Porta mediana viene monumentalizzata e gli edifici funerari che si affacciano sul nuovo asse presentano delle facciate monumentali, nella maggior parte prive però di un accesso diretto dalla strada. Si poteva accedere agli spazi funerari attraverso dei diverticoli secondari, gli ambitus individuati nei settori A19 e A18.

Le zone A19 e A42 sono state oggetto di studio nel corso della campagna del 2014, durante la quale sono stati indagati i primi $0,80 \mathrm{~m}$ di orizzonte stratigrafico. Queste indagini iniziali hanno confermato l'utilizzo come ambitus della zona A19, per permettere l'accesso agli spazi funerari A53 e A52 ad ovest e A42, A56 e A54 ad est. L'area in una fase successiva subisce un cambiamento nella destinazione d'uso, diventando spazio funerario. Le indagini condotte nel 2014 non permisero di precisare la cronologia di questa trasformazione.

Per quanto riguarda il monumento A42, nel 2014 ne erano state messe in luce tutte le murature, ed erano state indagate le ultime fasi di frequentazione dello spazio interno del monumento funerario, con lo scavo di alcune tombe in anfora e di una tomba alla cappuccina, riferibili a fasi differenti. Il rinvenimento di notevoli lacerti di intonaco policromo nella parte interna delle murature del complesso EFN42001, ha permesso un loro restauro e uno studio approfondito, che hanno consentito di trovare confronti con quelle di IV stile dell'area pompeiana.

Con la campagna di scavo del 2016 si è voluto indagare una delle due tombe " a bauletto " presenti all'interno del complesso EFN42001, per chiarire meglio il rapporto di queste strutture con il monumento stesso e con la stratigrafia adiacente e per chiarire alcuni dubbi sulla scansione cronologica rimasti irrisolti alla fine della campagna precedente. $\mathrm{Si}$ è, inoltre, proseguita l'indagine dell'ambitus A19 per meglio definirne la cronologia e il suo utilizzo prima come accesso alle aree funerarie circostanti e poi come luogo di sepoltura. 


\section{II monumento funerario EFN42001}

91 Con lo scavo di quest'anno si è cercato di dare maggiori agganci cronologici alle strutture scavate nel corso della campagna del 2014, andando ad indagare soprattutto una delle due sepolture "a bauletto" visibili già alla fine della campagna precedente. Sono state chiarite alcune delle fasi di vita del monumento EFN42001 e suoi successivi riutilizzi (fig. 31). Il recinto funerario ENC42001 si presenta a pianta quadrangolare, con i lati che misurano tra i 6,57 e i $6,70 \mathrm{~m}$ e che creano una superficie interna di circa $30 \mathrm{mq}$. Le murature presentano uno spessore tra i 0,42 e i 0,45 m per i muri nord (MR42004), est (MR42001) e ovest (MR42003), mentre la facciata (MR42002) ha uno spessore di $60 \mathrm{~cm}$ per la presenza di nicchie, due di forma rettangolare e due semicircolari.

FIg. 31 - PIANTA DEL MONUMENTO FUNERARIO EFN42001.

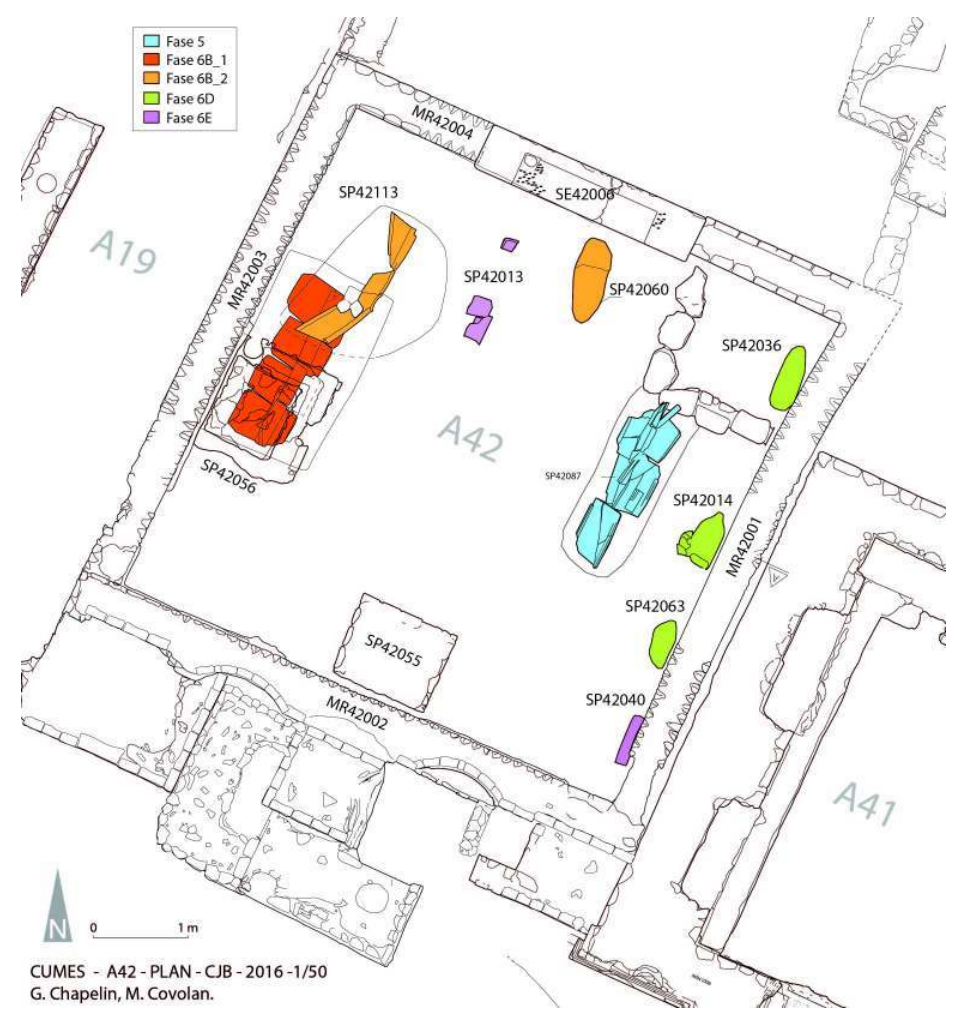

Dai dati emersi possiamo definire almeno sei fasi di frequentazione del complesso EFN42001, a partire dal I secolo d.C. per arrivare al IV-V secolo d.C.

\section{Fase 5}

Nella prima fase, collocabile in un periodo precedente alla costruzione del recinto funerario ancora oggi visibile, l'area doveva essere stata oggetto di un'occupazione per lo meno temporanea e della quale si conservano i resti di una tomba alla cappuccina (SP42087), venuti alla luce nella zona centro orientale dell'insieme EFN42001. Altre strutture precedenti alla costruzione del recinto in esame, potrebbero inoltre aver condizionato il dislivello di $0,34 \mathrm{~m}$ che si riscontra tra la risega di fondazione del muro nord MR42004 e quella del muro sud MR42002. Di queste ipotetiche strutture però non è emerso alcun resto nelle zone indagate nel corso delle due campagne di scavo che hanno 
interessato l'area. Possiamo ipotizzare che questa fase si possa collocare nella prima metà del I secolo d.C., facendo leva sui confronti con le strutture rinvenute all'interno delle zone adiacenti.

\section{Sépulture}

SP42087 (2014). Sépulture primaire individuelle en fosse, avec coffre et couverture de tuiles en bâtière. Elle est située dans la partie est du monument. La tombe SP42087 est, orientée nord-est/sud-ouest, tête au sud-ouest. Elle présente une architecture complexe : l'individu a été placé dans un coffre de moellons de tuf, et peut-être également dans un coffre de bois; puis des tuiles, disposées en bâtière, ont été placées l'une contre l'autre au-dessus du coffre; enfin, une couverture de petits blocs de pierres a été aménagée à $0,80 \mathrm{~m}$ au-dessus de la partie sommitale des tuiles. Du mobilier a été découvert en place : un petit gobelet en céramique (US 42100) aux pieds du défunt (le squelette SQ42095) et une monnaie au niveau du crâne (US 42101).

\section{Fase 6A}

La seconda fase è quella nella quale viene costruito il recinto funerario EFN42001, con accesso da nord e composto dai quattro muri perimetrali realizzati in opera reticolata con catene angolari in blocchetti parallelepipedi di tufo: rispettivamente il muro nord identificato con il numero MR42004, il muro est MR42001, quello sud MR42002 e il muro ovest MR42003. Dai dati emersi dagli scavi eseguiti è verosimile che la struttura EFN42001 si possa datare tra la fine del I secolo a.C. e i primi decenni del II secolo d.C.

\section{Fase 6B}

La terza fase si può suddividere in due sottofasi : una prima in cui vengono edificate all'interno del recinto funerario EFN42001 due tombe «a bauletto " (SP42055 e SP42056) ed una seconda nella quale si assiste alla sistemazione di altre due sepolture (SP42113 e SP42060). Queste ultime sono rispettivamente una tomba alla cappuccina ed una ad enchytrismos. La sepoltura SP42113 si va ad impostare al di sopra della struttura sottoterra nord-orientale del bauletto, asportandone di conseguenza parte dei livelli di riempimento (fig. 32). 
FIg. 32 - LA TOMBA « A BAULETTO » SP42056 E LA SEPOLTURA ALLA CAPPUCCINA SP42113 (৫ CJB).

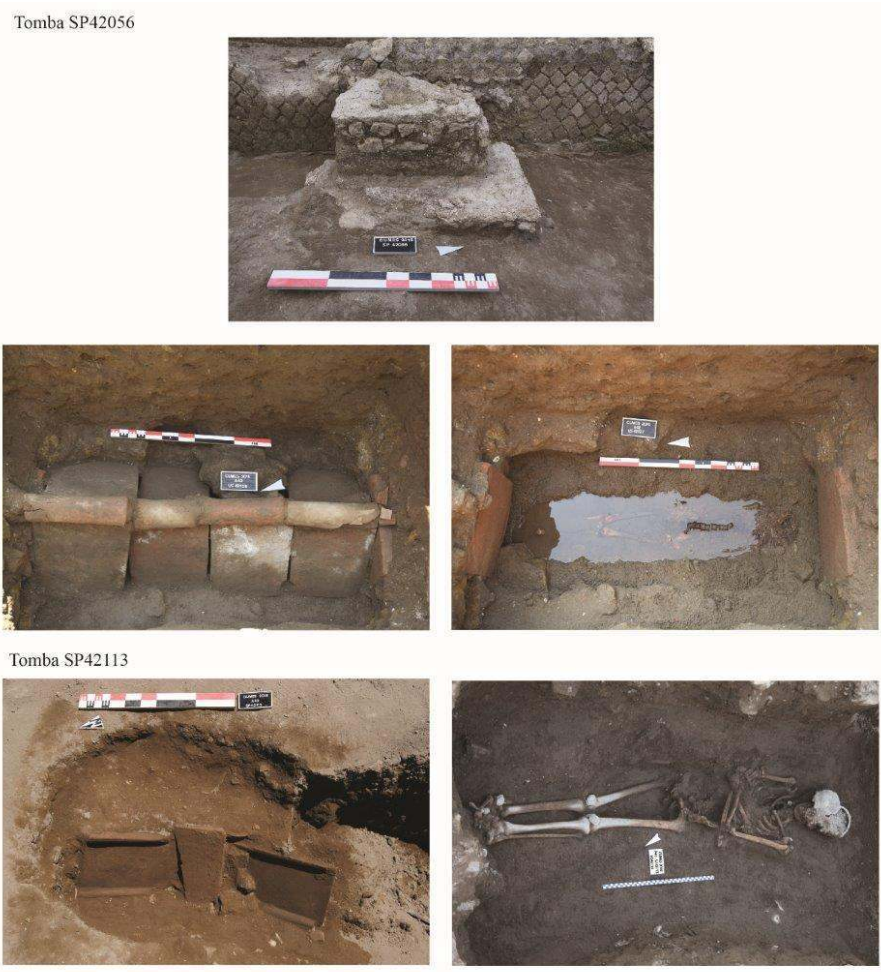

\section{Sépultures}

contre la paroi ouest MR42003, en position centrale. La partie emergée est constituée par un cube maconnée et parmenté en opus vittatum avec un revetement d'enduit blanc. Elle est installée sud-nord, la tête au sud. La fosse d'installation pour le corps est creusée dans le substrat, le corps une fois déposé a été recouvert d'un aménagement de tuiles en bâtière, recouvert d'un niveau de béton. L'individu déposé est de sexe féminin et âgé entre 20 et 29 ans. L'individu est bien représenté mais la conservation des ossements est variable à cause de l'immersion des vestiges lors de la remontée de la nappe phréatique. L'individu (SQ42127) est sur le dos, les membres supérieurs sont en extension, les mains reposent contre et sur le bassin, les membres inférieurs sont en extension, les chevilles jointes. La conservation de l'architecture et les différentes observations de la position du squelette permettent de déterminer que la décomposition s'est effectuée en espace vide. Aucun élément mobilier n'a été mis au jour associé au squelette.

SP42113. La sépulture SP42113 est une sépulture primaire individuelle à demi-bâtière. Elle est installée dans le remplissage du «bauletto » (US 42118) et la demi-bâtière contre le bord de la fosse d'installation de la tombe à «bauletto » SP42056. Elle est orientée sudouest/nord-est. La sépulture est bien conservée: le squelette présente une bonne conservation et une bonne représentation. L'individu (SQ42115) déposé sur le dos, la tête au nord-ouest, les pieds au sud-est, est de sexe masculin, âgé entre 30 et 59 ans. Les 
membres supérieurs sont fléchis à hauteur des coudes, les mains ensérant les bras. Les membres inférieurs sont en extension, les genoux et les chevilles joints.

Un faisceau d'arguments permet de proposer une décomposition en espace vide. Il est à noter pour cet individu, la présence d'un dépôt exubérant de tartre sur la deuxième molaire supérieure gauche qui pourrait être mise en relation avec des activités paramasticatrices. Une monnaie a été découverte déposée sur la mandibule de l'individu.

SP42060 (2014). Sépulture primaire individuvelle en amphore située immédiatement au sud du seuil SE42006 du monument A42. Aucun creusement n'a pu être mis en évidence. La sépulture est orientée nord-est/sud-ouest, tête au sud-ouest. Après le dépôt du corps (SQ42072), l'ouverture pratiquée dans l'amphore, une amphore africaine indeterminée, a été obturée par de petites pierres et par une plaque d'enduit peint (US 42067), probablement récupérée à l'intérieur même du monument. La tombe comporte très peu de vestiges osseux. En effet, si l'état de conservation est relativement bon, l'état de représentation est très mauvais: ne restent du sujet que son crâne, sa mandibule, quelques vertèbres cervicales, et ses diaphyses fémorale et humérale droites incomplètes. Il était âgé de moins d'un an. Plusieurs indices confirment la présence d'un espace vide au moment de la décomposition du corps. La tombe comportait quelques vestiges mobiliers : une perle en céramique associée à une chaînette en métal qui ont été découvertes à une altitude supérieure au corps, dans le comblement de l'amphore (US 42065) ; une perle en position anatomique, probablement portée dans le cou du sujet, une petite clochette en bronze et un petit vase en céramique (US 42081) ; à l'intérieur de ce dernier une monnaie.

Ce sujet a très probablement été placé dans un contenant textile au moment de son inhumation: en effet, des empreintes textiles ont été découvertes sur l'un des vestiges mobiliers mis au jour dans la tombe, la petite clochette en bronze. Cette clochette a visiblement été cousue, ou en tout cas posée sur le linge entourant l'enfant (langes? linceul ?).

\section{Fase 6C}

103 Nella quarta fase è attestato il crollo della parte alta delle strutture che costituiscono il recinto funerario EFN42001. Il crollo è documentato dall'US 42032, indagata nel corso del 2014 e che ha restituito materiale edilizio quale tufelli dell'opera reticolata, frammenti di intonaco e malta. Il livello di abbandono è localizzato all'interno del monumento e sembra aver coinvolto anche la parte fuori terra delle sepolture « a bauletto » SP42055 e SP42056, di cui sono stati rinvenuti alcuni mattoni della muratura (US 42027, US 42057).

\section{Fase 6D}

104 Sui livelli di crollo (US 42032) e su successivi strati di sedimentazione (US 42025 e US 42016) vengono ad impostarsi nuove sepolture, di cronologia incerta, in assenza di elementi datanti a livello stratigrafico e di materiali in associazione. Si tratta di tre sepolture in anfora, distribuite lungo il muro est MR42002 : la sepoltura SP42036 a nord, la SP42014 nel mezzo e la SP42063 a sud. Si può ipotizzare che si collochino proprio lungo questo muro in quanto potrebbe essere quello che ha subito meno danni nel corso della distruzione, situandosi in prossimità del mausoleo A41, costruito nei primi decenni del III secolo d.C. Le tre sepolture accoglievano resti ossei di soggetti immaturi. 


\section{Sépultures}

SP42036 (2014). Sépulture en amphore située dans la partie nord-est du monument A42, contre le mur MR42001. Aucun creusement n'a été repéré mais l'amphore repose sur le niveau de destruction US 42032. Cette amphore, orientée nord-est/sud-ouest, est constituée d'un fragment "principal» d'amphore, idéntifiable vraisemblablement avec une amphore globulaire africaine de type Scorpan VIII-B (VI ${ }^{\mathrm{e}}-\mathrm{VII}{ }^{\mathrm{e}}$ siècles ap. J.-C.), et de nombreux autres fragments d'une amphore lusitanienne de type Almagro 51c utilisés pour fermer l'espace funéraire.

Aucun squelette en place n'a pu être observé; seuls quelques fragments osseux et os erratiques ont été mis au jour dans l'amphore. Il est possible qu'une perturbation postérieure (eau d'infiltration, racines...), couplée à un sédiment acide, et/ou à une perturbation plus importante (fouisseur?) ait rendu impossible la conservation du squelette. Seuls quelques os ont été récupérés (os longs, fragments crâniens); l'âge du défunt a pu être estimé entre 0,5 et 4 mois.

SP42014 (2014). Sépulture située contre le mur MR42001 et composée de deux amphores encastrées, dont deux amphores africaines tardives. L'amphore sud est fragmentée. Elle contient les restes d'un sujet immature (SQ42021), très bien conservé. L'individu est allongé sur le dos et partiellement sur le côté droit, bras et jambes en extension. Le corps a été placé en partie contre une des fragments de l'amphore US 42014. De nombreux indices sur le squelette confirment un espace vide dans l'amphore au moment de l'inhumation.

SP42063 (2014). Sépulture en amphore située dans la partie sud-est du monument A42, contre le mur MR42001. Cette tombe, orientée nord-sud, est réalisée avec un fragment d'amphore principal, accueillant le corps, puis pour combler la fosse ont été utilisés également différents fragments d'amphore et des pierres. La dalle de pierre posée en oblique par rapport à l'amphore devait accueillir les membres inférieurs du sujet (SQ42073). Ceux-ci ont en effet glissé par la suite vers l'amphore, totalement déconnectés. De nombreux autres ossements étaient également sans connexion, indiquant la présence d'un espace vide, permettant l'infiltration d'eau ou de racines par exemple. Seuls le thorax et le bassin voient leurs connexions bien préservées. Le sujet parait être un individu âgé de moins d'un an, déposé sur le dos sans mobilier dans la tomb. Le défunt a cependant bénéficié d'une architecture funéraire soignée et bien délimitée dans l'espace

\section{Fase 6E}

L'ultima fase che si riesce a delineare per questa zona, è quella che vede un nuovo reinterro dell'area (US 42017) e l'impostazione di altre due nuove sepolture. Per quanto riguarda la potenza dell'interro e soprattutto la sua estensione, non si hanno molte informazioni, in quanto di questo strato non è stata scavata che la parte inferiore, mentre quella superiore è stata asportata in periodo moderno per la regolarizzazione del terreno per scopi agricoli. In questo livello si trovano tagliate due nuove sepolture, questa volta alla cappuccina (SP42013 e SP42040), ma non sappiamo se queste si impostassero direttamente nello strato US 42017 oppure in uno strato a lui sovrapposto. 


\section{Sépultures}

SP42013 (2014). Sépulture primaire individuelle à inhumation en fosse avec couverture de tuiles en demi-bâtière installée devant le seuil SE42006 de l'enclos funéraire. Elles se trouvaient en position quasi verticale. Aucune trace de fosse n'a pu être mise en évidence. Elle est orientée nord-est/sud-ouest, tête au nord-est. Le sujet correspond au squelette SQ42070. La majorité du sujet est absente, le bas du corps étant la partie la mieux préservée. L'état de conservation est bon, bien que l'état de représentation soit mauvais. Le sujet est placé sur le dos, probablement partiellement sur son côté droit, bras droit en extension, jambes légèrement fléchies sur la droite. La position du bras gauche ne peut être déterminée.

Bien que le corps soit très incomplet, les jambes comportent de nombreuses connexions bien préservées au niveau des genoux et des pieds. De plus, la jambe gauche n'a pas chuté dans l'espace « vide » présent au-dessus du genou droit. Ces indices tendent à indiquer un colmatage rapide de la tombe. L'individu aurait pu être inhumé dans un contenant textile, bien que ceci soit à noter avec précaution au vu de la mauvaise représentation du sujet. D'un point de vue biologique, le sujet est probablement un adulte de par le format des os conservés, et par leur maturité osseuse.

SP42040 (2014). Sépulture primaire individuelle à inhumation en fosse avec couverture de tuiles en demi-bâtière installée contre le parement interne du mur MR42001. Aucun squelette en place n'a pu être observé.

\section{L'ambitus A19}

Nel corso della campagna 2014 si era iniziato ad indagare l'ambitus A19, ovvero quel piccolo diverticolo stradale che si dirama perpendicolarmente alla via Domitiana e permetteva l'accesso ai monumenti funerari A53, A52, A42 e A54. Si trova delimitato a est dai muri MR42003 e MR54001, mentre a ovest dal muro MR53001 e dalla struttura in mattoni, tegole e malta (definita dalle unità stratigrafiche US 52001, US 52002 e US 52003) che si trova a coprire la fronte est del monumento funerario A52. Con la campagna precedente si era riusciti ad individuare due differenti fasi di utilizzo e lo scavo di quest'anno mirava proprio ad una miglior comprensione dell'area stessa (fig. 33 e 34 ). 
Fig. 33 - PiANTA Delle diverse fAsi 6 (G. ChAPELIN, M. COVOLAN, @ CJB).

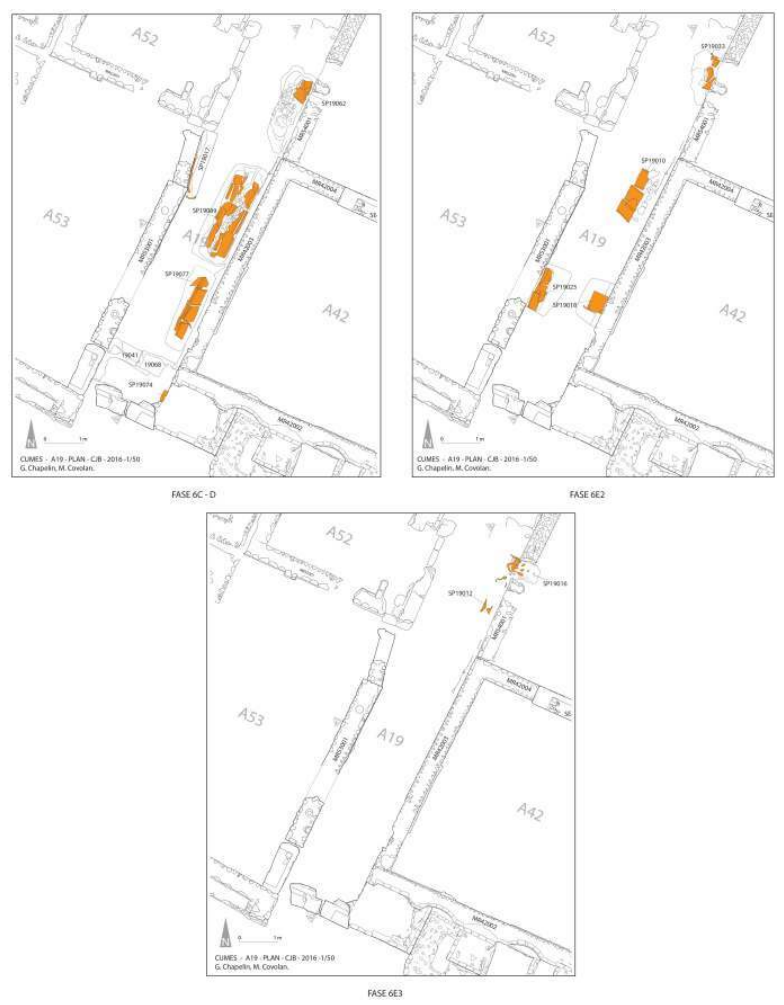

Fig. 34 - RILIEVo AEREFotogRAMMETRico (RÉAL. G. SACHAU-CARCEL, ( CJB).

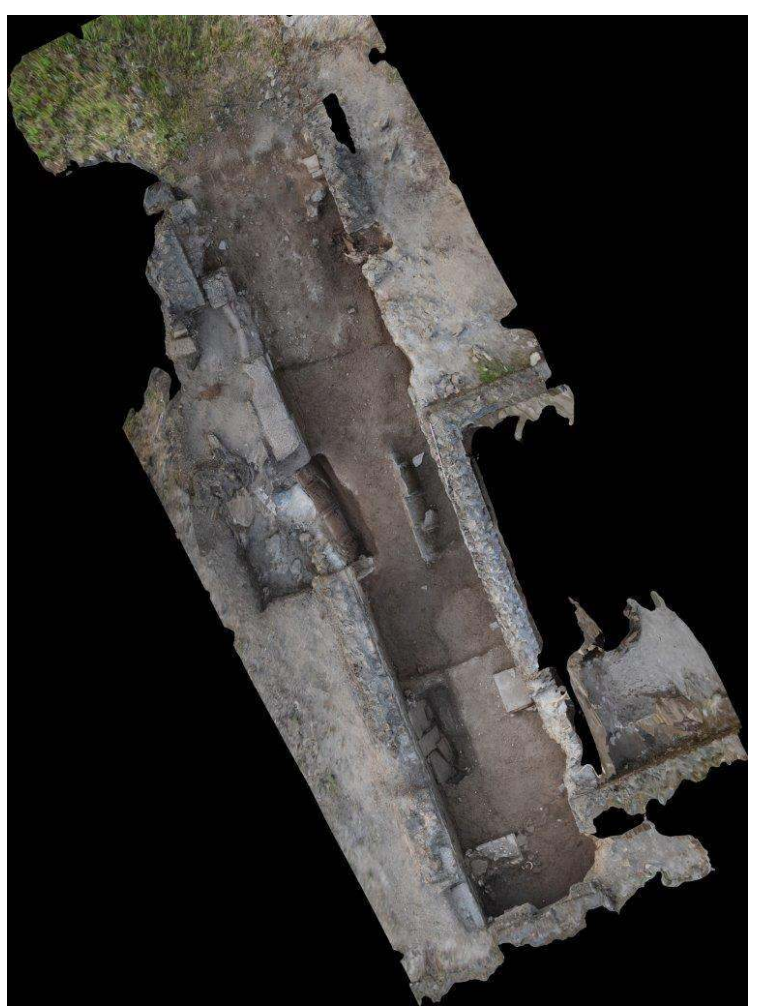

109 Sono state così individuate in totale sette fasi di frequentazione del settore in esame, partendo dalla prima che non è ancora stata indagata e arrivando alle ultime fasi di 
rioccupazione dell'area, scavate nel corso della campagna del 2014 e terminate quest'anno.

\section{Fase 5}

110 La prima fase, non totalmente indagata, corrisponde all'utilizzo dell'area di A19 come passaggio per permettere l'accesso all'edificio funerario A53. Il settore in esame non doveva avere le fattezze attuali, in quanto verso est non era ancora delimitato dal recinto funerario EFN42001, ma sicuramente, vista la presenza dell'entrata relativa al recinto funerario EFN53001 verso est, l'area in esame doveva essere libera da monumenti funerari per permettere il passaggio.

\section{Fase 6A}

111 Nella seconda fase di quest'ambitus si circoscrivono le dimensioni dello spazio di A19 così come lo vediamo ancora oggi, soprattutto per quel che riguarda il limite est, definito dal muro ovest MR42003 del recinto funerario EFN42001, che viene costruito tra la fine del I secolo a.C. e i primi decenni del II secolo d.C. È in questa fase che il settore viene utilizzato sicuramente come ambitus per permettere l'accesso alle strutture funerarie A53 e A42 e, per le informazioni che finora si hanno, anche ad A52, A54 e A56. Nella parte sud del settore è stato individuato un livello di battuto (US 19067) composto di malta mista a frammenti lapidei e fittili, che si può ipotizzare essere il piano di calpestio in fase con la costruzione del recinto funerario EFN42001 (fig. 35). In relazione con l'utilizzo come ambitus del settore A19 sembra da collocarsi anche la struttura muraria US 19071 e la soglia SE19068 individuate in corrispondenza della zona meridionale, ma la cui funzione non è ancora ben definita. Si potrebbero interpretare come chiusura dell'ambitus verso la via Domitiana.

FIg. 35 - VISIONE D'INSIEME DEL LIVELLO DI BATTUTO US 19067 (๑ CJB).

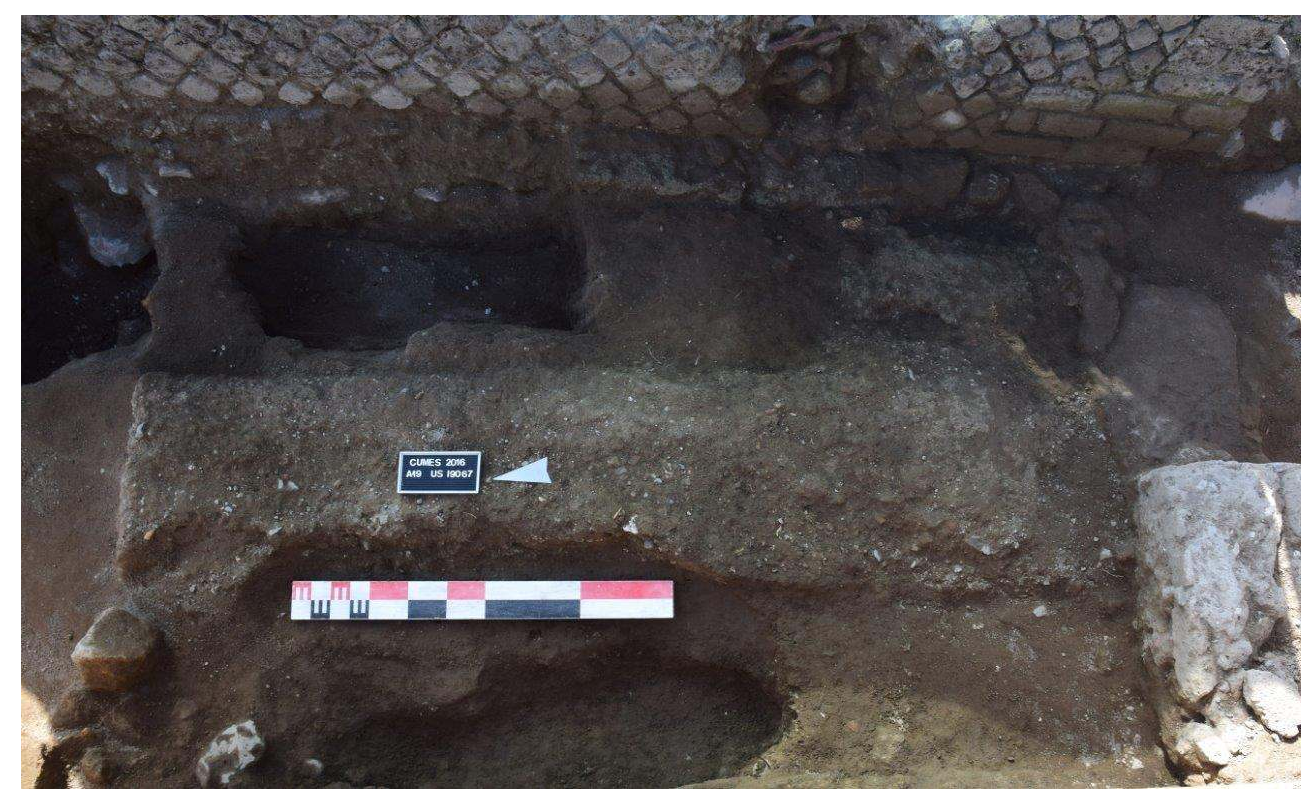




\section{Fase 7C (fig. 33 e 36) 6C-D?}

112 Questa fase corrisponde al momento di cambio di destinazione d'uso dell'ambitus A19, che diventa anch'esso spazio funerario. Si crea infatti una chiusura dello spazio verso sud e al suo interno si impostano sepolture di differente tipologia, sia alla cappuccina (le tombe SP19077, SP19089, SP19017 e SP19062) sia in anfora (sepoltura SP19074). In contemporanea con questa trasformazione si ha anche l'apertura di un nuovo ingresso per il recinto EFN53001 e la chiusura di quello vecchio che si trovava a quel punto ad essere all'interno della nuova area funeraria. Il nuovo ingresso si situa a sud della struttura US 19071, al di fuori di quello che è lo spazio che in questo momento viene destinato ad uso funerario.

\section{FIg. 36 - TAVOLA CON LE SEPOLTURE : SP19062, SP19017, SP19089, SP19077, SP19074 (৫ CJB).}

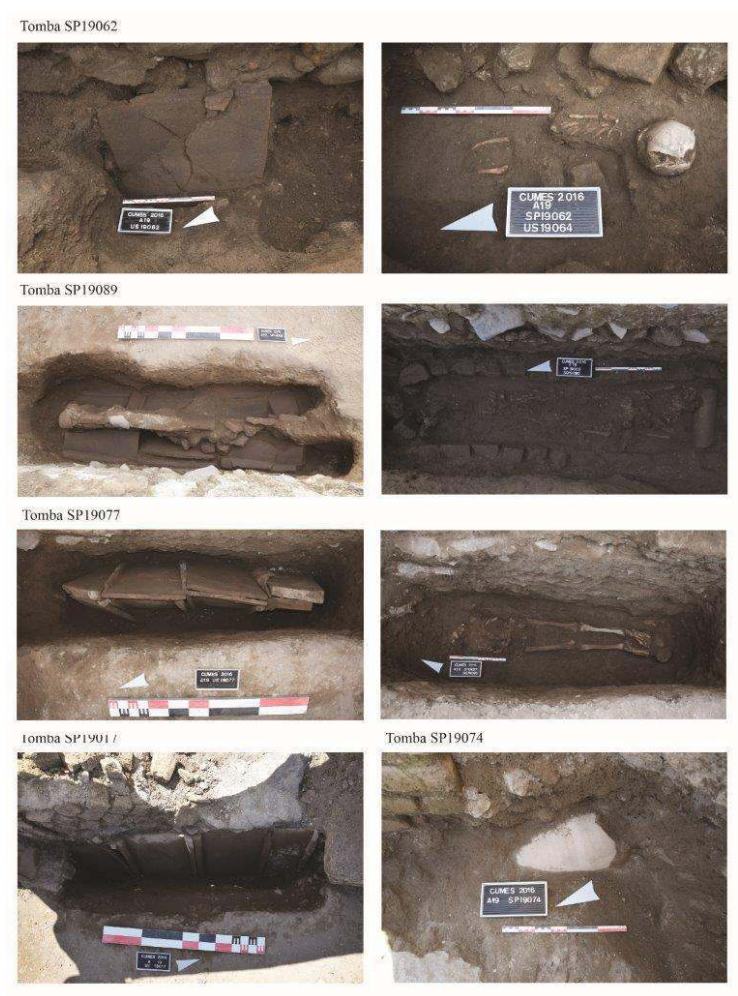

\section{Sépultures}

SP19062. Sépulture primaire individuelle en fosse à demi-bâtière, située en dessous et au sud de la SP19033. Elle est orientée, sud-nord, la tête au sud. Deux fragments de tuiles et une tuile complète (US 19062) sont disposés contre le mur MR54001 formant ainsi une demi-bâtière ou demi-cappuccina. Le remplissage (US 19083) présentait différentes inclusions de cendres et d'ossements brûlés. L'individu est déposé sur le dos; la position des membres n'est pas déterminable au vu de la fragmentation et de la répartition des ossements. Ce sujet immature est âgé entre 3 et 9 mois; les os longs étant fragmentés, seules les dents ont permis de donner un âge. La conservation et la représentation sont moyennes. Toute la partie supérieure gauche du squelette (SQ19064), de l'épaule jusqu'au fémur, est absente, la colonne vertébrale également. La décomposition s'est visiblement déroulée en espace vide au vu de la mise à plat totale des côtes droites. La perturbation du 
squelette et l'absence totale de la colonne vertébrale ainsi que du bassin pose question. Lors de la fouille du remplissage aucune perturbation n'a été repérée que ce soit en lien avec l'action d'un fouisseur ou le recoupement par une autre structure ou avec les inclusions cendreuses. Le fond de la fosse est composé d'un pierrier.

SP19017. Sépulture primaire individuelle à inhumation en fosse avec couverture de tuiles en demi-bâtière installée contre le bouchage de l'entrée septentrionale du monument EFN53001. Le squelette a été observé (SQ19036), mais la tombe n'a pas été fouillée à cause de sa position en dessous de deux dalles de trachyte.

SP19089. Sépulture primaire individuelle à inhumation en fosse avec couverture de tuiles en bâtière, installée le long du mur MR42003. L'architecture de la sépulture se compose d'un ensemble de pierres (US 19098) recouvertes de six tuiles disposées à plat (US 19089) recouvertes de deux imbrices (US 19087). La fosse d'installation du corps est bordée par un coffrage de pierres équarries à l'ouest et à l'est, un ensemble de pierre de calage au pied au nord. Un imbrex est placé au sud et délimite la sépulture. Le corps est orienté sud-nord, la tête au sud. Il s'agit d'un individu adulte dont la conservation est mauvaise et la représentation est moyenne. Le squelette est très arasé, les os sont particulièrement friables. L'individu est un adulte d'après le format des os et le dégré de maturation, l'âge n'a pu être déterminé, ni le sexe. Le sujet est sur le dos, les membres supérieurs et inférieurs en extension. Cet individu s'est décomposé dans un espace vide comme le montre la mise à plat de la scapula gauche, de l'ilium droit et les différents mouvements observés pour les membres inférieurs. La sépulture a été comblée après la décomposition par l'infiltration de sédiment entre les tuiles. Le squelette est très dégradé et semble comme écrasé à hauteur du crâne et du bassin ce qui laisse supposer que les tuiles en bâtière se sont effondrées lors de l'installation des sépultures postérieures comme le suggère la cavité crée par l'affaissement de la seconde tuile au sud.

SP19077. Sépulture primaire individuelle à inhumation en fosse avec couverture de tuiles en bâtière (US19077). La sépulture SP19077 est plus profonde et affleurait pour la partie nord sous la sépulture SP19018, elle est orientée nord-sud, la tête au nord. L'individu inhumé est un adulte de plus de 20 ans (SQ19095) d'après le format et le degré de maturation osseuse. La conservation du bassin n'a pas pu permettre la détermination du sexe. L'individu est déposé sur le dos, la tête au nord, les membres supérieurs et inférieurs en extension. La partie supérieure du squelette présente une mauvaise conservation, la partie inférieure est par contre bien conservée. La représentation au vu de la conservation est moyenne. L'espace de décomposition est vide, état qui s'est prolongé pour le haut du corps au vu des différentes torsions de la colonne vertébrale mais colmaté rapidement par l'interstice entre les tuiles à hauteur des pieds (remplissage différentiel du sud vers le nord) pour les pieds avec le maintien des connexions et des volumes. Le calcanéus, le cuboïde et le cunéiforme latéral droits sont soudés.

SP19074. Sépulture primaire individuelle en enchytrisme, située en correspondance de la limite sud du sondage. La tombe a été individualisée, mais elle n'a pas été fouillée.

\section{Fase 6E1}

114 Con il tempo tutta l'area subisce un processo di reinterro, inserito all'interno della quarta fase di frequentazione, che è successiva ad alcuni interventi di asporto e alla deposizione di una sola sepoltura (SP19096) di cui non resta comunque molto a causa di successive deposizioni. Si attribuisce a questa fase l'innalzamento di una struttura a secco con l'impiego di numerosi blocchi lapidei e elementi fittili per creare un nuovo limite sud 
dello spazio A19. Si può ipotizzare che possa inquadrarsi in questa fase la messa in opera di un architrave reimpiegato come soglia al di sopra della struttura sopra citata.

\section{Sépulture}

SP19096. Sépulture primaire individuelle à inhumation en fosse située au-dessus de la sépulture SP19089. Un individu immature entre 10 et 14 ans a été identifié (SQ19096).

\section{Fase 6E2 (fig. 33 e 37)}

In seguito all'innalzamento del piano di calpestio, si ha l'impianto di un nuovo gruppo di sepolture ad inumazione in corrispondenza di quelle che erano le tombe delle fasi precedenti. Si tratta ancora di tombe a fossa con copertura alla cappuccina (sepolture SP19025, SP19010, SP19033) e di una a fossa in contenitore fittile (tomba SP19018).

FIg. 37 - TAVOLA CON LE SEPOLTURE : SP19033, SP19010, SP19018, SP19025 (@ CJB).

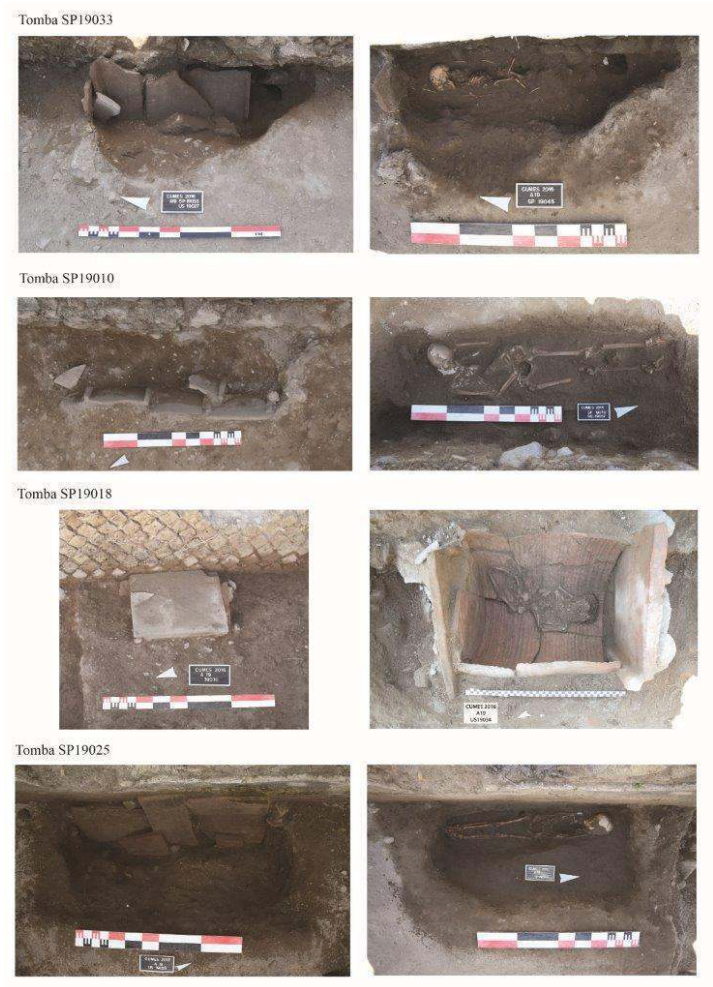

\section{Sépultures}

SP19033. Sépulture primaire individuelle à inhumation en fosse avec couverture de tuiles en demi-bâtière, installée contre le mur MR54001. La sépulture est orientée nord-sud, la tête au nord. Un ensemble de tuiles de chant et des fragments d'amphore recouvrait la SP19033. Plusieurs fragments de tuiles recouvraient deux tegulae entières (US 19033) qui reposaient contre le mur, fermé au nord par une tuile de chant. L'individu inhumé est un sujet immature, dont l'âge se situe dans la première année. La conservation est bonne et la représentation moyenne. La sépulture est perturbée en plusieurs endroits, l'hémithorax gauche est complètement absent, les tibias sont bouleversés sur les fémurs, l'ulna droite est au-dessus du crâne. Ces perturbations correspondent à l'action d'un animal 
fouisseur, le creusement de l'animal a pu être suivi dans les différentes US adjacentes à la sépulture. L'individu (SQ19045) est déposé sur le dos; les membres supérieurs sont en extension et les mains reposaient sur les iliums. Au vu de la position des métatarsiens les membres inférieurs devaient également être en extension. La décomposition du corps s'est réalisée dans un espace primaire vide : chute du membre supérieur droit, ouverture du bassin associé à un colmatage progressif comme le montre le maintien du volume des côtes droites et la connexion des corps vertébraux thoraciques et lombaires avec les arcs vertébraux. Des cavités sont également visibles à hauteur des tibias et au sud de la fosse liées à la présence de la sépulture sous-jacente SP19062.

SP19010. Sépulture primaire individuelle en fosse avec couverture de tuiles en demibâtière, installée le long du mur MR42003 et orientée sud-nord. Elle présente une architecture de tuiles disposées en demi-bâtière reposant contre le creusement de la sépulture SP19089 à l'ouest. Des effets de paroi sont visibles liés à la présence des tuiles et à la rectitude des bords du creusement. Des vides secondaires ont, comme pour les autres sépultures précédemment décrites, été explorés et ont permis de mettre au jour une sépulture sous-jacente. L'individu inhumé est un adulte d'après le format et le degré de maturation dont l'âge et le sexe n'ont pas pu être déterminé. Ce sujet (SQ19057) repose sur le dos, la tête au sud, les membres supérieurs fléchis sur le bassin; les membres inférieurs sont en extension et parallèles. La conservation est moyenne et la représentation est bonne. La décomposition s'est opérée en espace vide d'après les différents mouvements observés tels que la mise à plat complète des côtes droites, la chute des mains à l'intérieur du bassin. Lors de la mise en évidence du creusement puis de la fouille du remplissage de la sépulture SP19089, un individu immature, installé dans le remplissage de celle-ci a été mis au jour. Sa représentation médiocre est sans doute à mettre en relation avec le creusement de la sépulture SP19010. Aucun marqueur de surface et aucun élément architectural n'ont été mis en évidence pour la sépulture SP19096 ce qui pourrait expliquer sa perturbation.

SP19018. Sépulture primaire individuelle en enchytrisme d'un sujet immature. Une tuile est déposée à plat sur un creuset utilisé pour la fabrication du bleu égyptien. Le creuset, entier et non utilisé, est ceint au sud et au nord par deux tuiles de chant et des pierres de calage. La tuile de chant, au nord, est recouverte d'un enduit peint. Le creuset est entier : les différentes fractures, tout comme la percolation du sédiment, sont intervenues après la décomposition du jeune sujet. La longueur du creuset est trop petite pour le corps, ce qui explique la position des membres inférieurs redressés contre la paroi est du creuset. La sépulture, primaire et individuelle, contient un sujet (SQ19034) dont l'âge se situe entre zéro et un an, vraisemblablement entre le premier et le $9^{\mathrm{e}}$ mois. Il est déposé sur le dos, la tête au sud, les membres supérieurs fléchis, les mains sur les dernières lombaires. D'après la position des dents maxillaires et mandibulaires; le crâne semble reposer sur les premières vertèbres cervicales; la mandibule est fermée. Le membre supérieur droit est remonté contre la mandibule au-dessus de la clavicule, le long de la paroi du creuset ; l'effondrement contre le crâne est lié à la gravité. La main droite apparaît par sa face dorsale au-dessus de l'ilium droit et croisée avec la main gauche. Les membres inférieurs sont en extension, légèrement fléchi pour le droit, les chevilles resserrées. Les chevilles sont resserrées mais les pieds sont absents. Les membres inférieurs forment un angle d'environ $30^{\circ}$ avec le bassin. Ce changement d'axe s'explique par la contrainte des membres inférieurs lors du placement du corps dans le creuset. En effet, celui-ci est d'une longueur insuffisante pour permettre aux membres inférieurs d'être étendus dans le même axe que le reste du corps, les membres inférieurs sont redressés contre la paroi 
pour permettre l'insertion complète du corps. Les pieds ne sont pas conservés, la position des membres inférieurs redressés contre la paroi induisent la chute dans le creuset, toutefois aucun élément n'a été découvert lors du tamisage des sédiments. La décomposition du corps a eu lieu en espace vide d'après les mouvements des côtes et des vertèbres, la mise à plat du bassin. La tuile de chant au sud n'a pas empêché la percolation du sédiment ce qui explique le maintien des connexions telles que les mains et le maintien des membres inférieurs en équilibre contre la paroi. Au vu des différents mouvements observés et de la position générale du corps, aucune enveloppe souple en matériau périssable de type textile n'a pu être identifiée. Aucun mobilier n'a été mis au jour dans la sépulture. Un balsamaire en céramique a été découvert dans le remplissage du creusement pour l'installation de la sépulture. Le squelette ne présentait aucune lésion. Lors de la mise au jour du creusement de la sépulture SP19018, il est apparu des cavités au sud laissant présager un espace vide sous-jacent. La poursuite de la fouille a permis de découvrir la sépulture d'un adulte, en partie sous la sépulture SP19018.

SP19025. Sépulture primaire individuelle en fosse avec couverture en demi-bâtière, située à l'ouest contre le mur MR53001. L'architecture de la tombe se compose d'un ensemble de tuiles déposées de chant contre le mur MR53001, formant ainsi une demi-bâtière pour protéger ou le corps. Elle contient un individu immature (SQ19048) dont l'âge se situe entre 10 et 14 ans. La conservation du squelette est de moyenne à bonne, la représentation moyenne. L'individu est sur le dos, la tête au nord, les membres supérieurs en extension, les mains contre le bassin, les membres inférieurs sont également en extension, les genoux resserrés, les chevilles jointes, le pied gauche sur le pied droit. L'ensemble du squelette (SQ19048) est en connexion mais l'absence de la partie centrale du squelette pose question. Cette absence pourrait correspondre à l'action d'un animal fouisseur ; toutefois aucune galerie et aucune perturbation n'ont été repérées lors de la fouille du remplissage (US 19047) de la sépulture. Aucun matériel n'a été découvert dans cette sépulture. La décomposition s'est opérée dans un espace vide rapidement colmaté, l'étroitesse de la fosse a également maintenu une partie des volumes, comme le bassin. De part et d'autre du squelette, au niveau du bassin, des vides secondaires sont visibles. Ces vides sont probablement dus comme pour les sépultures SP19018, SP19010 et SP19033 à une sépulture sous-jacente. Pour la sépulture SP19025, les vides secondaires n'ont pas été explorés lors de cette campagne.

\section{Fase 6E3 (fig. 33 e 38)}

Questa fase corrisponde ad un periodo in cui si viene a creare un parziale interro del settore A19 con ancora delle sepolture che si vanno ad impostare ancora in corrispondenza di sepolture precedenti. Il livello di reinterro dell'area non è omogeneo su tutta la superficie, indice forse di una parziale obliterazione del settore verso sud e di una prosecuzione di vita in corrispondenza della parte settentrionale. Qui troviamo due tombe in anfora (sepolture SP19012 e SP19016) e una alla cappuccina (tomba SP19007). 
FIg. 38 - TAVOLA CON LE SEPOLTURE : SP19016, SP19012, SP19007 (๑ CJB).

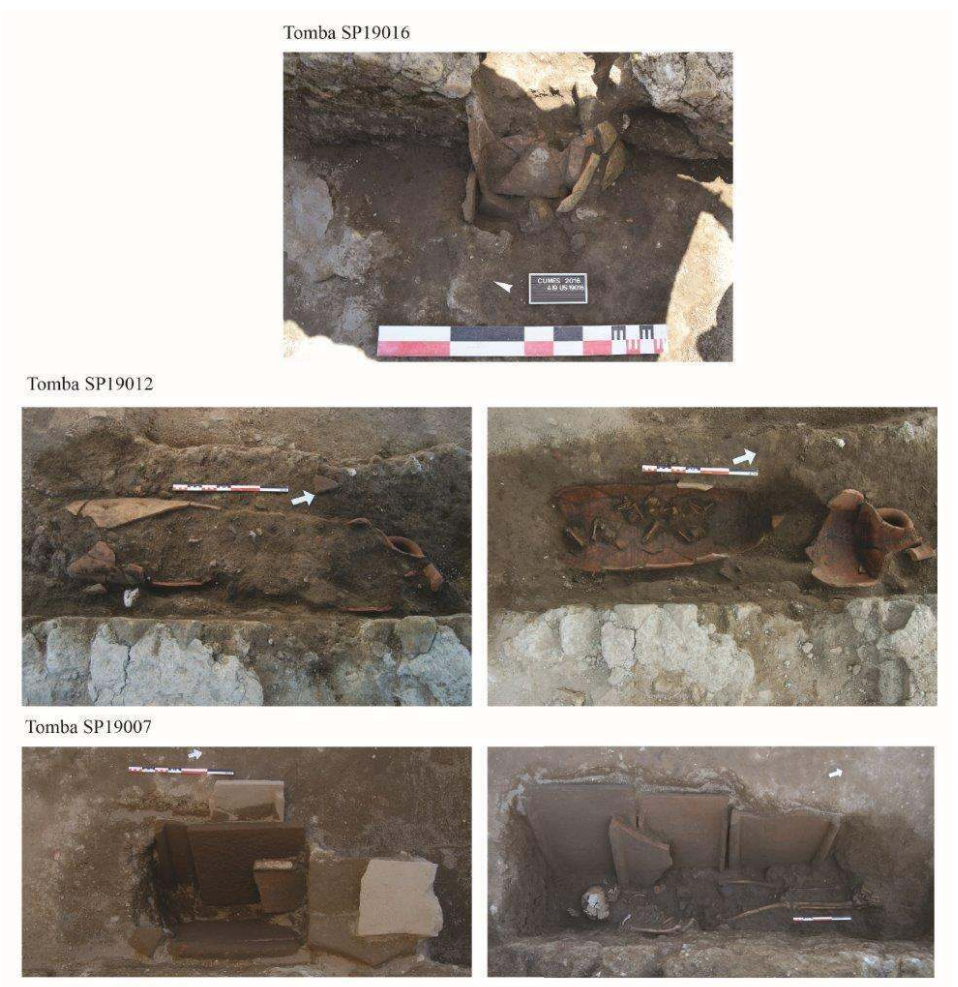

\section{Sépultures}

SP19016. Sépulture primaire individuelle en enchytrisme d'un sujet immature individualisée au dessus de la tombe SP19033. Aucun squelette en place n'a pu être observé et la tombe était particulièrement perturbée.

SP19012 (2014). Sépulture primaire double en amphore située contre la partie sud du mur MR54011 et contenant les restes de deux individus (SQ19014 A et B). Elle est installée dans l'US 19006. L'architecture funéraire est constituée de deux gros fragments de panse d'amphores proches l'un de l'autre, et d'un comblement entre les deux constitué d'autres fragments plus petits d'amphores. L'intervalle entre les deux fragments principaux d'amphore, deux amphores africaines, dont un exemplaire corréspondant à une variante d'une Keay LII, paraît avoir été remanié. L'absence de "logique » dans le processus de comblement peut être mise en relation avec le fait qu'aucune couverture n'ait été découverte pour cette sépulture : une perturbation postérieure aurait ainsi détruit la couverture et bouleversé la tombe. Cette hypothèse est confortée par les observations réalisées sur les sujets eux-mêmes : aucune connexion n'a été observée pour l'ensemble de la sépulture. Nous n'avons pu constater la présence de deux sujets distincts uniquement que par des différences de taille entre plusieurs ossements (iliums et fémurs notamment). Seule une logique anatomique sur un bras et quelques fragments de côtes droites a pu être notée, ainsi que sur une portion de thorax (quelques vertèbres thoraciques et côtes). Les os étaient totalement bouleversés sur une épaisseur d'environ $7 \mathrm{~cm}$. Il n'est donc pas possible de suggérer la position de ces individus. Aucune information spécifique ne peut être précisée pour ces sujets, si ce nest qu'ils se sont décomposés sur place, au vu des nombreux ossements de très petite taille mis au jour. Les 
sujets appartiennent tous deux à la classe [0] : 3-4 mois pour le sujet A, 1,5 moins env. pour B.

SP19007 (2014). Sépulture primaire individuelle en fosse avec couverture en bâtière, située contre la partie nord du mur MR42003. Aucun creusement de tombe n'a pu être mis en évidence. Elle est orientée sud-ouest/nord-est, tête au sud-ouest et elle est installée dans une large fosse profonde, avec un espace vide visible sur le corps. La tombe contenait les vestiges osseux d'un immature (squelette SQ19011) âgé dans les 10-14/15-19 ans, en bon état de conservation. Son état de représentation est également assez bon, malgré l'absence notable d'une partie des bras gauche, avant-bras droit, thorax et bassin. Le sujet a été placé sur le dos, membres inférieurs en extension.

\section{Fase 8}

L'area subisce poi un processo di interro causato molto probabilmente dall'abbandono della zona. In questa ultima grande fase che si è voluto identificare, vengono compresi tutti quegli interventi che hanno interessato l'area fino all'epoca moderna. Si tratta infatti molto spesso di azioni di asporto, difficilmente collocabili precisamente in termini temporali.

\section{BIBLIOGRAPHIE}

Brun et al. 2013 = J.-P. Brun, P. Munzi, L. Cavassa, G. Chapelin, A. Cormier, H. Duday, S. Gualandi, S. Le Berre, B. Lemaire, N. Meluziis, D. Neyme, J.-M. Piffeteau et A. Watel, Cumes, dans Chronique des activités archéologiques de l'École française de Rome [Online], Italie du Sud, 2013. URL : http:// cefr.revues.org/989; DOI : 10.4000/cefr.989.

Brun et al. 2015 = J.-P. Brun, P. Munzi, L. Cavassa, G. Chapelin, L. Cavassa, Marina Covolan, P. Duneufjardin, S. Le Berre, B. Lemaire, M. Leone, S. Mailleur, N. Meluziis, D. Neyme et A.e Watel, Recherches archéologiques à Cumes (Campanie, Naples), dans Chronique des activités archéologiques de l'École française de Rome [Online], Italie du Sud, 2015, URL : http://cefr.revues.org/1444; DOI : 10.4000/cefr.1444.

Hervé et al. 2016 = G. Hervé, P. Munzi-Santoriello, P. Lanos, J.-P. Brun, P. Caputo, C. Regis, Datation archéomagnétique de deux fours du haut Moyen-Âge à Cumes (Campanie, Italie), dans ArcheoSciences, revue d'Archéométrie, 40, 2016, p. 35-45.

\section{NOTES}

1. Brun et al. 2015.

2. Brun et al. 2013.

3. Brun et al. 2015.

4. Hervé et al. 2016. 
INDEX

Mots-clés : Cumes

institutions Centre Jean Bérard (USR 3133 CNRS-EFR), Collège de France, Soprintendenza Archeologia Campania, Ministère de l'Europe et des Affaires étrangères (Paris).

\section{AUTEURS}

\section{JEAN-PIERRE BRUN}

Collège de France - jean-pierre.brun[at]college-de-france.fr

\section{PRISCILLA MUNZI}

CNRS, Centre Jean Bérard (USR 3133 CNRS-EFR) - priscilla.munzi[at]cnrs.fr

\section{GUILHEM CHAPELIN}

CNRS, Centre Jean Bérard (USR 3133 CNRS-EFR)

\section{MARINA COVOLAN}

Università degli Studi di Padova - Centre Jean Bérard (USR 3133 CNRS-EFR)

\section{BASTIEN LEMAIRE}

Université Paul-Valéry Montpellier III, UMR 5140 Archéologie des Sociétés Méditerranéennes / Collège de France

MARCELLA LEONE

CNRS, Centre Jean Bérard (USR 3133 CNRS-EFR)

NICOLA MELUZIIS

Centre Jean Bérard (USR 3133 CNRS-EFR)

GÉRALDINE SACHAU-CARCEL

Université Paul-Valéry Montpellier III, UMR 5140 Archéologie des Sociétés Méditerranéennes 